ira in (2) 1.

$5+2-1))^{2}$

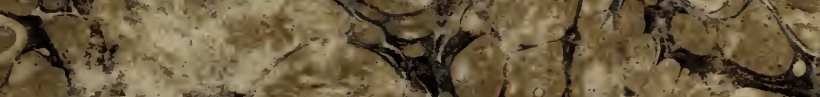

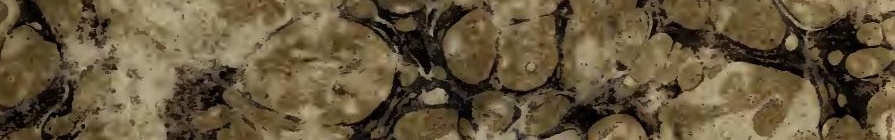

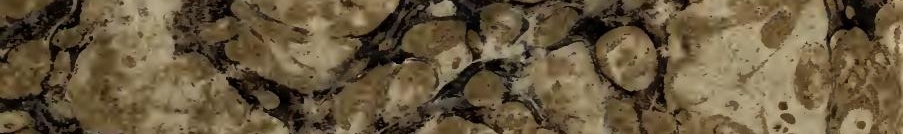

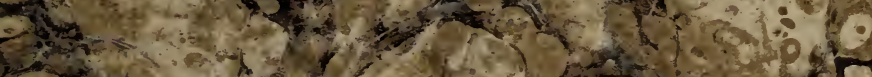

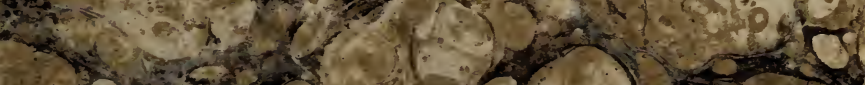

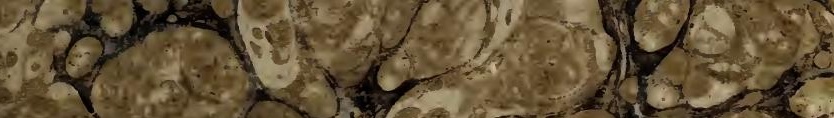

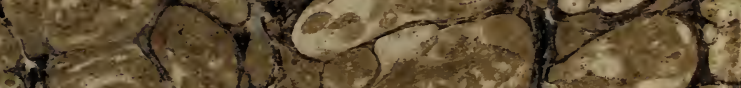

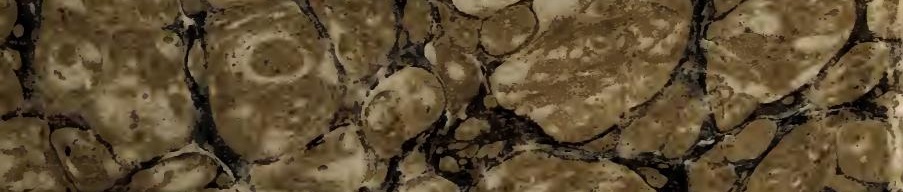

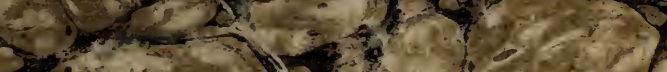

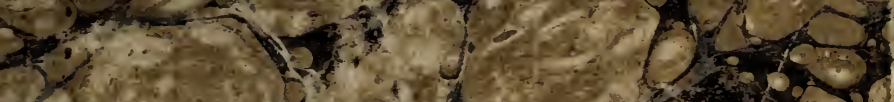
(2)

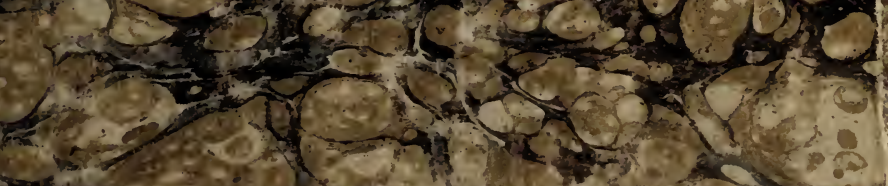




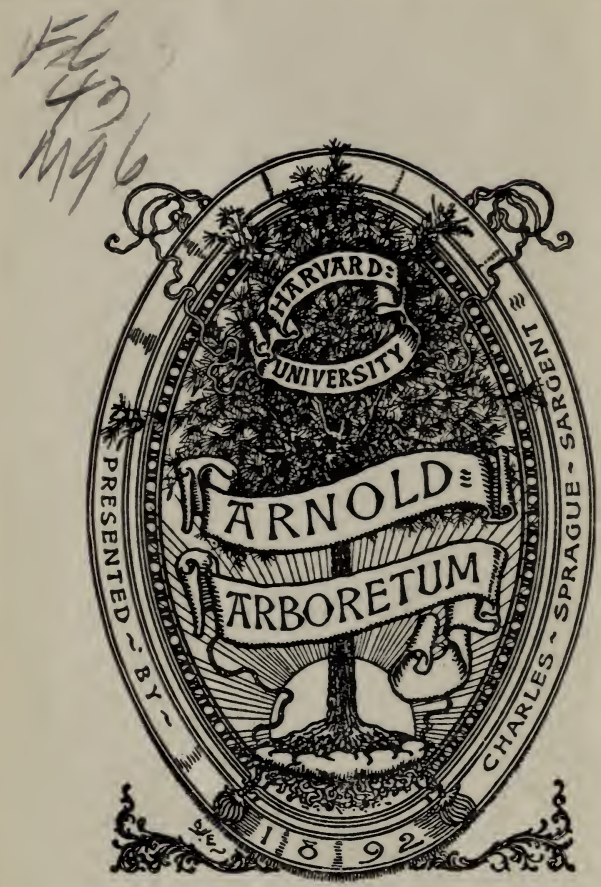


Q1-2Tat oplik 107018

alle: 



\section{IO. ANDREAE MVRRAY D.}

MEDICINAE ET BOTANICES PROFESSORIS R. ACAD. SCIENT. SVEC, MEMBRI

\section{PRODROMVS}

DESIG NATIONIS STIRPIVM

\section{GOTTINGENSIVM}

CVM FIGVRIS AENEIS

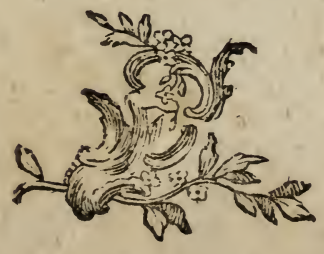

\section{G O T T INGAE}

IMPENSIS 10. CHR, DIETERHCH, 1770 . 
VIRO

\section{PERILLVSTRI ET GENEROSISSIMO}

\section{ALBERTO}

\section{A B H A L L R}


uum ad TE, qui primus Florae in bac litterarum jede antiftes fuifii, omnis firpium noftrarum cultus E omne inde repetendum meritum bonosque redeat: $\mathcal{T} I B I$, vir perillufris, potifimum opella praesens sacranda eft; tenuis quidem, nec tanto nomine praefigendo digna, fida tamen 
men animi, fumma objeruantia $T I B I$ dediti, interpres, guo $T E$ profequi inter iucundiffima vitae refert

\section{Perilluftris $T V I$ nominis}

\section{cultor perpetius}

$$
\text { I. A. MVRRAY. }
$$




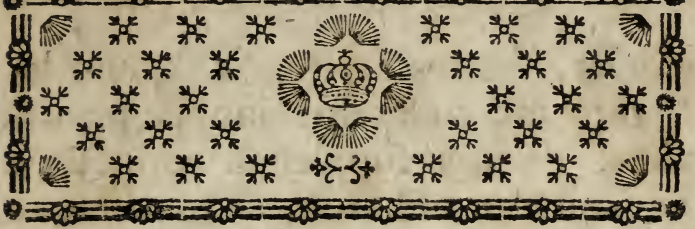

PRAEFAMEN.

D eftauratio horti occupatiffimum licet me adhuc teneat, \& hic quoque longe adhuc abfit $a b$ eo nitore eaque ftirpiumque abundantia, quam illi decreui : non defuerunt tamen caufae, quae accelerandam hancce, quae horti praecipue rationem habet, fcriptionem voluerunt. Etenim pietati aduerfum iudicaui, fplendidam illam illuftriffimi c vRATORIS in hortum munificentiam, quae inde $a b$ initio muneris mei noui * 4 efful- 
effulfit, diutius celare. Et quum la. borare ifte videretur inopia plantarum: de hac fupplenda tempertiue cogitandum mihi fuit. Quo fine, ne tempus catalogis confcribendis perderetur, opus erat typis expreffo indice, ex quo cognolcerent exteri botanici, quorum adiumentum implorandum, quaenam plantae nos deficiant, quaenam rurius a nobis grati animi teftandi caufa exfpectarı poffint. Nolui ideo initio vltra horrum euagari, \& praeter eiusdem hiftoriam Linnaeanis nominibus praefentem ftirpium, quas alit, congerıem enumerare.

Quoniam autem in horto multae etiam fpontaneae - tractuum noftrorum collectae exftant, numerofae tamen remotius crefcentes, quarum poffeffio grata vtilisque futura, defunt: neceffe duxi indigenas fingulari indice complecti \& adiecta litrera $b$ praefentiam earum in horto indicare. Quae earum ab hortenfibus diuulfio 
PRAEFA MEN.

in itineribus botanicis quoque aliquod leuamen pollicebatur.

Inexfpectato igitur ad fignnificandas indigenas obitrictum me vidi, tempore a botanicis laboribus alieniffimo, media hyeme. Qua impedi. tus, non porui de quibusdam plantis, renouatum fcrutinium expofcentibus, mihi omnino fatisfacere; fed de hifce lectores monui. Alias paucas in priftinis catalogis omiffas ex fido examine addidi, \& varias, quas b. ZINNIVS Linnaeanis nominibus inlignire non potuit, iisdem definiui, ita vt in hac re fupplementi inftar catalogi cel. huius viri effe poffit. Stationum fertiliorum, quibus ego cum aucitoribus ftirpes lego, indicem vna cum plantis praecipuis ibidem crefcentibus praemifi, licet, vt in ipfa opella confeffus fui, quaedam \& alibi apud nos reperiantur, \& vix vnquam ftationes plantarum latioris cuiusdam tractus ab homine, publico officio adftricto, quod integros

$$
* 5
$$

dies 


\section{PRAEFAMEN.}

dies vel hebdomades pro arbitrio impendere non finit, ea accuratione indicari poffint, qua $a b$ alio, qui fuae fpontis eft.

Facili negotio fubnectere cuilibet tam indigenarum quam exoticarum fpeciei ex ill. A L INNÉ libris potuiffem, vt multi folent, defcriptiones, \& fynonyma ex eodem fonte mutuari, quo formam liber infignioris operis haberet, \& fpeciem maioris eruditionis: fed fuum cuique tribuens nolui peregrina opera fuperbire, nec, nouitati litans, praecipitanter aliquid agere. Hinc fola fere hoc loco nomina praetuli, quippe praefixo mihimet fini fatis opportuna. $\mathrm{Nec}$ caret iucunditate diuitias horti celebrioris, poft varias in primis mutationes, noffe, etiamf L INNAEI exemplo in differtatione, Demonftrationes plantarum borti VPSalienfis 1753. ") infcripta, per fola nomina fieret.

*) Recufa in Amoenit. acad, Vol, 35 P. 394. 
Adfperfi, idem illuftre exemplum fequutus, proprias quasdam obferuationes de plantis vlteriori dilucidatione dignis, iis nimirum, quae vel aegrius $a b$ aliis diftinguuntur, vel in quarum definitione aliquid labis in libris, qui vulgo confuluntur, reperiffe mihi videor. Peculiari autem fectione defcriptiones quarundam prolixiores fubiunxi, quum nihil in vniuerfum tantum tam ad certiorem fingularis fpeciei cognitionem, quam ad affinitatem ftirpium eruendam, facere exiftimem, quam ftirpes obuias per fingulas partes, fub varia earum aetate \& ftatione, perfequi.

Hortorum botanicorum par fere ac maris aeftus ratio eft. Affluunt quotannis multae nouae ftirpes, multae quoque quotannis fefe fubtrahunt, a quarum interitu faepe ne vigilantiffimi quidem praefecti prouidentia caueri poteft. In hoc ineuitabili fato praecipue quaerant velim leEtores caufam, cur multis hortus 


\section{PRA EFA M N.}

priftinarum fuarum ciuium iam deftituatur; quarum vero abfentiam copia aliarum nouarum a me conquifitarum refarcit.

Auctores de ftirpibus noftris bene meritos recenfere ab idea prodromi alienum non credidi : in aëris autem noftri tempeftatisque indolem inquirere, arctior eiusdem cum hiftoria horti cognatio me iuffit. Quae de horti initiis \& prifca eius cognitione retuli, haurire illuftriffimus academiae cVRATOR ex fchedis numerofiflimis manu feriptis indulgentiffime mihi conceffit, quae, inter reliquas ad academiae noftrae inftituta pertinentes, Hannouerae feruantur. In nouis aufis recenfendis non vereor, ne minutias nie nimis fectatum mihi obiiciatur, certe non ab illis, qui ipfi ad hortos botanicos recens inftruendos animum aduertant, quorum ex litterarum commercio fcio varios effe celeberrimos viros, quibus, exercitio medicinae 
PRAEFAMEN.

praecipue addictis, hoc ipfum officium iniunctum, nec ideo eiusmodi laborum compendium difplicebit. Quam viam egomet in firpium cultu fequar, nec hucusque fucceffu orbatus, paucis luggeffi.

Atque hifce acquiefcere iuuat, donec defignationem ftirpium noftrarum completiorem fuis definitionibus, fynonymis, \& propriis obferuationibus, quarum bonam copiam aduerfaria continent, ftipatam fuppeditare vacet, Quam, quoad hortenfes, fpero tanto pleniorem intra breue tempus fore, quo ardentior in rebus noftris herbariis juuandis, botanicorum, quos in opella laudaui, animus eft; vtque alii eadem beneuolentia horto noftro adfint, de mutuis officiis conuicti, impenfe rogo.

Vtinam inter ftirpes horti noftri iam numerare liceret eam, quam I INNA EVS felici indagine illuftriffimi CVRA TOR Is nomine fplendidam red- 
reddidit, MVNCHHAVSIAM Speciofam, qua aduenis commonftrata, hi nifi turelae, qua Botanice Maecenatıs indulgentia fruitur, quam quidem totus hortus eloquitur, recordentur, deuotiffimae venerationis tamen, qua cultores artis tantum lumen profequuntur, meminerint. Fauore autem perilluftris \& generofiffimi Regis Satrapae L. B. o r roNIS A MVNCHHAVSEN, in quem communio denominationis huius ftirpis proprio iure tranfit, contigit, vt fub hoc ftirpis in hurto defectu icone eiusdem libellum praefentem ornare queam. Adiungo illi defcriptionem, eam nimirum LINNAEI, quam inferuit perilluftris vir operi, quod in incrementum botanices \& oeconomiae, in fui gloriam, \& purpuratorum decus, fub titulo der Hausvater (Vol. S P. 1. p. 356.) edit.

\section{$M \mathrm{~V} N \mathrm{CH} H \mathrm{~A} V \mathrm{~S} I \mathrm{~A}$.}

CAL $\times$, Periantbium monophyllum, obovatum, torulofum, femifexfidum, laciniis patulis, perfiftens. 
C O R OLIA, Petala fex, obouata, patentia, viguiculata, calyci inferta.

ST AMINA, Filamenta numerora, capillaria, calyci inferta, petalis breuiora; $A n$ therae reniformes.

1 IS I I L V M, Germen fuperum, ouatum. Stylus filiformis, declinatus, faminibus longior; Stigma obtufum.

1' ER ICARI' I v M, Capfula ouata, acuminata, calyce tecta, fexlocularis.

SEM INA plurima.

M VNCHHA VSIA jpeciofa.

Boengoer Iauanis.

Habitat in Iaua, China. $\hbar$.

Arbor ramis alternis, patulis, teretibus, laeuibus. Gemmat biualues.

Folic alterna, petiolata, ouata, f. ouato-oblonga, acuminata, integerrima, glabra, fubtus pallidiora, Petioli breuilfimi. Stipulae nullae.

Racemi terminales, fubramofi, erecti, pedales, fricti, teretes, laeues.

Flores alterni, breuiffime pedunculati, fpeciofiflimi. Calyces fubtomentofi, torulis fex canaliculatis; Petala calyce quadruplo maiora. Stamina, peralis dimidio breuiora. Stylus primum ftaminibus aequalis, dein vero longior euadit. 
Sanctum mihi eft nomen $\mathrm{MV} \mathrm{NCHHAV-}$ SIORVM, quorum L. B. GERLACHVS ADOLPHVS DE MVNCHHAVSEN, Primas Hannouerae, Floram in horto Gottingenfi fplendide habitare conceflit; U т то

DE MVNCHHAVEN, Satrapa, rem herbariam non tantum folide coluit, fed \& fpecialem eius vfum in vita communi introduxit \& determinauit.

- Huc vfque ill. A I INNÉ. Hortum Vpfalienfem intrauit primum arbor, vt litteris mihi expofuit cel. vir, anno 1748 , \& fubfequenti flores fero autumno tulit, qui vero absque fructu perierunt. Quin ipfa poftea ftirps ob defectum folis per hiemem periit. Fructum tamen definire ex ficco exemplo, ante biennium ill. Equiti miffo, licuit. 


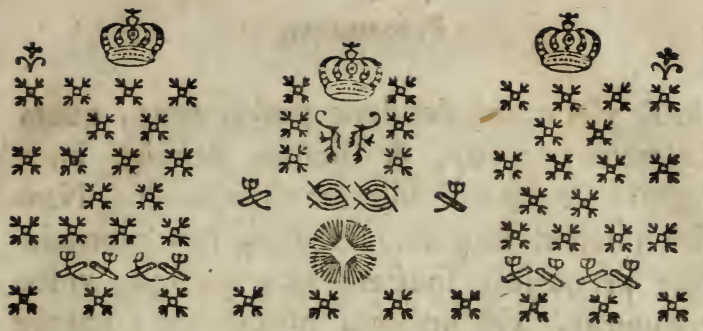

PRODROMVS

DESIG NATIONIS

STIRPIVM GOTTINGENSIVM.

\section{ROO E M I V M}

ui hucusque in academia noftra Florae Gottingenfis diuitias adumbrarunt Bo2. tanices ductores celeberrimi, his ftirpes fponte crelcentes cum iis, quas hortus alit, copulare, eodemque libro vtrumque genus complecti, vifurn eft. Quo nexu etfi numerus ftirpium cognofcendarum audior euafit: nemo tamen molefte id feret, quum 
doai viri opera defideria potius noua, quan fatietntem pariat, \& limites definire inter hortum \& rus difficillimum omnino fit. Nam fi vtilitatem ftirpium, cognitam iam plurimisque probatam, fpectes, qua plerique vnice trahuntur, vel nocendi poteftatem : multae inter indigenas exiftunt peregı inis, longa etfi \& operofa \& fumtuofa arte cultis, pretiofiores \& nocentiores, t.nto proinde digniores, vt a quolibet nofcantur. Quis faltim noftris in terris, etiamfi rem herbariam bfcitantius tractet, Myagrum fatiuum *) vel Chryfanthemum fegetum ${ }^{* *}$ ) vel Belladonnam ***), vt alia exempla non attingam, quorum vis omnium

*) Quam fruetuofa eius, olei caufa, cultura fit, experimentis in hifce terris captis demonfira. tur in Hannoul. Magaz. 154 n. 34.1766 .17 .78 , $\&$ in Naclrichten d. Hannow. Landwoirtbfoba ftsgefellfchaft I. B. p.6gR.

**) Praemio excirauit ciues ill, focietas oeconomica Hannou, ve detegerent rationem perniciofum hocec fegetum vitium eliminandi, in A Actis fuic (I. B. p. g.) Confilia in hunc finem praecipue leguntur in A\&tis iftis (I. B. p. Iro.p. 300 ) in Heussater Tom. 3 p. (II \& in Hannou. gelebrt. Anzeigen 1753 p. 1195.

-**) Inclaruit venenatiffima planta heic loci, ob vim radicis \& foliorum in rabie canina, in lue bnuina \& cancro, percepram, de qua multis in locis refurt Hanrous. Magazin $a$. 8768 eे $176 \%$. 
omnium apud nos in ore verfatur, diftinguere fine ignuminia nefciret? Inque comparatione fpecierum \& cognitione certiori tantum faepe ponderis vulgares, \& quae pedibus calcantur, firpeshabent, ac vix rariores; nec in charactere generis ftabiliendo, quod vero doctoris but nici in primis eft, carere illis vl. lo modo poffunus.

Hifce rationibus ductus, nec ego in fequenti fcriptione alcerutri harum ftirpium generi praerogatiuam tribuam, fed easdem indicibus modo diftinctas proponsm, quae dis. iunctio vel cumr videtur vfum habitura, ve \& iis, qui harum alterum genus figillatim fine mora vel operofa lectione cognofeere cupiunt, fiat fatis, \& botanices apud nos cultores mox fciant, quasnam plantas in campis, quasnam in horto, quaerant.

\section{Sectio 1.}

AVCTORES DE STIRPIBVS AGRIET HORTI GOTTINGENSIS

Colere vero maxime fas eft memoriam illuftrium clarorumique virorum, qui litterariis fuis monimentis de ftirpibus noftris meruerunt, quorum igitur fcripta, fecundum A 2 eum 
eum temporis ordinem, quo primum quod. libet prodiit, mox in limine operis fignificabo. En ifta !

I OAN IS THALI, medici NortbuSani, Sylua Hercynia, fiue catalogus plantarum fponte najcentium in montibus, so locis vicinis Hercyniae, quae refpicit Saxoniam. Francofurti ad Moenum 1588. 4. pgg. 134. Vitam eiusdem defcripfic F R I D. L E S SER a. 1747. Opus vero pofthumum eft, edicuma 10 A C H IM O C A ME R A R IO, cui codicem manu fcriptum miferat, vna cum proprio Horto medico E pbilofopbico. Aliam editionem anni 1654 citat LESSER V S, \&a. 1674.4 .5 E G VIER \& generofiff. A M V N H A VSEN. Iconespligneas rudesque editor adiunxic. Ordine alphabetico plantas in fylua hercynica \& monte Bructero a fe collectas, vna cum locis natalibus exhibet, quarum multae poftea non inuentae, aliae vero pofterorum modo opera innotuerunt. Difficilis faepe intellectu, ob defcriptiones iufto breuiores \& neglectos characteres generum, quae interdum multae nimis diuerfae plantae ingrediuntur, Alfines, Conyzae, Chondrillacearum, Graminum, Rapunculi exemplo.

IOHANN ROYFR's Befchreibung ses ganzen Furfll. Braunfblow. Gurtens zu Hejern 


\section{Sect. 1. Auctores.}

Hefen - und was fir Simplicia in den benacbbarten Wäldern Bergen Ec. zu findon. Braunfchweig 1653. 4. Ed. 2. pgg. 98. Opus eft hortulani fignificati horti, in quo praerer ea, quae ad digeftionem horti in ambulcia $\&$ aress \& ad ornamenta pertinent, ftirpes inftructifimi olim horti, quoad nomen modo, indicantur, additis ad finem libri horticulturae rcgulis. Inter fpontaneas, Hercyniae quasdam \& m. Bructeri incolas recipit, quarum hae diftinctae a reliquis adiecto nomine Broccenbergicae ftirpis. Non inhabilis auctor, \& multarum forfitan plantarum primus in Germania inuentor, modo vbiuis ex folis nominibus intelligeretur. Catalogus harưm feiunctim etiam tefte SEGVIERO a. 1657 Brunfuigae prodiit.

HENRICI IVLII MEYENBERG, Einbecc. Med. cultoris Flora Einbeccenjis fiue enumeraiio plantarum circa Einbiciam indeque ad duo milliaria fponte nafcentium cum auctorum Synonymis; locis natulibus E tempore quo florent, ordine alpbabetico confcripta. Gottingae 1712 8. pgg. 102. Continet mera nomina cum locis natalibus, \& virtutes nonnullas medicas proletaria adiectas. Non praeteruidit tamen Cytifum Laburnum, Hefperidem matronalem aliasque in monte GruA 3 ben- 
benhagenfi vicino crefcentes. Acunitum Napellum, Dictamnum album, Adianthum capillum veneris (Adianthum nigrum), Afplenium Scolopendrium, ad fpontaneas - retulit, an iure, filentibus fequentis aetatis botanicis? Gramina pauciltima habet, quae nollem auctorem in minori pretio habuiffe.

HENRICI BERNHARDI RVPP Flora lenenfis, editore H. sCHVTTE lenae 1718 , auctior, curante D.F R O E L IC H $17 \geq 6.9$.prodiit. Inter auctoris amplilitima per Germaniam icinera, in hercyniae montium humiliora quoque fe contulit, plantasque ibidem a fe lectas Florae inferuit. Stationes harum curatius commemoratas vides in editinne tertia ill. H A L LE R I , a.1745.8 reliquis longe perfectiori \& nitidiffimis iconibus ornata.

ALBERTI AB HALLER Obferuationes botanicae ex itincre in fyluam bercyninm fufceto. Difputationis forma prodierunt primum a. 173 3.4. dein recufae in Opusculis butanicis 1749.8 . p. 77 /qq. lungit ill. vir cum propria defcriptione mụltarum plantarum, vel obliuioni fere eoufque datarum vel antea non fatis definitarum, pro eruditionis fure apparatu, criticam fynonymorum numeroforum difquifitionem, interfpergens animadueriones alias 
alias lectu digniffimas idque fecundur itineris facti feriem. Montem Bructerum fimul afcendit Wernigerodamque \& fpecum Baumannianam falutauit. In hoc itinere Silymbrium fuum, paluftre album follis inis Barbareae re-

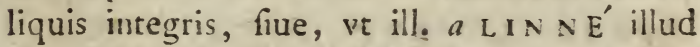
prae obferuantia in auctorefn vocari mauult, Arabin Halleri, primus veris characteribus inAtruxit, icune libro addita.

EIVSDEM breuis enumeratio ftirpium borti Gottingenfis. Accedunt animaduerfornes aliquae \& nourrum defirptiones. Gottingae 1743. pgg. 90. Prima fuit ill. audonis horti diuitiarum \& ftirpium, intra milliare ab vrbe crefcentium, adumbratio, fecundum propriae methudi normam. Ornat eam Cucubali fibirici icon. Lacupletior vero hoc indice ma= gisque elaboratus alter, qui decem annis ferius prodiit, fub titulo Enumerationis plantarum borti regii \& agri Gottingenfis, Gottingae 1753.8. In hoc fpontanearum copia auctior longe, extenfo nimirum Florae Gottingenfis dominio. Vterque liber ex cryptogamicis nonnifi Filices enumerat.

EIVSDEM Oberuationes botanicae, commentariis focictatis regiae fientiarum Gottingenfis Tomo is p. 201 fqq. Tomo 2. p. 
337. 999 . infertae, pariter hic memorari debent, vtpote in horto botanico enatae, quibus, vel nouae omnino, vel antea non curate fatis defcriptae, ftirpes exhibentur, iconibus praeftantiffimis illuftratae.

EI VS D E M Hiftoria firpium indigenarum Heluetiae incboata, Bernae 1768 Fol. Interuallo 26 aunorum, poft editam Enumerationem ftirpium belueticarum, Hiftoriam euulgauit ill. autor, quae non ideo modo huius loci eft, quod plerasque germanicas complectitur, fed quod nominatim hercynicas multas, pro ifta foli varietate cum Heluetia communes, recipit; idque indicatis de rarioribus plautis earum in tractibus noftris fationibus. Supplementi quoque inftar eft, proue \& eius R v P I Florae editio, fpontanearum Gotting. catalogi, in quo (ve dixi) ftirpium flore carentium, Filicibus exceptis, nulla nen. tio fit.

A L BERTI RITtek, Colleg. Ilfeld. Prorect. Relatio Hiflorico-ciriofa de iterato itinere in Hercyniac montem famofisimum Bructerum. Helmitadii $174^{\circ} .4$ plagg. 7. c. tab. aen. 5. Verfio mala prodiit germanice Magdeb. 1744. Librum non vidi: ex citationibus aliorum autem cognofco, eum inter alia', quae ad rem naturalem montis attinent, plan- 
tarum, quâs gerit, nomina indicaffe; an pro. pria \& fuificiente botanices luce? Pauca horum addidit in Supplemento fcriptorum fuorum Helm:f. 1748 p. 80, quod coram habeo.

FRANCISCI ERNESTI BRVCKM A N I Epiftola itineraria 85. fiftens plantas quasdam bercynicae jyluae ad ill. AL B ERT VM HALLER c. fig. aen. Wolfenb. $274^{\circ}$. - Item EIVs D. Epift. itin. 86 ad A LBERTVM RITTER. Addenda quaedam duxit fcriptione vberiori notus auctor ill. H A LLERI de ftirpibus hercynicis obferuatio. nibus. Quae addidit ad vires potius firpium, quam botanicam notitiam fpectant. Trollium europaeum \& Cypripedium Calceolum hercynicis accenfet.

CHRISTIANI LVDOVICI WIL. LIG. Diff. inaug. Obferuationes botanicae $E$ snedicac, praef. ill. A B H A L L E R Gott. 1747. 4. Botanica difputationis pars continet fparfas animaduerfiones de plantis quibusdam fpontaneis regionis noftrae, quibus $\mathrm{cl}$. vir characterem earum magis firmat, \& acceffiones quarundam fpecierum, tum temporis nondum indici infertarum.

EIV S DEM de plantis quibusdam obferA 5 
nationes Gottingae 1762. 8. pgg. 76. Enatae hae funt plurimam partem ex indagine ftirpium horti vel agri Gottingenfis, nonnullas hortus Catleburgenfis \& Nannianus, qui Herzbergae fuit, fuggeflit. Hifee mixtim propofitis quasdam plantas curatius cel. A. definiuit, varietates ad fpecies fuas reduxit, \& vitia quaedam in fynonymis $a b$ aliis commiffa emendauit, De combinatione nonnullarum ftirpium fcitas coniecturas, viteriori fcrutinio tradendas, exhibet.

E I V S D EM Illufrationes quaedam botanicae Gotingae $1766.8 . \mathrm{pgg}$. 55 . In incepto tramite hic perrexit cl. auktor, praeterquam quod de pluribas peregrinis, vel olim in horto proprio cultis, vel ab aliis fibi mif. fis, difquifiuerit.

\section{PHILIPPI CONKADI} LEONH AR D DifJ. inaug. de nous aquae Jalfae fonte detecto Es experimentis confirmato Gott. 1753. 4. pgg. 24. In commendationem quidem praecipue fontis falini Harftenfis, iam dereliai, confcripta fuit, fimul tamen tangit ftirpes in vicinia \& aliis locis, fale praegnantibus, crefcentes, quo inde indicium latentis fa. lis peti poffit, 
IOANNIS GOTTFRIED ZINN Objeruationes quaedam botanicae Es anatomicae ad ill. W E R L H O F I V M, Gott.1753. 4. pgg. 40. Botanica epiftolae particula agit de monftrofa quarundam plantarum fabrica, de diuerfitate calycis in quibusdam tirpium familiis, \& de quibusdam fpeciebus tum temporis nondum fatis definitis. Quum hifce hortus botanicus anfarn dederit, omitti hic libellus in hac tabula nequit.

E 1 VS DE M Catalogus plantarim borti academici of agri Gottingenfis Gott. 1757. 8 . In ordine plurimam , artem ill. H A L L E R V M fequutus, quasdam tamen alia ferie, naturali cognationi', vt exiftimauit, propiori, propofuit, praemiflis plerumque characteribus claffium \& generum. Plantas obícuriores ampliori defcriptione illuftrauit. Icon iuncta Zinniae pauciflorae, in memoriam eius a L INNAEO ita nominatae.

- EIVGEM Obferuationes botanicae commentariis Jocist. $R$. fcientiarum Gotting. traditae exftant Tomo 3.p. 425. /qq. quae ad nouarum quarundam ftirpium vel nondum rite diftinctarum cognitionem faciunt. Plures locietati ill. obtulit quinto commentariorum tomo, qui vero non prodiit, deftinatas. 
Der Hausvater Tom 1. Edit. 2. Tom. 2, 1766. Tom. 3. 1768 . Tom. 4. Hannouer 1769. \&. Oeconomiae quidem praecipue perficiendae intentus, perilluttris \& generofiffimus huius libri auctor OT TO L. B. A M VNCHHAV$S \Sigma N$, rem herbariam tamen, line qua oeconomia vacillat, nouis fimul inuentis auxit; \& applicato ad vitam communem viu venerabilem reddidit. Hic vera primus inter animantia \& ftirpes vincula, coniectura potius antea \& ingeniofo ratiocinio, quam obferuatione texta, naturain fungorum verminofam demonftrando, nexit; Hic experientia longa nixus hortos cum certiori redituum fpe maiorique decore colere docuir, agros prataque vel gramine fponte foeta vel foenoris infignioris caufa plantis fuccedaneis confita, rectius adminiftrare, fepesque firmius \& ornatius inftruere. Huius perfpicaciflimi viri auxiliis oeconomus plantas procurandas ad veras definitasque fpecies redactas videt, \& quae arbores fruticesque noftra clima ferant, quae repudient, cognofcit. Quae quoniam noftra regione explorata funt, noftroque in primis coelo adaptata : perenni merito \& fplendidiffimo honori noftri botanici ducant, tantum virum, totque aliis grauioribus negotiis obrutum, nec eorum agellum in defpectu habuiffe. 
DAVID SIGISMVNDAVG. E i T T NER. Selectiorum horti ftirpium defriptiones edere cum iconibus fecum conftituerat, fed non praeftitit valetudine aduerfa, quum viuerer, dein morte praepeditus. Imagines tamen quasdam eleganter pingendas curauerat, quae iam in heredum poffeffionem tranfierunt, inter quas fuiffe memini Erythrinam Corallodendron, Atraphaxin vudulacam, Polygonum frutefcens, Scurellariam lupulinam, Delphinium grandiflorum, Peloriam. Conferuae gelatinofae icon annexa eft nuperrime Differtationi de plantis cryptogamicis Gottingenfibus.

10 HAN TA V BE's Beiträge zur Na. turkunde des Herzogtbums Zelle. I. Band, Zelle; des Herzogtbums Luneburg 2. Band 1769. 8. Secundam partem huc proprie refero ob ftirpes varias, a cel. viro in itiuere per ducatum Luneburgenfem lectas, omiffas vero in euul. garis hactenus catalogis, quum eorum auctores arctioribus cancellis fpontaneas ftirpes complexi fint. - Liceat addere propria quaedam leuidenfia :

IOANIS ANDREAE MVRRAY Commentatio de Arbuto Vua vrfi, Gottingae 1764. 4. pgg. 66. Edita fub aufpicium muneris 
Profefforis. Vtiliffimae ftirpis Cellis petitae naturam botanice, \& chemicae analyfeos ope, vfum infuper medicum, \& oeconomicum, ex propriis obferuationibus \& experimentis, perfequitur.

EIVS DEM Abbandlung ron Scbober's Nitraria inferta plagulae $6_{5}$. libri Hannou. Magazin 1769. Operae pretium videbatur rariffimam hanc horti incolam, quae eoufque, etfi per plures annos adfucrat, flores non emiferat, nec vix alibi nifi affufa aqua falita, tanquam primitias noui muneris defcribere. -

FRIDERICI GVILIELMI WEIS Difr. inaug. Plantae cryptogamicae Florae Gotting. Gott. 1769. 8. Quae differtationis titulo prodiit fcriptio initium eft maioris, qua firpes hae fyftematico ordine exhibebuntur, characteribus fuis \& fynonymis inftructae. Fungos vero, vtpote animalis naturae, exulare iubet. 


\title{
Sectio 2.
}

- tirpiva sponte crescentiva

\author{
R A T 10 .
}

\section{1 .}

Qusm autem in limitibus inter hortenfes plantas \& agreftes conftituendis obtinere difficultatem fupra dixi, eadem denuo fefe exferit, dum de fpontanearim finilus ab vrbe noftra difquiritur, nifi fecundum tempus apud nos itineribus botmicis impendi folitum, h. e. dimidiae diei fpatium, metiri illos velles, quod nimirum rarius ob fudiofam follertiam, qua plerique bocanices alumni in reliquas do. ctrinas incumbunt, excedere licet. Hac lege fne dubio motus illuftris A B II ALLER initio ${ }^{*}$ ) nonnifi ftirpes, intra milliare primum circa vrbem fponte crefcentes, hortenfibus adiunxerat. Transgredi tamen hofce cancellos in indice ad minimum \& proftancia haud exigui plantarum remutiorum numeri, \& ardentior quorundam in flores amor, iubent.

\section{2.}

*) Enumeratio Pir piun borti Gotting. 1743. Praef. 
16 Sect. 2. Stirpes Jpontaneae.

\section{§. 2.}

Senfin ideo ampliatus fpontanearum campus eft, collectis \& in Hercynia ad Bructerum montem, Wernigerodam, fpecum Baumannianam, Blankenburgum, arcem Regenftein, \& Stollbergam vfque plantis ; iisdemque in plagis feptentrionem fpectantibus circa Hannoueram, Cellas, ad ericetum Luneburgenfe vfque, conquifitis; ratione quoque habitaftirpium vicinạe Eichsfildiae dextrorfum ab vrbe fitae partis, vbi lacus Seeburgenfis praecipue, praeter ea loca, per quae in Hercyniam tenditur, ve Giebelhaufen, Lindau, frequentsri folet; nec plane neglecta finiftrorfum fylua Sollingenfi; migratione denique verfus meridiem per Mundam in Hafliam ad vrbem Witzenhaufen, Caffellas fere vfque \& montem Weiffner inftituta. Fructu fane non caruit, haecce omnia loca perquirere, quippe quae multarum plantarum notitiam dant, quae confinia vrbis nofrae fugiunt, quarum haud paucae etiam in aliis regionibus raritatis nota fe commendant.

\section{3.}

Nam Hercyria vegetabilibus non minus, quam metallis diues, montofa \& fyluis abieguis confita, quas pafcua tamen fertilifima fac. 
faepe dirimunt, copiam Suecicarum \& Helueticarum, earum nimirum, quas ill. $\triangle B$ B A LLER ${ }^{*}$ ) quinto a vertice numerato alpiun fuae patriae articulo legit, fuppeditat. $\mathrm{Ha}$ rum inter praeftantiores, \& in locis vrbi propioribus vel deficientes vel parce obuias, re. ferendae Melampyrum fyluaticum, Arenuria faxatilis, Digitalis purpurea \& Digitalis lutea magno flore c. B., Senecio nemorenfis, Centaurea phrygia, Polygonum Biftorta, Calium faxatile, Circaea alpina, Phyteuma orbicularis, Hypocheeris maculata, Arnica montana, Tuffilago alba, Viola tricolor, paluftris \& montana, Chaerophyilum hirfutum, Cordamine hirfuta, Orobus tuberofus, Dianthus carthufianorum, Ly hnis vifcaria, Thefium Linophyllum, Genifta pilofa, Sanguiforba officinalis, Athamanta Meum, Geranium pratenfe \& fanguineum, Pinus Larix \& fylueftris, Lunaria rediuiua, Statice Armeria, Euphorbia Cypariffias, Sambucus Ebulus, Pyrola vniflora, minor \& fecunda, Vaccinium Vitis idaea, Aretium Lapps capitulis glabris, \& quae omnibus reliquis tam ob nemen quam pretium praemitti debuiflet, Hercyniae fere propria, Arabis Halleri. Circa Herzbergam occurrit iam, vbiuis per Hercyniam crefcens,

Vio.

*) Hifforia Pirpium beluet. Praef. pag. 8.

$B$ 
Viola tricolor, porro Herniaria glabra, Cy. nogloffum apeninum, \& Chryforplenium oppofitifolium.

Bructero monti non eae quidem diuitiae Itirpium funt, quae vulgo cenfentur, ita ve vix minimo Heluetiae monti aequiparari poffit. Afcenfum tamen, non tam decliuitate quam vliginofo folo \& faxis grandioribus moleftum, remunerant Anemone al pina, Hieracium alpinum, Sonchus alpinus (qui tamen \& inferius reperitur), Ranunculus aconitifolius, Empetrum nigrum, Satyrium albidum, Betula nana, certiflima montis ciuis, \& in vligino. fis \& turfaceis crefcentes ftirpes, Vaccinium Oxycuccus \& vliginofum, Andromeda Polifolia, Drofera rotundifolia \& longifolia; varietates denique quaedam notatu digniores, vt Rumex acetofa $\varepsilon$, fiue Acetofa montana latiori folio rotundo в о C c., Solidaginis virgaureae varietas, $f$. virga aurea Broccenbergenfís т н A L., Phyteuma fpicata f́ica ouali obefa, Salicis capreae var. foliis longioribus \& rugofis H A LL. Betulae albae varietas humilis $f$. Betula pumila $z$ AN ON. Delectauit me quoque in fylua, quae fenfim ad ip. fum montis faftigium ducit, videre varios flores coeruleo aliss colore imbutos, album prae fe ferentes, egr. in Campanula decur- 
rente, Prunella vulgari ${ }^{*}$ ), quam diuerfitatem in alpibus Lapponicis iam ill. A LINNE $\left.{ }^{* *}\right)$, in Helueticis ill, A В H A L L ER ${ }^{* * *}$ ) obferuarunt, \& pedetentim ingruentem ftirpium pro diuerfa altitudine $* * * *$ ) mutationem fcrutari, fiue haec a diuerfa aëris preffio. ne, fue calore diuerfo, fiue foli natura dependeat. Multae ceteroquin plantae Bructero competunt, sliis locis communes, fed ftaturae minoris, habitus horridioris \& villofum tegmen haud raro contrahentis.

Difficilior adhue graminum \& cryptogaB 2 mi-

*) Sed et extra Bructerum in Hercynia ipfa haec co. lorum mutatio mihi occurrit in Campanula totundifolia, Serratula aruenfi, Arctio Lappa, quod pallidius rubrum apparuit, prout in $\mathrm{m}_{\text {。 }}$ Pletfenfi vicino Serratula tinctoria albo colore obuia cft. An aëris frigidioris ea vis eft? ficur in hortis flores cocrulei iufo ferius autumno erumpentes, egr. flores Senecionis ele. gantis, Afteris chinenfis, impallefcere con。 fpiciuntur.

**) Flora Lappon. Proleg. $5.16, k$. ***) Hiff. fir.p. Helu. Praef. pag. \&.

****) Ex calcuí cel. H O L MA AN I (Commerit. foc, R. Jc. Gott. Tum 4. p. gz.) barometricis obferuationibus fuperfiructo, Bructeri vertex 2571 , vel, menfura barometri alitcr nonnihil aeftimata, 2799 pedes Parifinos fupra Go5. tingenfe folum eminet. 
micarum firpium Hercyniae delectus eft, quarum vero copia inopiam propiorum vrbi noftrae tractuum abunde refarcit. Inde petas Nardum ftrictum, Carices varias rariores, Scirpum cefpitofum, Eriophorum vaginatum, Iuncum fquarrofum \& pilofum $\delta, f$. gramen nemorofum hirfutum latifolium $\mathrm{S} \mathrm{C} \mathrm{H} \mathrm{E} \mathrm{V} \mathrm{C} \mathrm{H-}$ ZER I; inde Lycopodia praeftantiflima, annotinum, Selaginem, alpinum, complanatum, Polypodium aculeatum, Pteriden aquilinam, Ofinundam Lunariam \& Spicant, Lichenem islandicum, Lichenis ericetorum varietatem, pelta feffili plana ( $\mathrm{I} \times \mathrm{N}$ N. Syjt. "rat. Ed. 22. Tom. 2. p. 709. н а L L. Hift. ft. belu. n. 2050) Sphagnum paluftre vtriusque varietatis, Bysfum iolithum, Byffum longiflimam tenerri. mam niueam (H A L L. Hiff. $n, 2108$ ) in fodinis, Mnium polytrichioides, Clauariam co. ralloiden \& faftigiatam, Equifeta varia, fylueftre, fluuiatile, paluftre $\beta L_{L}$ I N N. $f$. minus polyftachyon $C_{0} B_{0}$, eiusque varietatem aliam f. varietatem floriferam, apice caulis longe in nudam virgam producto (Var. III. H A L L. Helu. n. 1677.).

Tractum circa Blankenburgum acceptum reddunt botanicis praecipue variae rupeftres plantae, vt Saxifraga petraea, Semperuiuum tectorum, Sedum rupeftre, Laferpitium latifo- 
tifolium, Athamanta Ceruaria, Centaurea paniculata, aliaeque quaedam in pretio maiori habendae, nifi \& in vicinis nobis rupibus Waakenfibus minori opera colligerentur. Aconitum napellum primus, quantum fcio, a. 1768 in prato praeftantifimis herbis inftructo, quesd a monte marmoreo Krockenberg Blankenburgum ducit, detexi, certe cum Aconito lycostono flore cosruleo (OE D. Flora Dan. Tab. 133.), licet varietatem vulgarem fl. luteo fociam haberet, non a me confufum. Nullibi copiofiorem vidi Lathyri tuberofi, ob tubers oeconomis dilecti, prouentum, quam in aruis Blankenburgum inter \& Wernigerodam; cuius pofterius dietae vrbis prata vmhellatae variae, Peucedanum Silaus, Chaerophyllum aureum aliaeque quaedam iam dictae, cum Spiraea Filipendula, Centaurea Calcitrapa, ornant.

Ad montem Altenftollberg \& viciniam inuitant praecipue Allium angulofum, $\mathrm{An}$ thericum ramolum, Aftrantia maior, Afperula tinctoria, Galium boreale \& montanum, Melampyrum criftatum, Cheiranthus eryfimoides, Achillaea nobilis, Gyplophila faftigiata, Orobanche maior, Inula falicina, Athamanta Libanotis, Ribes alpinum. Non vltra bofce terminos, vixque ad arcem Regen-

$$
B_{3}
$$

ftein, 
Atein, finit euagari fpatium 14 dierum, quod in itinere in Hercyniam \& viciniam confumi folet. Nullus t men dubito, quin ftirpes variae Hercynicae а ти д г 0 olim lętae, quae iam interiiffe videntur, reuiuifcerent iterum, imo aliae hucusque praeteruifae in confpeCum venirent, modo otium fuppeteret, denfas fyluas locaque a commeatu hominum remotiora peragrandi, nec obftarent alia impedimenta, quae incidere frepe in tractus cuiusdam Flora edenda ill, A B H A L LER ${ }^{*}$ ) dolet.

\section{4 .}

Rarius, ob diftantiam locorum fumtusque impendendos, in duicatum Cellenfem \& affinem terram ftirpiam caufa excurritur, qui igitur tractus vberrimorum fpicilegiorum fpem non exftinguunt non modo, fed accendunt. Eft vero eius regionis, ob numerum mineralium, quae inter pix in arena \& fontibus reperiunda \& falinae celebriores, \& petrefactorum, pifcium praeterea concharumque, quas riui fluminaque ibidem copioíe alunt, \& aliis naturae ferutatoribus acceptae, triplex plurimam partem natura, vel paludofa turfaceaque, vel arenofa, vel erica fociis-

que

*) Flora Ienenfis R V P P. Praef. p. 4. 
que plantis confita, quae igitur, vtpote $a b$ indole propioris nobis terrae magis aliena, rariores ibidem varias apud nos plantas progignit. Laeti ideo reportarunt Gottingenfes botanici Hydrocotylen vulgarem, Myricam Galen, Hottoniam paluftrem, Gentianam Pneumonanthen \& filiformem, Ericam Tetralicem, Salicem rosmarinifoliam, Callam paluftren, Schoenum album \& Schoenum fpicis gemeilis obefis HA L L., Iuncum caule brachiato foliis fetaceis floribus fafciculatis ad ramos fefilitibus н А L. , Pini fyluefres var. $\gamma$. fue Pinaftrum pumilionem c Lvs.; \& ex arenofis, Illecebrum verticillatum, Linum Radiolam, Scleranthum peren. nem, Ornithopum perpufillum, Geniftam anglicam, llicem aquifolium, Corrigiolam littoralem, Verbafcum Thapfum ftigmate bicolei н A L L., Thymum Serpyllum S. f. anguftifolium hirfutum C B ; quibus addo inclytam noftro tempore Arbutun vuam vrfi, \& Senecionem aquaticum HV DS ON. Numerofae vero grauifimaeque Florae noftrae acceffiones futurie effent, fi \& tractus cius plagae remotiores circa Luneburgum, Vlzam, Dannebergam, quin omnis reliqua Hannouerana terra cis Albim fita, quod fumen ibidem pro termino effe poffet, perquirerentur. A qus luitratione, quantum fructuum redundatu- 
24 Sect. 2. Stirpes Spontaneae.

rum effet, a cel. т $\Lambda$ $\vee$ в E* ${ }^{*}$ ) in itinere confignatis plantis colligi iam poteft. Nam obuiam illi venerunt Erica fcoparia, Mentha Pul gium. Teucrium Chamaedrys, Saxifraga Cotyledon, Statice Limonium, Stratiotes aloides, Illecebrum P'aronychia, Elymus arenarius, Arundo arenaria, Globularia vulgaris multaeque alise nondum receptae.

\section{5 .}

Mons Weiffner Hafliacus, fyluiger plurimam partem, mufcola vero fupra planitie depreffus, (lithontracibus, qui ad radicem eius effodiuntur \& vicino pago Almerode, vbi crucibula ifta per totam Germaniam \& extra acceptiffima parantur, \& fchifto aluminari, qui paullo remotius frangitur, celebrior) vix vllas fert plantas comparatione cum vicinioribus locis facta, fibi genuinas, excepta Trollio europaeo, aliquas cum Hercynia commu. nes, ve Atnicam montanam, Polygonum Biftortam, Ribes alpinum, Orobum tuberofum, Thefium Linophyllum, Nardum Atrictam, Eriophorum vaginatum. Neminem tamen illum arire ob praeftantes in via repe. riundas nobisque pretiofiores plantas poeni. tebit, ve circa pagum Grofienfchneen, $\mathrm{Li}_{\text {. }}$ tho.

*) Beitrige zur Nuturkunde des Herzogtbums Laneburg, zwosis. Stück, Zelle 3769. 
thofpermum purpuro-coeruleum, Euphorbiam Cyparifiam, Eryfiphe ibidem faepe confpurcatam, remotius, Spartium fcoparium, Pyrolam minorem, Geniftam germanicam, Pedicularem fyluaticam; \& fi per vrbem $\mathrm{Haff}_{\text {. }}$ Witżenhaufẹn, quae proximas nobis vineas alit, tenditur, elegantiffimam Germaniae arborem, Mefpilum Germanicam, copiofius ibidem cultam, robuftis vero, fi fponte fefe diffeminat, fpinis munitaın.

$$
\text { 5. } 6 .
$$

Mundam migrare, Antirrhini Cymbalariae, abunde ex fiffuris rupium vicinarum efflorefcentis, Lylimachiae nemorum, Teucrii fcorodoniae \& Spartii fcoparii caufa, operae pretium. - Spiraeam Aruncum, quam ill. AB HALLER \& hercynicis annumerat, ad fyluas circa Caffellas transfero.

\section{7 .}

Reliata hac plaga leuiter \& atcingenda illa dextrorfum ab vrbe noftra fita, ad Eichsfeldiam vel pertinens, vel illi vicina, frequentari a botanices cultoribus folita. Chryfanthemum fegetum, peftem illam frumenti in ducatu Cellenfi, nullibi propius, quam inter pagum Hannoueranum Ebergözen $1 \frac{7}{2}$ milliare diftantem \& pagum Eichsfeldenfem Wull- 
26 Sect. 2. Stirpes fpontaneice.

brechtshaufen reperi, terra magis arenofa \& Spergulae artienfis prouentui fauentio: i. Fertiliorem longe meflem fuppeditat vicinus lacus Seeburgenjis, ab vrbe duo milliaria diftans, copia aquaticarum plantarum defideratiffimus. Ibi inter notatu digniores crefcunt Cicuta virofa, Ranunculus Lingua, Nymphaea lutea, Sagittaria fagittifolia, Potamogeta varia, Myriophyllum fpicatum, Butomus vmbellatus, Comarum paluftre, Scirpus lacuftris, Vtricularia vulgaris, Hydrocharis Morfus ranae, Spergula nodofa: quarum varias \& in lacu Denkershaulen \& Landolffshaufen etiam reperies; ve taceam alias, quas e longinquo non petas, quum e vicinia poffis.

$$
\text { §. } 8 \text {. }
$$

Ad ftirpes circa Nordbsimum, nec Gottingae, obuias referas Herniariam glabram, \& Parietariam officinalem, de quibus vero multo me vberius \& exactius celeberrimus w I L IC II, Nordheimenfium olim iam vero Clausthalienfium medicus, qui felici connubio medicinae exercitium cum ie herbaria iungit, dieturus effet, qui \& Polygonum du. metorum, nouam Florae Gott. ciuem, \& Montiam fontanam var. $\beta$ minorem, vicinis vrbi ifti plantas, mecum communicauit. Mittere quoque placuit viro $\mathrm{cl}$. Chenopodium vrbi- 
vrbicum, pariter omiffum, in prsefectura Rotbenkircbon autem ab ipfo lectum; ad quem locum in primis mons vicinus Grubenbagen, plantis onuftus, in quo Cytitus Laburnum fpontaneus, inuitat. Acorus Calamus vix propius quam circa Einbeccam repertus. In lacu Denkersbaufen/i Nordheimo non multum disiuncto, Senecio foliis tomentofis, inis femipinnatis fuperioribus lingulatis amplexicaulibus н A L z. Gott. n. 8. p. 402. \& Selinum paluftre crefcunt.

\section{9.}

In horum omnium locorum prouentibus colligendis induftria botanicorum Gottingenfium verfata eft. Verum non defunt in vicinioribus bene multae ftirpes non folum in re herbaria initiandis, fed \& botanicis ipfis gratiflimne. Nam \& terrae infignis varietas exftat \& ftationum. Fo flie quidem fuburbanae \& aquarum receptacula, quae olim munimenti partem effecerunt, paluftrium ftirpium maiorem ante bellum, quam nunc, repletis iftis \& in hortos vel agros laetos commutatis, aluerunt; vnde multas quidem longinquius iam conquirere oportet. Per latum ambitum autem vrbem vel agri fine taediofis artificiis, operam plerumque lucri fpe fallentibus, praeftans frumentum proferentes cir- 
cumdant; vel pascua \& prata, aliquantum $\mathbf{v d a , ~ \& ~ o b ~ T r i g l o c h i ~ p a l u f t r i s ~ n o n ~ i n f r e q u e n - ~}$ tem mifcelam, pecori tanto magis expetita \& falubriora; vel borti, magis tamen vbertate fructuum, quim decore placentes, mox iepimento cincti, mox aperti \& culinaribus herbis, quas inter Solanum tuberolum latifimum fpatium occupat, referti. Nicotiana aegrius videbis folum homines in vicinia corrumpere. Vbi haec definunt, colles montesque furgunt, partim fteriliores, nec vllam fere culturam admittentes, ve mons Heynbergenfis, partim Jylua nemoreque tecti. Plures remotius paullo fyluae exftant, fatis denfae, ex Fago plurimam partem, Quercu, Carpino, Salice capraea, Populo tremula, Acere pfeudo-platano \& campeftri, Corylo; vel Cratnego torminali, Pyro, Malo, Cerafo inter reliquas mixtis; Fraxino, rarius Betula alba, cuius tamen pone praefecturam $\mathrm{Ra}$ dolffshaufen infignior fylua; quarum variarum truicos Hedera fcandendo ornat. Rariores nobis arbores VImus *) \& Acer platanoides funt, folitariae fere femper. Taceo iftas, ad foffas, vt Salices varias, Alnum, Populum nigram,

*) Vulgaris in Suecia, etfi vltra Helfingiam \& Finniam verfus feptentrionem vix reperiunda. I I N N. Flor. Suec, n, 286, Flor. Lapp. Proleg. \&ै, $\gamma$. 
\& ad vias \& pagos, ve Sorbum aucupariam, Sambucum nigram, Tiliam, apud nos ve alibi, crefcentes, Minus fauens folum noftrum coniferis arboribus, abiegnas fyluas nonnifi arte, egr. prope praedia Heffendreifch \& Kerflingeroderfeld profert, \& vix Iuniperos, nifi exiles mifereque flexэs, nec ad eam dignitatem ac in Suecia affurgentes. Taxus tamen in monte Pleffenfi hinc inde crefcit. Dumeta frequentiora margines faepe agrorum pafcuorumque occupant, ex vulgaribus plerisque iftis fruticibus, Euonymo. Corno fanguinea, Opulo, Oxyacantha, Pruno fpinofa, Rofis variis, Rubis, Rhamnis, Ribibus, Xylofteo, Liguftro, rarius Berbere, conflata; quos haud ingrato fpectaculo Clematis Vitalba obuoluit. Admifcent fefe gratiores exteris Sambucus racemofa, Lonicera Periclymenum \& Staphyllaea pinnata. Quas arbores \& frutices vel ideo attingere non fuperuacuum, quod attentior exinde faepe foli naturam, quin plantas herbaceas vicinas, colligere poteft. Nec defunt nobis campi aprici, vifum Ononide, nares Serpyllo recreantes, ouibus ad minimum, nifi aliis, Feftucae ouinae pabulo inferuientes; vligines fertiliores inundataque tam natura quam arte formata; porro rupes haud fpernendae, ad pagos Waaken \& Rheinhaufen, ex quarum filturis 
30 SeEt. 2. Stirpes Jpontancae.

angulisque fuccofae multae plantae Filicesque emergunt; quin, licet a inori nobis disiunctiffimis, ad pagum Harfte tamen varias maritimas legere datur. Arenofarum vero infrequentiam dolet botanicus non oeconomus; neque eae inter ftirpes flore carentes fuppetunt diuitiae, quae in feptentrionalibus ex pino va. ria fyluofis montanisque magis regionibus.

Sub hac locorum varietate arrident tamen quaedam prae reliquis copia \& pretio herbarum, tum \& propinquitate ea, vt iter fpatio dimidii vel vnius diei abfolui poffit. Horum igitur felectus iam eft indicandus.

\section{10.}

Vicinum fabricae $W e b n d e n / i$, qua charta paratur, nemus, in quod primo vere excurri folet, commendabile praecipue reddunt 'Tuffilago hybrida, Ranunculus lanuginofus, Galeopfis Galeobdelon, Arum maculatum, Circaea lutetiana, Marchantia polymorpha, $\mathrm{Pe}$ ziza fcutellata, Campi fuperius fiti ferunt Li. num tenuifolium, Sium, Falcariam, Bupleurum falcatum, Anemonem ranunculoiden, Allium oleraceum a Zinnio omifum. Et in fylua lupra hos eminente Sambucus racemofa viget, 


\section{S. II.}

Mons Plefenjis, quem adbue rudera arcis antiquiffimae venerabilem reddunt, vna parte fylua nectitur, vel iple arboribus veftitur, altera laceribus praeruptis calcareis, omninoque fere nudis, terminatur. Multas cum monte prope pagum Lutielengen gerit communes plantas, alias tamen proprias. In hoc Orchidearum multas conquirimus, ve Serapiam latifolian, grandifloram, cum varietate foliis enfiformibus HALL., rubramque ( L I N N. Syft. ant. Ed. 12.), Ophrydes nidum auis, ouatam, infectiferam, Orchides varias; Atropam Belladonnam, Chryfanthemum-corymbiferum, Aconitum lycoctonum, Impatientem noli tangere, Serratulam tinctoriam, Conuallariam Polygonatum, Melicam nutantem, Cynofurum coeruleum. Propriae vero funt monti Bupleurum longifolium, rariffima alias extra moncana Heluetiae planta, Phyfa. lis Alhekengi, Authericum Liliago, Teucrium Botrys, Hefperis matronalis, Hippocrepis comofa, After Amellus.

$$
\text { S. } 12 .
$$

Nemo moleftum ducat in itinere ad $\mathrm{pa}$ gum Waake diem confumere, quem eundo per pagum Rohringen \& praedium Heffendreifch 
32 Sect. 2. Stirpes Jpontaneas.

dreifch attingimus, tam ob ftirpes in via, quanı ad ipfum pəgum colligendas.

Grata eft fub aduentum ad p. Rohringen Ophrys Monorchis; circa Heffendreifch vero Anemone fylueftris, Trifolium montanum, Iafione montana, Cardamine amara, Ophioglorfum vulgatum. Magis vero allicit ipfa me. ta; rupeftris enim partim eft tracuus Waakenfis, partim vliginolus, partim fyluofus. In rupibus Filices numerofas, Acroftichum adeo feptentrionale, Rumicem Acetofellam nobis rariorem, Dianthum Armeriam \& proliferum, Iherin nudicaulem, Trientslem euro. paeam, reperies; vliginofa vicina, Veronica fcutellata, Pedicularis paluftris, Hierscium paludofum, Menyanthes trifoliata, Epilobium paluftre, Eriophorum polyftachion, oc. cupant; \& paullo remotius Hypericum humifufum crefcic. - Vifu quoque in pago dignus eft hortus, quem perilluftris \& generofiff. Regis archipincerna, A WANGENHEIM, ad aedes fu's inftruendum curauit, ve qui ad normam hortorum anglicorum adornatus, multisque egregiis arboribus borealis Americae, etfi adhuc iunioribus, referrus.

\section{13.}

Solum circa pagum Rbeinbau/en, ifti in multis fimile, multas vtrique communes ftir- 
pes gignit, quas inter Dinnthum deltoideum, Gnaphalium arenarium, Sedum Telephium Var. $\varepsilon$, maximum, Sedum album, Trifolium alpeftre, Hieracium vmbellatum, numinare fufficit. Nec minus fertilis fuppetit in via illuc tendente, per pagum Geifmar, in cuius fylua olim Prunum Padum, etfi folit riam, inueni, \& vill m Diemern, collectio. Lathyrus latifolius \& Allium carinatum exempla funto.

\section{14.}

Alienae ab hifce omnibus naturae pratum quoddam amplum, a pago Harjte paffibus circiter ducentis diremtum, plantas profert, vtpote fale marino impraegnatum, in quo Glaucem martimam, Afterem Tripolium, Arenariam rubram $\beta$ maritimam, Triglochin maritimum, \& Atriplicem haftatam, quae quidem \& alibi reperiunda, inuenies.

$$
\text { 5. } 15 .
$$

Dilectae quoque ftationes funt praedium Kerfliingeröderfeld, ad quod in primis exfpatiari operae pretium ob Leucoium vernum, Geum riuale, Valerianam dioican, Gentianam Amarellam, ciliatam, \& cruciatam, quae vero remotius crefcit, \& Conuallarian verticillatam; pagus Lutielensen, in cuius monte vicino, plantis ditiflimo, legitur Litholpermum purpuro - coeruleum, Anemone 


\section{Sect. 2. Stirpes Spontaneae.}

fylueftris. Praedium Rafemïble, quod adeun: tes in via prope pagum $R o \int d$ dorf \& vltra Sal. uiam pratenfem quierimus, placet ob plantas aquaticas, Zanichelliam, Hippuridem aliasque in pifcina reperiundas. Gratus etiam tractus circa m. Clausberg. Quibus addo fyluam fupra pagum Elliebaufen fitam, prope quam rariorem alias apud nos Orchidem coriophoram \& Serapiadem longifoliam ( $\mathrm{L}$ I N N.Syft.n.) legi.

Sunt \& alia in vicinia quaedam loca, quae herbarum caufa vtiliter perquiri folent, vt tractus circa diuerforium Eichenkrug, vbi Adoxa mofchatellina, Lathraea Squamaria; tractus Eulenloch; mons Hagen, vbi Peplis Porcula, Cochlearia Coronopus; variaegue praefecturac. Sed fupra dicta pro indicato temporis termino primaria funt, vixque, nifi longinquiora, infrequentioribus quibusdam plantis, idque non tan confpicua fpecierum vbertate, locum dant. Ita \& hinc inde propius vrbi quaedam ftirpes proftant, apud nos non vulgares, quse tranieundo ad remotiores ftationes decerpuntur, vt Lythrum Hyffopifolia in agro pone molendinum Gräzelii, Trifolium fragiferum circa molendinum prati INafch, Thalictrum flauum in prato prope hortum Saxii, Saponaria officinalis in ipfo adeo aggere, crefcens. 


\section{Sect. 2. Stirpes Spontonleae,}

\section{\$. 16.}

Exemplit modo dediffe me, exclufis ma. xime vulgaribus, non perfectum cuiuslibet loci flirpium indicem, vel me non monente, quiliber perfpicit; quae tamen ad induftriam ftirpes quaerentium excitandam, normamque quandam itinerum, praeeunte ill. A $L_{1 \mathrm{~N}}$ $N E^{\prime}$ ) exhibendam, aliquid ponderis habent。 $\mathrm{Nec}$ de omnihus plantis exiftimatum velim, quod extra ftationes indicatas non occurrerent: perinde nimirum eft, quo praecile loco ftirpes innotecant, modo in notitiam veniant. Selectum exteris placiturum facere difficilius adhuc eft, fiquidem multae exiftunt plantae, vtut in quibusdam locis vulgatae, ina. liis tamen infrequentiores, vel plane deficientes. It defunt in fercilifima plantarum, earunique cultorum, Suecia, Phyteuma fpicata, Aiuga reptans, Scrophularia aquatica, Galium fyluaticum, Holofteum vmbellatum, Crepis foetida, Lacluca virofa, vulgares maxime apud nos; \& nuperrime **) modo Arum maculatum, Matricaria Parthenium, Serapiades quaedam,

$$
\mathrm{C} 2 \text { aliae, }
$$

*) Differtatio, Herbationes Vifalienfes in $A$. moen. acad. Vol. 3. p. 425 Sq7.

**) R F TZI v $\mathrm{s}$ in Kongl. Veten $\int k$. Acadomiens Handlingar 1769 . p. $24359 q$. 
$3^{6}$ Sect. 2. Stipes Spontanear.

aliae, ius ciuitatis obtinuerunt. Anglia *) deftituitur Anemone Hepatica, Pulmonaria officinali, Lonicera-Xylofteo, Orobo verno rel. Et hoc quoque edocemur, quod haud raro intereant plantae vel Iponte, vel hominum opera, vbi ante copiofe emerferant, quod vel Gottingenfis Flora experta eft in Lythro Hyfropifolia, in Allio vineali, in va. riis paluftribus, ve Limofella aquatica, Butomo vmbellato, Potamugetis variis, olim in foltis fuburbanis repertis, aliisque. Ratione ftationum in perfectiori Flora non fatis curate locus definiri poteft, quum faepe accidar, ve intra anguftum modo fpatium plantae fpecies coarctetur, ve in Lithofpermo purpuro-coeruleo, Teucrio Botryte, apud nos apparet.

\section{17.}

Frequentius apud nos, quam in plerisque aliis academiis, excurfones, vt vocantur, botnnicae habentur, quauis fcilices hebdomade, quarum moleftias, fi quas, quoad botanices addifcendae ftudiofos, fecum vehane (nifi vnice in ducem, ob interceptam fpem nouarum detegendarum redundent), abunde compenfat folidior vegetabilium notitia, quae ne iisdem quidem in horto cultis acquiri poteft

*) Linna e Difr. Flora Anglica in Amoen. acad. Vol. 4 pag. 92. 
eft. Magna enim foli vis in mutanda facie, ftatura coloreque plantorum eft. Quas in horto, per pauca modo exempla \& vinico loco reclufa, in natali folo per nillena multisque aliis remixta vides, quae ipfa fua frequentia tanto magis animum afficiunt tantoque firmius memoriae fefe infigunt. Vt ne dicam, multas ftirpes, e. c. Filices, Mufcos, \& aquaticas, nifi arte fumtiofa prouideatur, naturae effe eiusmodi, ve in hort. feruari nequeant.

\section{18.}

Paucifimae, poft editos indices, fpontanearum accelfiones factae func; quid enim perfpicaciffini HALLERI aciem facile effugiet? $\mathrm{Nec}$ multum fpei felicioris in pofterum fpicilegii fupereft, nifi Florae noftrae limites amplientur, quod gratum femper vtileque futurum videtur, etiamfi nonnifi mutato noftrae, in Florae Hannoueranae titulum, nomine eueniret. Quas vero adhucdum, fecun Jum fupra defcriptum ambitum, comprehendat plantas, fequens index fignificabic, in quo iftas a b. z I N I o praecipue omiffas v, hortenfibus annumeratas, fed a me lectas vil ab aliis mecum communicatas, litteris diuerfae formae notabo. Virias autem, recenter modo ab ill. I IN N A O commemoratas vel curatius ab iplo determinatas, fecundum nouiflimam eius 
mentem indicabo; quod vt fiat luculentius, loca librorum allegabo. Et ne in omiffionis culpam incurram, ill. HALLER I aliorumque obferuationes, vbi opus videtur, in fubfidium vo abo; eandem ob rem in varietati= bus colli gendis ftu tiofus. Exiguus modo inter has numerus eft, (exceptis iis, quas Cellenfis ducatus profert,) egr. inter Carices, quem ipfe non legerim: ' nefas vero effet fidem aliorum cell. virorum in dubium vocare. Adiecta quibusdam littera $b$ indicio efto, easdem in horto quoque reperiri. Ex cryptogamicarum claffe, quarum examen femper facilius longe, quam graminum, exiftimo, praeter generum nomina, fpecies modo, vfu medico vel oeconomico celebriores, nominabo, vfque dum fingulas in abfolutiori indice vna cum reliquis defcribere vacet.

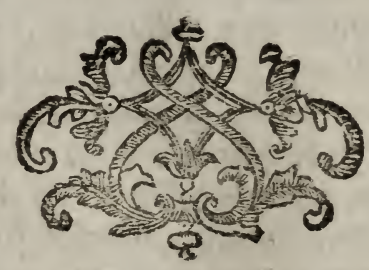




\title{
FLORA GOTTINGENSIS. Clalfis 1 . MONANDRIA.
}

\author{
MONOGYNIA.
}

H IPP VRIS vulgaris

Variecas, fpiralis *)

DI G Y N I A.

C ALITRICHE verna.

- - - attumnalis**) L OESEZ. Flor. PruIJ. Tab. 38. G ME L. Fl. Sib.3. Tab. I. F. 3。

Clalfis 2.

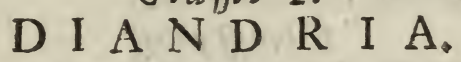

MONOG Y N IA.

I I GVSTR VM vulgare. h.

CIRCA E A luteriana, $h$. alpina.

VER O N ICA fpicata

- - officinalis h.

- - - ferpyllifolia.

- - Beccabunga.h.

- - Anagallis a quatica.

- $\quad$ - fcutellata.

C 4 $\checkmark \mathrm{E}$ -

*) Bina feruo memorabilia exempla , in pifcina praedii Rafemiihle a me reperta, quorum folia non verticillatim inferta, fed in fpiram contorta, caulem afcendunt. An alibi idem vifum conftantiusque, ita vt non varietates, fed fpecies 2, Hippuris verticillata \& H. fpiralis, confticui poffent? Nihil in fpirali alias deforme vidi.

**) Sexus partes non quidem examinuui, fed folia vbiuis linearia \& apice bifida fatis eam ab al. tera diftinguunt. 
VER ONICA montana. IINN, $S p, p l, E d, 2, p, x]$.

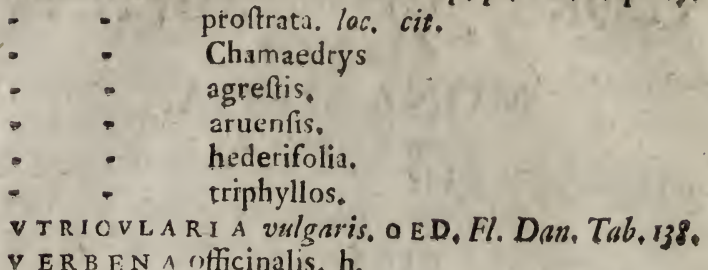

LY COP VS europaeus. $S$ A L V I A pratenfis. h,

D I G Y N I A.

ANTHOXANTYM Odordtum.

\section{Claffis 3 . \\ T R I A N D R I A. \\ MONOGYNIA.}

VALERIANA dioica, $\delta$, flore maiori; $\{$, minori, $h$.

- - officinalis. h.

- Locufta a, olitoria. h.

I R I S Pfeud-acorus. h.

$$
\delta \text {, dentata. }
$$

SCH OENVS Marifcus

- Gote. p. fpicis gemellis, obefis. HALL

CYPERVS flauefcens,

SCIRP VS paluftris.

$-\quad$ - cefpitofus,
- lacuftris.
fyluaticus.

I R O PHORVM vaginatum. 


\section{Sect. 2. Stirpes fpontaneae.}

ER IOPHORYM polyftachion.

NA R D V S ftricta.

$$
\text { D I G Y IA. }
$$

PH A LARIS phleoides.

arundinacea. ce, non picta.

P A N I CV M gla cum.

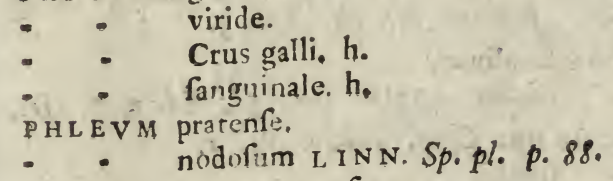

A L OPECVRVS pratenfis.

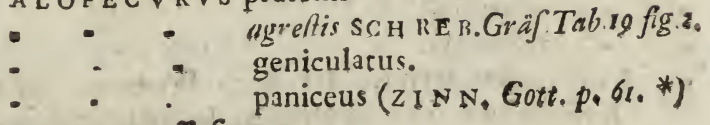

MILIV M effufum.

AGROSTIS fpica venti。

- rubra.

A I K A criftata.

$$
\text { capillaris. }
$$

- aquatica.

- cefpitofa.

- montana.

MELIC A nutans.

Po A aquatica.

- triuialis.

- anguftifolia,

- pratenfis.

- annua.

- compreffa.

- nemoralis.

BRIZA media.

*) Sub nomine Cynofuri panicei, quod vero ill, A LINNE repudiauit in $\$ p, p l, ? E d .2$. p. go. 
DACTYL IS glomerata.

CY NOSVR V S criftarus.

- - - coeruleus.

PESTVCA OUIna.

- duriufcula.

- elatior. SGHREB. Griff Tab. 2.

- fluitans. loc. cit. Tab.3.

B R O MI v fecalinus.

- - mollis linN. Sp. 'pl. Ed. 2. p. 113. S CHREB. Graj. Tab. 6. Fig. 1.

- fterilis.

- - aruenfis.

- $\quad$ teftorum.

- - afper mIHI. Ita voco Bromum foliis hirfutis per oras afperrimis, locuftis glabtis, teretibus nouemfloris. HAL L. Hift. jt. Helu. n. $1503 . *$ )

- pinnatus.

A VENA elatior, $\alpha$,

$\beta$, Gr. nodofum auenacea panicula radice tuberibus praedita $C_{0}, B,(Z I N N$. Gott. p. 69.)

- - fatua h.

- $\quad$ flauefcens.

- pratenfis.

- $\quad$ pubefcens (LIN S. Sp.pl. 2, App.p.166j) quam L I N N. antea (Sp.p. IIq) Varietatem $\beta$ Auenae pratenfis habuit. Eft Au. itriantha, lo.

*) Habitu proxime ad Bromum giganteum (schreB. Graf: Tab. it.) accedit, cui vero fpiculae quadriflorae. $\mathrm{Cl}$. W I L L I CH Nordheimi inuenit, ego in fylua Pleffenfi. 


\section{Sect. 2. Stivpes fpontanead.}

locuftis teretibus ereftis, petiolis fericeis gluma exteriori lacera H A L L. Hifl. 13, 1498*)

ARVNDO phragmites.

L'OL IV M perenne。

HOKDEVM murinum.

- - cylindricum miHI, f. Hord: fpicis rigidis cylindricis calycinis glumis ariftatis - HA L L. Hill. 12. 1537 .

TRITICVM repens, $a$, muticum MIHI $\beta$, ariftutum $\mathrm{M}_{0}{ }^{* *}$ )

T R I G Y N I A.

MONTI fontana $\approx$,

$\beta$, Var. minor M I CHEL:

HOLDSTEVM vmbellatum.

\section{Clafis 4. \\ T E T R A N D R I A.}

MONOGYNIA.

DIPSAC v s fullonum. $h$.

- pilofus $\left.{ }^{* * *}\right)$, h.

SC ABI OS A 1uecifa, h.

- aruenfis. h.

- columbaria.

SC AERA I DIA aruenfis.

A SPER V L A odorata. h.

- $=$

tincturia.

$G A=$

*) Occurrit in collibus apricis.

**) Eft Var. $\beta$ haLI. Hift. n. 1426, cuam LIN N. o'im (Spec. Ed. r. p. 86) Triticum caninum vocauit; licet verique HALL. calyces 5 floros, non 4 floros, adfcribat. ***) Cr. in fylua, quae Gotringa ad pagum Edichaufen tendir. 


\section{$\$ 4$ Sett. 2. Stirpes fpontaneae.}

OALIV M paluftre.

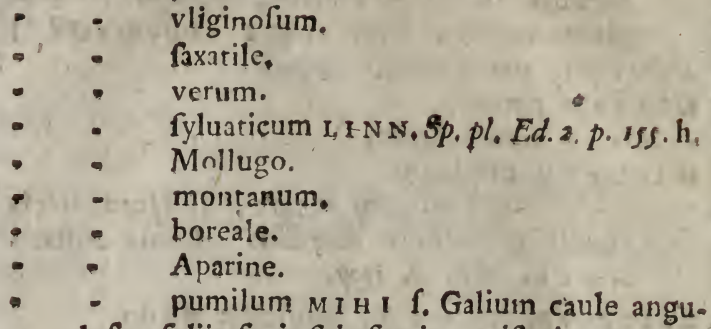
lofo, foliis fenis fubafperis, ariftatis, $\mathrm{H} \wedge \mathrm{L} \mathrm{L}$ Hif. belu. n. 715 .

Pl, A T A G O maior. h.

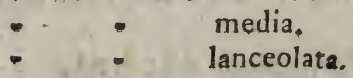

SANGVISORBA officinalis. h,

C ORNVS mas. h.

- $\quad$ fanguiriea, h.

IR A PA natans (ZINN.)?

A L C HEMILLA vulgaris h.

D I G Y I A.

APHA NES aruenfis.

Ci vS C T A curopaea $\Leftrightarrow$, maior.

$\beta$, Epithymum, $b_{\text {* }}$

TETRAGYNIA.

ILEX Aquifolium.

POTAMOGETON natans.

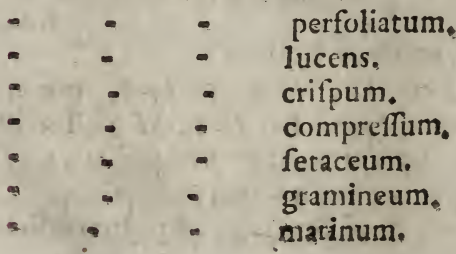




\section{Sect. 2. Stirpes fpontaneae:}

POTAMOGETON racemofum ( $f_{0}$ ramofum) anguftifolium C. B. Prodr. p. 10\%, n, I. Pin. p. 193. (ziN N. Gote. p. s6.j*)

SAG IN A procumbens.

\section{Claffis s. \\ PENT A N D R I A.}

MONOGY I A.

MYOSOTIS fcorpioides, $\alpha$, aruenfis.

$\beta$, paluftris.

- Lappula, h.

LI T H OSPERMV M officinale **) $h$.

- - a aruenfe.

ANCHVSA officinalis.

purpuro - coesuleum. h.

CXNOGLOSSVM officinale, h.

- - apeninum.

PVLMONARIA officinalis $\alpha$, folio maculofo, ho $\gamma$, fol, non maculofo. sYMPHYT V M 'officinale. Var. Flore albo. h. ASPERVGO procumbens.

IY C OPS IS aruenfis.

EC H I V M vulgare.

RRIMVLA veris, $a$, officinalis, $b$,

$\beta$, elatior, $h$,

MENYANTHES trifoliata. HOT TONIA paluftris.

I Y SIM $\Omega$ CHIA vulgaris, $\boldsymbol{a}$,

$\beta$, fos

*) Nonne haec eadem fpecies cum Potam, fe. taceo ?

**) Circa Blankenburgum inueni. 
46 Sect. 2, Stirpes Spontaneac.

ß. foliis binis, ternis,
quaternis н $A$ LL. $\left.H i \Omega_{0}, \sigma_{30}{ }^{*}\right)$

LY SI M A C H A nemorum.

- - Nummularia.

ANAGALLIS aruenfis, $\alpha$, flore phoeniceo, $b$ :

$\beta$, fi. coeruleo.

CONVOLVVLVS aruenfis.

\section{- - Cepium. \\ CAMPANVLA rotundifolia.}

- - Ceraicaria - Cfr. H A L L. Gote.

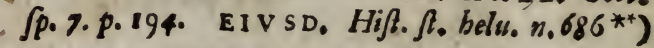

- : Rapunculus h. - C Cul. tura haud parum mutatur. Hortenfi enim

Ra.

*) Eadem lex imponit hanc fpeciem, pro di. uerfo foliorum numero, in varietates diuclle. re, quae Lythrum Silicariam. Varietas $\beta$ in foffis hercynicis crebra.

**) Huius loco b. ZINNIVS (Flor. Gore. p. s.f2) Campanulam thyrfoiden $L I N N$. , alpinam plantam, pofuir, feductus, vt videtur, B AVH I I Pinace $\beta .94$. $n$. ro. vbi proxime dieta, Campanula foliis echii, vocatur. Quod vero BAVHINI nomen in Prudromo eius p. 36. Campanulae Ceruicariae quoque trubuitur, ad hanc praecife; vi ex icone addi. ta pater, transferendum. Infrequentior ceteroquin apud nos ftirps, \& remotius creo Icens, fcilicet vitra pagum Rheinhaufen, in fylua incer diuerforium Eichenkrug \& Duderfae dium, prope Nordheimum in fylua Mandel bergenfi, in $\mathrm{m}$. Alrenftollberg. 
Rapunculo non ea hirfuties eft, necitantz pidunculorum fimplicitas.

Campanula decurrens LiNN. $\int p \cdot p l, E d, 2 \cdot p \cdot 23 z$.

- rapunculoides. h.

- $\quad$ Trachelium. $h$.

- $\quad$ - glomerata.

- - Speculum.

PHYTEVMa fpicaia a, fpica oblouga $h$ :

ß. var. fpica ouali obefa.

- $\quad$ orbicularis. $h$.

L ONICERA Periclymenum h.

- - Xylofteum. $h$.

VERBA \& CVM Thapfus. $d, h$.

Var, bicollis $M I H \mathrm{I}, \mathrm{f}$. Verb. fo॰

liis ouatis, vtrinque tomentofis, inferioribus petiolatis, ftigmate bicolli. н A L L. Hifl.n.582.*)

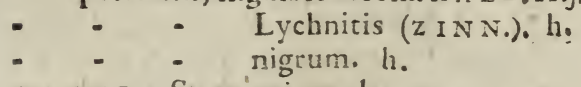

D A T v R A Stramonium, $h$. H Y O SCY A M V S niger. $h$. A T R OP A Belladonna. $h$. PHY SALIS Alkekengi. h. SO L A N y M Dulcamara, h.

- - nigrum, ce, vulgatun. h.

RHAMNVS catharticus. $\delta$, 우․ $h$.

- Frangula. h.

EV O NYMVS europaeus. $\boldsymbol{\theta}_{\text {, }}$, tenuifalius. bi

R I B E S alpinum. co, fructu dulci, $h$.

- $\quad$ nigrum, h,

$\mathrm{R}$ I.

*) Cellis crefcir (wilzi ch DifJ. Obferu. bot. do med. p. 10.) in arenofis, HALLERo fpecies diuerfa eft; fatetur tamen, nondum fibi eadem fatisfieri. Thapfo, es, mauult ad. 1cribi folia lanata. 
RIBE S Vua crifpa. h.

HEDER A Helix. \&, arborea.

$$
\gamma \text {, fterilis. }
$$

IL LECEB R VM verticillatum.

GL A V X maritima. h. TH ESI V M Linophyllum.

vINCA minor. $h$.

$$
\text { D I G Y N I A, }
$$

A S C LEPI AS Vincetoxicum. $h$. HER NNIR I A glabra, CHENOPODIVM Bonus Henricus, $h$.

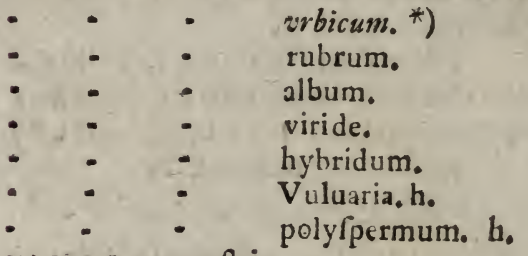

VL $M V S$ campeftris.

GENTIANA Pneumonathe,

- - Centaurium $\alpha$, procerius

- - Amarella. h. $\beta$, pumilum.

- - ciliata h.

- - cruciata. h.

- - filiformis.

ERYNGIVM campeftre.

HYDROCOTYLE vulgaris.

SAN IC VLA europaea, h.

ASTRANTIA major.

BVP LEVRVM rotundifolium, h.

- longifolium. $h$.

BV*

*) Leđtum in praefectura Rothenkirchen mific eel. W IL L I CH. 


\section{Sect. 2. Stirpes Spontaneac.}

BVPLEVRVM falcatum. h. TORDYLIVM latifolium. - - Anthrifcus.

C A V C A L I S grandifiora.

Ieprophylla.

D A v C v s Carota. $\mathscr{e}$, fylueftris.

C ONIVM maculatum. h.

SELINVM paluftre.

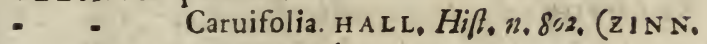
Gott. p. 22r. 12.3.) h.

A T HAMANT A Libanotis.

- - Ceruaria, $\alpha$, (Selinum zINN. Gott. p. 221, 12.2) h.

- - Meum, h.

REVCEDANVM Silaus.

I. A SERPITIVM latifolium. h,

IIERA CLEVM Sphondylium.

Varieras foliis anguftioribus. HALL. Hifl. n. 8c.. *)

ANGELICA fylueftris.

S IV M latifolicim.

- nodiflorum.

- Falcaría.

OENANTHE fiftulofa.

PHELLANDRIVM aquaticum.

C1CVTA virofa. $h$.

A ETHVSA Cynapium. h.

SCANDIX Pecten veneris, h.

- - Anthrifcus.

CHAER OPHYLLVM fylueftre.

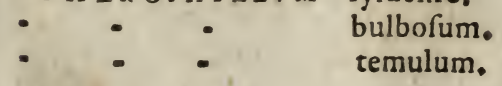

C F

*) Diftincta ab Heracleo anguftifolio L. IN N., Mant. p. s7. 
50 Sect. 2. Stirpes fpontaneae.

CHEROPHYL. L V M a Ureum.

- . . - hirfutum.

P A S I N A c A fatiua, $\alpha$, fylueftris.

CA R V M Carui. h.

PI MP INELLA Saxifraga $\alpha$, minor CB.

$\gamma$. maior, vmbella candida C $B_{0}{ }^{*}$ )

A PIVM graueolens $\boldsymbol{\alpha}$, paluftre. AE GOPODIVM Podagraria.

\section{T R I G Y N I A.}

VIB VRNVM Opulus, $\alpha$, flore fimplici. h:

$S A M B V C V S$ Ebulus. h.

- - nigra. $a$, fructu nigro $h$.

- - racemofa. h.

S T A P H Y E A pinnnata. $h$.

CO R I G I O A litoralis.

ALSINE media.

TET A G YN I A.

PARNASsIA palultris. ha

PENTAGYNIA.

3 T A T I C E Armeria. $\alpha$, maior $h$.

L1 N V M tenuifolium. $h$.

- catharticum. h.

- Radiola.

DR OSER A rozundifolia.

- longifolia.

POLYGYNIA.

MOSVRVS minimus.

*) Nifi LINNAEVS fatione varietatem $\propto$ in $\gamma$ mutari dixiffet, ob diferimen in habitu in fpe. cies diuerfas merito diuellerentur. 


\section{Claffis 6. \\ H E X A D R I A. \\ MONOGY NIA.}

1.ETC OIVM vernum. $h$.

A L LI VM arenarium.

- vineale

- - oleraceum *)

- angulofum, $\mathrm{h}$.

- vrlinum. h.

LILIVM Martagon $\boldsymbol{\alpha}$, fylueftre $h$.

T V L I P A fylueftris. $h$.

ORNITHOGAL VM luteum. h.

A NTHERICVM ramofum.

- - Liliago, $h$.

CONVALL AR I A maialis, $h$,

- - - verticillata.

- - Polygonatum.

- - - multiffora. h.

- - - bifolia.

A CORvs Calamus. $\alpha$, vulgaris $h$.

I V N C V S conglomeratus.

- - effufus.

- fquarrofus.

- $\quad-\quad$ articulatus, $\propto$, aquaticus.

$\beta$, cum vericulis.

$\gamma$, fyluaticus.

- - bulbofus, (zI N N. Gott.p. 80, n. 4.).

Iuncus caule brachiato, fullis fitaceis, flori, bus fafciculari, ad ramos feffilibus (Hi^ L L. Hifl. n. 1320.**)

$D_{2}$

I V N

*) In campis fupra Wehnde reperi.

**) Huic ill, H $\wedge$ L. L. (l. c.) defcriptionem Iunci bulbofi L I N No addit, a quo vero differre vide- 
IV v C v s bufonius.

\section{- - pilofus $\delta, \mathrm{Gr}$. nemorofum hirfutum la. tifolium maius SC HEVCHZ. ( 1 N N. Gott. p. 81. 11.9.$)$
- - $\quad \varepsilon, G r$. hirfurum anguftifolium maius SCHEVCHZ. ( ZINN. l. c. n. 10.)
- $\zeta$ Gr. hirlutum latifolium minus SCHEVCнZ. (Z I N. l. 6. n. 8.)
- campeftris.

BERBER IS vulgaris, h.

PEPLIS Portula.

\section{TRIGYNIA。}

R V M E crifpus.

- acutus. h.

- obtufifolius.

- aquaticus, h.

- Acetofa. $\boldsymbol{\alpha}$, pratenfish.

$\varepsilon$, Acetofa montana, lato ari folio rotundor o $C_{C}$.

- Acetofella: a, Acetofa aruenfis lanceolata,cB.b.

- conglomeratus M I I f. Laparhum petiolis latefcentibus foliis longe lanceolatis, floribus verticillatis verrucofis HALL. Hifl. ni $159 \%$. ZIN N. Gott. p. 40.n. 10.

- anthoxanthus M I I I. Lapathum perenne foliis longiffimis, calycibus ciliatis HALL. Gutt. p. 18 .

TRIGLOCHIN paluftre. $h$.

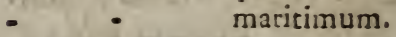

cO LCH I CV M autumnale, h.

detur, \& ad luncum fygium $\mathrm{L}$ N $x$, propius accedere. Circa Cellas crefcit; omiffus a ZINNIO, 
POL Y GIY N I A.

A L I s a Plantago aquarica. h.

$$
\text { Claffis } 7 .
$$

H E P T A N D R I A.

MONUGYNIA.

TRIENTALIS Europae?.

$$
\text { O. C T A N D R I A. }
$$

MONOGY I A.

IP I L OBIVM anguftifolium, $\approx$.

- hirfutum. $a$, ffore maiori $h$. 3 f. minori.

- $\quad$ montanum.

- paluftre.

vACCINIVM Myrtillus.
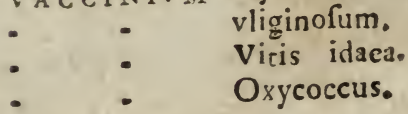

ERIC A vulgaris.

- Tetralix.

DAPHN E Mezereum, $h$.

T R I G Y N I A.

POLYGONVM Biftorta. h.

- $\quad$ amphibium.

- - Hydropiper.

- Perficaria. a, maculola, \& non maculofa, fl. albo \& rubrn. $h$.

$\beta$, anguftifolia

$\gamma$, foliis fubtus tomentofis $*$ )

D 3

P 0

*) III. H L L ER o varietates Linnaeanae $\beta$ \& y

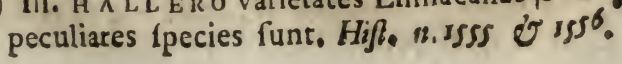


54 Sect. 2. Stirpes fporttanere.

POLYGONVA. $a$, latifollum.

$$
\begin{aligned}
& \beta, \gamma, \delta \text { anguftifolium. } \\
& \text { Conuoluulus } \\
& \text { dametorum *) } \\
& \text { T E T R A G Y N I A. }
\end{aligned}
$$

PARIS quadrifolia $h$.

A DOz A Nofchatellina. h.

$$
\text { EN NEA N D R I A. }
$$

HEXAGYNIA.

BvTomys vmbellatus.

$$
\text { DE GA N D R I A. }
$$

MONOTR OPA Hypopithys.

A NDROMEJA Polifoliz.

ARBVTVS Vua vrfr.

PYROL A rotundifulia.

$\therefore \quad$ : fecunda.

DI G Y IA.

CHR Y SOS PLEN IVM alternifolium. b.

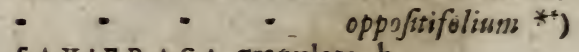

SA X IF R A G A granulat3. h.

$$
\text { oppofitifoliunb *') }
$$

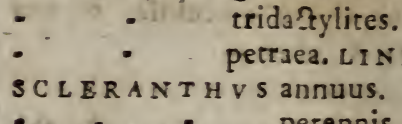

petraea. Lis N, Sp. pl, Ed, 2, p. 33. h.

SCLERANTHVS petreannuLS.

*) Nordheimi legit cl, w ILLICH.

GY*

**) Circa Hezzbergam occurrit. w I L L. Olferw. bot. $1762, p, 6$. 


\section{Selt. 2. Stirpes Spontanear.}

GXP S OPH IL A faftigiata $h$.

SAPONARIA officinalis. $\alpha$, vulgaris $h$.

- Vaccaria.

DIANTH V S cartbufianorum (ZINN.) h. Armeria. h.

$-\quad$ prolifer. $h$.
$\quad \quad \quad$ deltoides, $h$.
$\quad$ plumarius (zIN N.). h.

T R I GY N I A.

GV CVBALVS Behen.

SILENE nutans. h.

STELLARIA nemorum.

- - - Holoftea.

- - graminea, $\alpha$, aruenfis.

\section{$T$, paluftris.}

- - vliginofa miнt f. Alfine longifo.

lia, vliginofis locis proueniens, I $\mathrm{B}_{*}^{*}$ )

ARENAR I A trineruia.

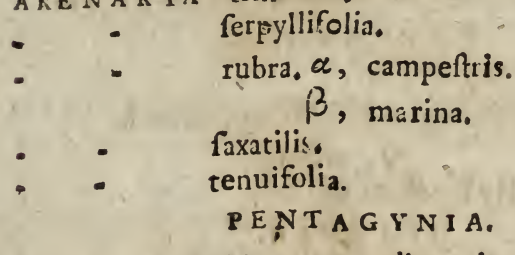

SEDVM Telephium, $a$, album b.

$\varepsilon$, maximumzi N N. Gott. 12. $\gamma^{\circ}$

- - rupeftre, $h$.

D 4 1E-

*) Eft Alfine foliis lanceolatis petalis bipartitis

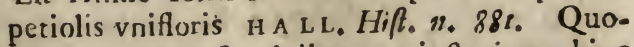
niam vero illa ftaminibus 10 inftruitur: hine a genere Alfines ad Stellariam, fecundum logem ill. A LINNE' amandanda. 
so SeẼ. 2. Stirpes Spontaneae.

S E v V M album. $h$.

- $\quad$ acre. $h$

- - 'Sexnigulare. *)

OX A L I S Acetofella. h.

A GROSTEMMA Githago, h.

LYCHNIS Flos cuculi.

- Vifcaria. h.

- dioica, h.

CERASTIVM vulgatum.

- - vifcofirm.

- - temidecandrum ( $\mathrm{z}$ INN.).

- - - aruenfe.

- - dichotomum (z I N N.). An fponte?

- - aquaticum **). MENTZEL.PUgill. Tab. s. fig. 3 .

SPERGVLA aruenfis. $h$.

- - nodora.
Cla ajis 11 .
D O D E C A N D R I A.
MONOGYNIA.

A S A K V M europaeum. $h$.

LY т н V M Salicarıa. $\alpha$, foliis oppofitis $h$.

$$
\gamma \text {, trifolia. }
$$

- Hyffopifolia h.

$$
\text { D I G Y N I A. }
$$

AGRIMONIA Eupatoria h.

TRIGY NIA.

RESEDA Luteols. h.

EVPHORBI A Peplus. h.

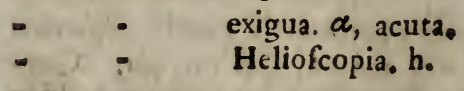

*) In campis apricis \& muris.

**) Vbiuis in folfis adultiori aeftate florens. 
Sect. 2. Stirpes Spontaneae.

EVPHORBIA platyphyllos.
Cyparifias. h.

- Cbaracias (L. B. A MVNCHHAV. SEN *).

fyluatica.

D O DECAGY N IA,

SEM PER VIV VM tectorum. h.

\section{Claffis 12. \\ I C O S A N D R I A.}

$M O N O G Y N I \Lambda$.

$P R$ V N v Padus. $h$.

- Cerafus. h.

- fpinofa. h.

\section{I G Y I A.}

CRAT A EGVS torminalis, $h$.
- - Oxyacantha. h.
T R I G Y N IA.

SORBV S aucuparia. h.

\section{PEN T A G Y I A.}

MES PILvS Amelancbier (A VELTHEIM **),

PYR v s communis, $\alpha$, fylueftris

- Malus $a$, fylu. h.

SPIR AE A Aruncus.

- Filipendula. h.

- VImaria. h.

D 5 PO

*) Perill, vir inter Luneburgum \& Netze inuenit. v. Hausv. Vol, 4, P. 2. p. $1 \sigma_{1}$.

**) Ex teftimonio generofif. huius viri \& acutifimi botanici, perilluftri L, B. A M V N C H* H Avsen (Hausv. Vol. 4. P. z. p. 360) dato, bercynica ciuis eft. 


\section{POLYGYN\A.}

ROS a eglanteria. h.

- villofa. h.

- canina. h.

RV.BVS idacus $\alpha$, fpinofus $h$.

- - caefius. h.

- fruticofus.

FRAGARIA vefca. $\alpha$, fylueftris

POTENTJLLA Anferina. h.

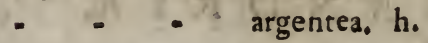

- - - verna.

- - reptans. h.

T ORMENTILI A eredta. $h$.

GEV M vrbanum, h.

- riuale. $h$.

C OM ARVM paluftre.

\section{Clafis 13. \\ P O L Y A N D R I A.}

MONOG Y NIA.

A C T A E A fpicata. $\alpha$, nigra $h$.

CHEIIDONIVM maius, $\alpha$, vulgare.

PAPAVER Argemone.

- dubium (zIN N.Gott. n6 4.) b.

- - Rhoeas, h.

NY M P HA E A lutea.

- - alba.

I IL I A europaea. $\gamma$, folio minori. *) $h$. Cis t v Helianthemum.

$$
\text { T R I G Y I A. }
$$

DELPHINIVM Confolida. h.

- A CONIT VM Lycodtonum. h.

*) An vere fpontanea? 


\section{Sect. 2. Stirpes fpontaneàe.}

A C ONIt v M Napellas *) h.

\section{PENTAG Y IA。}

$A$ QVILEGI A vulgaris. $\alpha$, fylueftris $h$.

NIGELLA aruenfis, $h$.

$$
\text { POLYGY NIA. }
$$

A NEM ONE Hepatica. h.

- $\quad$ alpina.

- . fylueltris, $h$.

- . nemorofa.h.

- ranunculoides, $h$.

CLEMAT is Vitalba. h.

THA L ICTRVM flaum. **) h.

ADONIS autumnalis $\alpha$, flore citrino elation

н A $L$ L. $H i f$. n, $11 ; 8, \mathrm{~h}$.

$\beta$, fl. cinnabarino humilior l. c. h.

$R$ A N V N C V L V S Flammula ce, foliis integerrimis.h.

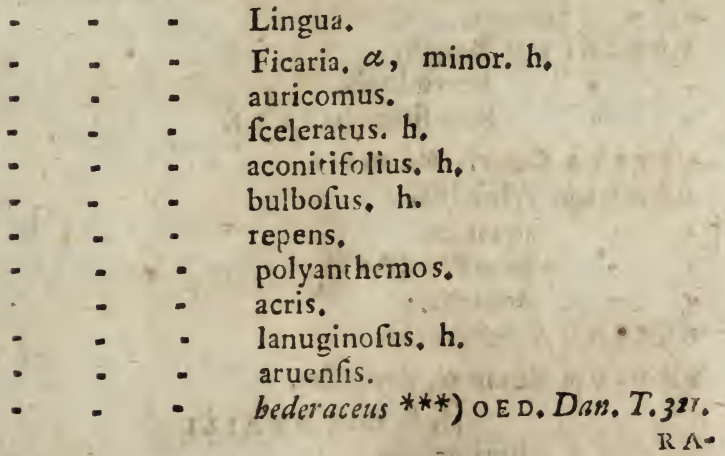

*) Vid. \$. 3. Blankenburgi, Hortenfibus olinz annumeratum.

**) Spontaneum in prato, Saxii horto vicino. ***) Gottingae lectam refciuit $\mathrm{cl}$, w IL L IC H Illufhr. bot, 1766. p. 22. 
R A NVNCVLV's aquatilis. $\propto$, foliis inferioribus capillaceis; fuperioribus peltatis. L I N N. $\beta$, foliis omnibus capillaceis circumferiptione rotundis. LI N N.

$\boldsymbol{\gamma}$, foliis capillaceis circumfcriptione vaga breuioribus. HALL.

$\delta, f_{n}$ liis omnibus capillaceis circumferiptione oblongis, ROY EN. *)

TROLLIVS europaeus. $h$.

HE LLEB OR V S viridis.

CALTHA paluftris.

\section{Claffis 14. \\ D I D Y N A M I A}

G YMNOSPERM 1 .

A IVGA pyramidalis.

- reptans.

TE V CR I V M Botrys.

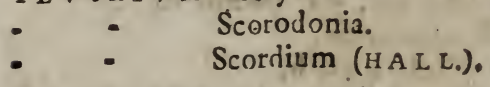

NE PETA Cataria $\propto$, maior.

MENTHA fylueftris.

- - aquatica.

- $\quad$ gentilis. (An?)

- - aruenlis.

GLECOMA hederacea.

I A IV $M$ album $c e$, flore albo.

$\beta$, fl. carneo v A I L L.

- $\quad$ purpurcum.

- amplexicaule.

GALEOPSIS Ladanum.

Var.

*) Ex quatuor hifce varietatibus 3 fpecies format ill, H A L L. Hift. P, 2, pog. 68 . 


\section{Sert. 2. Stirpes Spontaneae.}

Var. Ladanum fegetum lariori folio R I v. ${ }^{*}$ )

Tetrahit, $\alpha$, I. flore rubro 2. fl, albo.

$\beta$, corolla flaua, labio in.

feriori maculato, $\mathrm{L}$ IN N.

- - Galeobdolon.

B E T O N IC A officinalis. $\boldsymbol{\alpha}$, purptrea.

STACHY S fyluatica.

- $\quad$ paluftris

- alpina ${ }^{* *}$ )

- - annuiziN L. Sp.pl. Ed. z.p.813.

- $\quad$ aruenfis l. c. 814. a.

B A L L O TE nigra.

MARRVBIVM vulgare, el, parcius villofum.

IEON V R V Cardiaca, $a$, follis planis. h.

CLINOPADIVM vulgare, $\alpha$, flore purpureo, $h_{0}$ ORIGANVM vulgare. $h$,

т н Ү M V S Serpyllum. $\boldsymbol{c}_{2}$, vulgare minus C. B. h. $\beta$, vulgare maius $C_{B}$.

$\gamma$, vulg. minus capitulis lanugino.

fis T'OVRN. ***)

$$
\delta \text {, anguftifolium hirfutum } \mathrm{CB} \text {. }
$$

SCVTELLARIA galericulata.

PR̃VELLA vulgaris $\%$, flore minori. h.

$\beta$, grandifiora. $h$.

A N-

*) III. A в н A L L E R fpecies fingularis eft, Cellis, ve refert, crefcens.

**) In $\mathrm{m}$. Pleff crebrius vidi; hinc non hortenfibus, Z I N N I I exemplo, adiudicanda.

***) Varietas merito expungenda \& ad monitra vcgetabilia, infecto natz, ableganda. 


\section{A N G IOSPER M A.}

R H IN ANTH VS Crifta galli $\alpha$, humilior coma fufCa LI NN, Fl. Juec.p. ziz, h.

$$
\beta \text {, elatior. }
$$

E V P H R A S I A officinalis. $\alpha$, maior. $\beta$, minor. $h$.

$$
\text { Odontites. }
$$

MEL A MPYR V M criftatum.

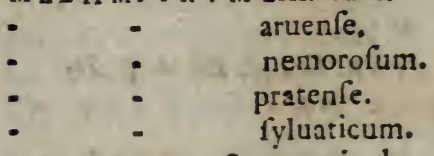

LATHRAEA Squamaria. h.

PEDICVLAR IS paluftris.

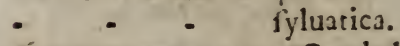

Á TIRRHINvm Cymbalaria. h.

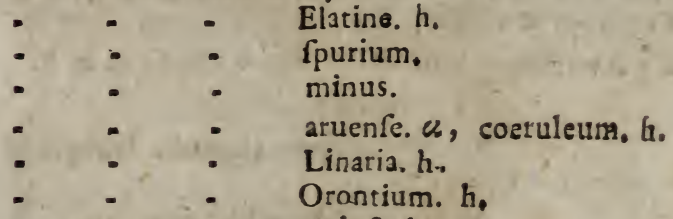

SCROPHVI ARIA nodora, $h$.

$$
\text { - }
$$
aquatica. $h$.

DIGITALI $\delta$ purpurea, $h$.

- ambigua miнif. Dig. lutea magno flore CB. Pin. p. 224. H A L L. Hift. n. $3 j^{r}$. Hanc ill. A LINNE' nondum recepit, ne varietatis quidem inftar. Diftinguitur vero merito a priori, fpeciei quoque nomine. Nam folia calycina funt lanceolata, non ouata. Corolla infra magis ventricofa, pallide flaua maculisque fufcis notata, labio fuperiori emarginato, laciniis lateralibus \& labio inferiori acutis. Brafieae longe anguftiores, Folia 2d. 
ad bafin quidem angufta, fed fenfim, non fus bito, vt in Dig. purpurea, latiora euadunt; fupra omnino glabra, infra pube vix con. fpicua diftin $t a$, quum in Dig. purp. fupra le. uiter fcabra, infra tomentofa, \& manifeftioribus venis inftrufta; margine ferrato, non insequaliter crenato, Caulis parumper modo hirfutus, non tomentofus, Planta denique tota tenerior.

L I MOSEL L A aquatica. OKO B ANC HE maior.

\section{Clafis 15 . \\ TE T R A D Y A M I A,}

$S I L I C V L O S A$.

MYAG RVM fatiuum. $c$, fylueitre $h$.

$\gamma$, Alyffon foliis auriculatis glabris profunde 'denratis H A L L. Hift. n. 489, $\gamma$.

D R A B A verna.

poniculatum. *) O E D.Fl.Dan.T,204.h.

LEP IDIVM ruderale.

THLASPI aruenfe.

- - campeftre.

- perfoliatum. h.

- Burfa paftoris.

IBERIS nudicaulis.

A L Y S S V M calycinum. I IN N. $S p$. pl, $E d, 3, p, 908$. LVN $\triangle R$ I A rediuiua. $h$.

SI LIQVOSA.

DENTAR I A bulbifera. h.

CARDAMINE impatiens.

- $\quad$ hirfuta.

- $\quad$ pratenfis. h.

*) Inter fegetes Gottingą.

C A R: 
64 Sect. 2. Stirpes Jpontaneae.

C ARDAMI N E amara.

s is Y M B R I V M Nafturtium aquaticum, h.

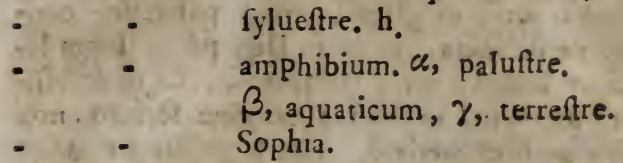

ER Y I MV M officinale. $h$.

- $\quad$ Burburea. h.
- $\quad$ Alliuria.h.
-

CHEIRANTH V S eryfimoides.

HES $P E R$ is matronalis. $h$.

A RAB IS Thalians, $b$.

- Halleri.

T VRRII is glabra. h.

- hirfuta, h.

BR A S S I C A campeftris.

$$
\text { - Napus *). h. }
$$

SI NAPIS aruenfis.

$$
\text { - } \quad \text { - alba. }
$$

RAPHANVS Raphaniftrum, $\alpha$, flore luteo,

$$
\begin{gathered}
\text { Clafjis } 16 . \\
\text { MONA albo. }
\end{gathered}
$$

DECANDRIA.

GERANIVM cicutarium.

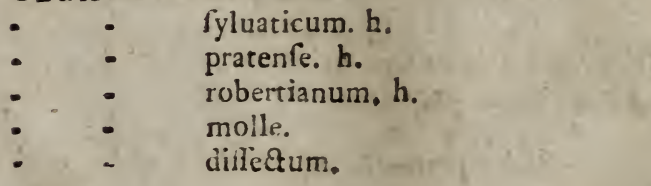

*) An vere fpontanea? 


\section{Stct. 2. Stirpes Spontaneat.}

GERA NIVM columbinum.

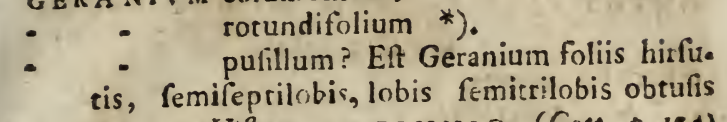
H A L L. Hifl. n. 940. ZI N NIO (Gott. p. 174) varietas Geranii rotundifolii.

$$
\begin{aligned}
& -\quad \text { fanguineum. } \\
& \text { POLYANDRIA. }
\end{aligned}
$$

MALVA rotundifolia.

- - fylueftris. h.

- Alcea h.

\section{Clafis 17 . \\ D I A D E L P H I A.}

HEXA N DRIA.

FVMARIA bulbofa. $\alpha$, caula b.

- officinali:. h. $\gamma$, folida.

$$
\text { OCTA N D I A. }
$$

POL Y GALA vulgaris.

- amara LINN. Sp.pl. Ed.2.p. 987. h, DE CAN DR I A.

SPARTIVM fcopariusn**)

GENIST A tinctoria. h.

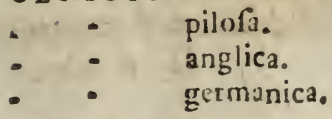

ON ON Is fpinofa. a, mitis. $h$.

$\beta$, pinofa.

*) An vera foli noftri ciuis?

A.No

**) Mundae \& inter Wernigerodam \& Blankerro burgum crefcir. 
A NTнY LIIS Vulneraria, $\alpha$, fore luteo $h$, $\beta$, fl. coccineo. $h$.

OROBVS vernus. $h$.

- - tuberofus.

- niger.

L A I HYRVS tuberofus $h$.

$-\quad$ pratenfis. h.
$-\quad$ fyluefris.
latifolius. $\alpha$.

H A L L. Gott. p. 390.

$\beta$, foliis anguntioribus

VICIA pififormis.

- - dumetorum.

- $\quad$ fyluatica.

- Craccs.

- fatiua, $\alpha$,

- fepium.

$\beta$, nigra, foliis anguftioribus.

ER V V M tetrifpcrmum.

\section{- hirfutum.}

C. XTISVs Laburnum. h.

ORNITHOPVS perpufillus. *)

HIPYOCREPIS COMAfa, h.

A STRAGA L V glycyphyllos. $h$.

TRI Y O I I M Melilotus officinalis. $\alpha$, flore lutco h. $\beta$, A. albo.

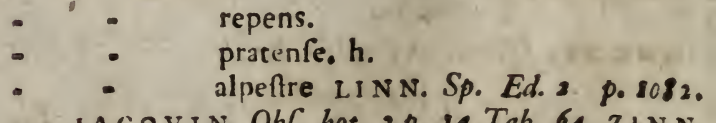
I A c eV I N. Obf. bot. 3p. 14 Tab. 64. $21 \mathrm{~N}$ N. Gott. Trifol. p. $36, n_{0}, s^{*+}$ )

T R I-

*) In arennfir verfus Cellas. H A L L. Gutt. p.264. **) In rupibus prope Rheinhaufen legi. 
Sect. 2. Stirpes Jpontaneat.

TR IFOLIVM aruenfe.

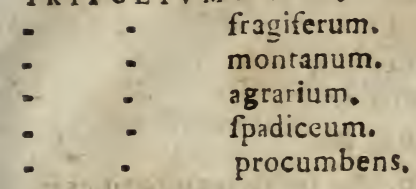

LO TVS corniculatus $\alpha$, creetior maior HALL,

$\beta$, proftratus, humilis

HALL. Hifl. n. 38 s.

MEDICAGO falcata. h.

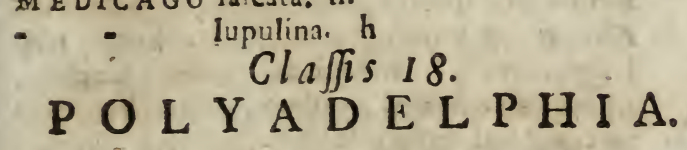

\section{POLYAN DRIA.}

HYPE RICVM quadrangulum. $h$.

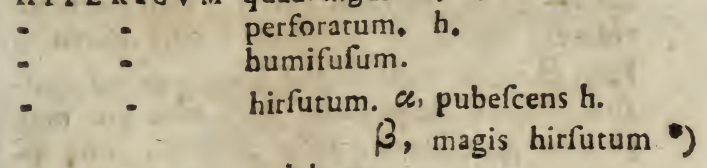

- pulchrum.

Claffis 19.

S Y NGE NE S I A.

POLYGAMIA AEQVALIS.

TRAGOPOGON Pratenfe. $h$. SCORZO NERA laciniara. h. PICRI' Hieracioides. h. so NCH Y aruenfis.

- - oleraceus, $\alpha$, laeuis, $h$,

$$
\gamma \text {, afper. }
$$

- alpinus.

LA G TVCA virofi, h.

E 2 CHON-

*) Synonyma auctorum V, in $z$ IN N, Gott. p. ife. 
CH ONDRILIA iuncea. PRENANTHES muralis.

LEONTODON Taraxacum. autumnale.

- $\quad$ hifpidum. $a$.

HIERACIVM alpinum, $a$, foliis anguftioribusin. tegris MIHI.

$\beta$, foliis larioribus dentatis NIHI. - Ita diftunguo duas plantas, quae, modo conftantia formae fit, fpecies merito diuerlae habentur. Hier. $\alpha$, in vniutrfum magis hirfutum, pilis 1 nglurbus, intruitur casle fimplici, nunquam ramolo, vnifloro, foliis lingularis integris vel rarius fubdenticulatis, obtulis, flore maiori, calyce hirfutiffimo. Ad hane cel. OE DER I ( Fl. Dan. Tab.2\%) ) icon pertinere videtur, etfí folia fiftuntur noftris acutiora. Hes. 3. gerit caulem vel fimplicem vel diuifum, magis flexuofum, flore mox vno mox pluribus pracditum, folia latiora, linuato. dentata, acuta, flores minores. Altirudo non femper eadem. Sunt enim quaedam exempla minora quam in $\alpha$, alia maiora. In minoribus autem nunquarn caulem diuifum vidi. Multiformem vocat fpeciem ill. HA LLERVS in Hift. no 49. cuius varietates in Bruftero inuentas deferipfit in Opufc. bot. p. 4.44.

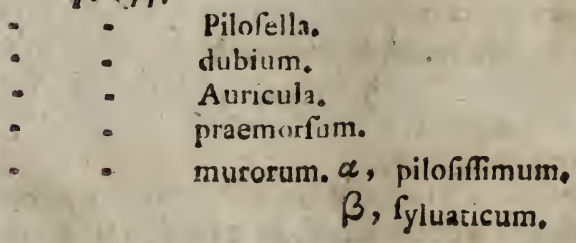


$\gamma$, folio longiori.

HIER A C I VM paludofum.

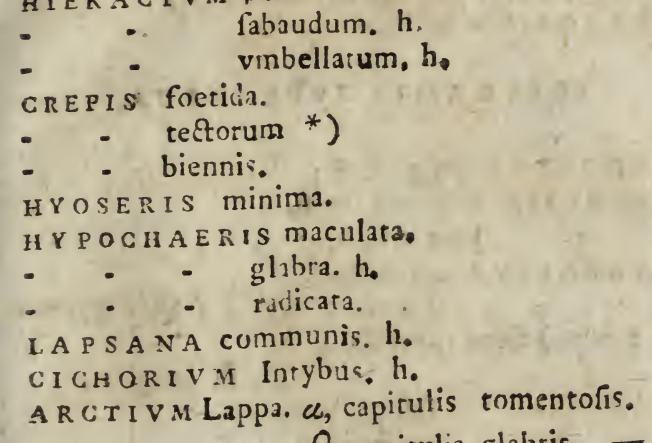

*) Cum hac Crepis zi N N. Gott. ". 2. fiuo Crepishirta, l I N N rumn Eis, s. cosluit, 
70 Sect. 2. Stirpes Spontaneae.

Var. $\beta$, radiata. Quae Coreopfsidis (Bidentis) (peciem effe facile imponit. ${ }^{*}$ )

EVPATORIV M cannabinum $h$.

POLYGAMIA SVPERFLVA.

TA NACETVM vulgare, $a, h$.

ARTEMISIA Abfynthium $h$.

- - vulgaris. b.

GNA PHALIVM arenarium.

- - dioicum, $\sigma^{7}$, (androgynum $\operatorname{zin} N_{0}$ ) flore rotundiori. $h$.

q, fl. longiori.

- - fyluaricum.

C ON Y Z A fquarrofa, $h$. vliginolum.

ERIGERON canadenfe.

- acre. h.

IVSSILAGo Farfara, h.

- $\left.\quad a l b n{ }^{* *}\right)$. h.

- - ybrida, h.

- - Petafites. h.

SENECIO vulgaris.

$-\quad$ vifcofus.
- $\quad$ Iacobacitolius.
$\quad$ aquaticus H.

*) Sed haud raro in aliis radiatis egr. Coreopfide frondora, Anthemide valentina, Senecionibus aliisque deficere radium ohferusmus.

*) Omifra in catalogis firpium Gött., fed inter hercynicas recepta $a b$ ill. HALLERO in $O$. pusc. boto po 80 . 


\section{Sect. 2. Stirpes fpontaneat. 71}

C. SCOPOLI Fl. Carn. p. 381 n. s. HAL. LER O Var. eft lacubacae $H_{1} / l$. u. 62, *)

3ENECIO nemorenfis, $h$

faricenicus h. - An verum intes

hunc \& praecedentem difcrimen, nec vnice a diuerfo folo dipendens, nondum liquet. Sen. furacenicus, folii 1 anguftioribus verinque glabris \& radio floribus fupras inftruetu, diffure videtur: led vidi in vno eodemque exemplo radios $5,6,8$. Hinc Senecio nemnrenfis numero quinario radio um, quem I A C Q I N (Objeru. bot. P. 3 p. is Tab.6s \& 66 ), vil oktono, quem LiNNAEVS Ill adrubit, non tuto faris dignoficur. Et quum fpccimi$\mathrm{na}$ in Bructero fummo folis infigniter lata \& valde infra villofa haberent, in loci profundioris fitus folia anguftiora euaferant, \& villo minus confpicuo notata; adco vt aliquan. do dici non poffet, verum flirps effet S en. faracenicus, an nemorenfis. Haud vero ita diffi. cile fuit, collatione facta inter plantam ex Bructero \& plintam in fylua ad radicem montium enatam. In forrato margine nihil çonftantiae, \& folia Senecionis in fyluis nobis propinquis crefcentis femper anguftiora, \& glabra.

Senccio foliis tomentofis, imis femipinnatis, fupericrous lingulatis, amplexicaulibus, HA L Lo. Gott. p. 402, **).

\section{E 4}

*) Miffus a cel. w $\mathrm{ILL} \mathrm{ICH,} \mathrm{qui} \mathrm{cum} \mathrm{in} \mathrm{fylus}$ ducarus Celienlis, die Sprake, inuenit.

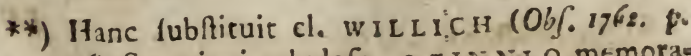
76) Senecioni paludofo, a ZIN I I O memora. to. V. fupra p. $2 \%$, 
72 Sect. 2. Stirpes Jpontaneat.

A STER Tripolium, $h$.

- Amellus h.

SOLIDAGO Virgaurea. h.

Var. Virga aurea Broccenbergenfis $\mathrm{T}$ н $A \mathrm{~L}$ Y Y. An Solidago minuta LINN.î. HALL. Hif。 n.79. Var. $\gamma$ ?

IN VL A dyfenterica.

- Pulicaria.

- falicina, b.

A R N I C A montana. $\alpha$, pratenfis.

$\beta$, alpina. *)

BELLIS perennis. $\alpha$, fylueftris. $h$.

CHRY SANTHEMVM corymbiferum. h.

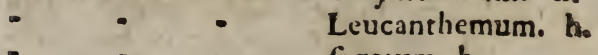

- - - fegerum. h.

MATRICARIA Patthenium, $h$.

- - Chamomilla. h.

ANTHEMIS aruenfis.

- - Corula. h.

- - tinetoria, $a$, radio huteo, $h$. ACH IL L A E A Ptarmica. $h$.

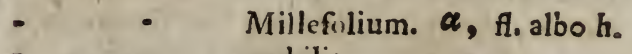

- - nobilis.

POLYGAMI A FRVSTRANEA.

(COREOPS is Bidens Vid. Bidens cernua. p. 6q)

CENTAVREA phrygia h.

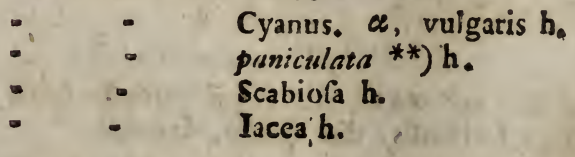

*) In Bruqtero.

po-

**) In muro circa viuatium Blankenburgenfo mihi occurtit. 


\section{SeCt. 2. Stirpes Spontaneaie. 73}

CENTAVREA Calcitrapa.

POLYGAMIA NECESSARIA.

FIL A G o gerrnanica, h.

- montana.

- aruenfis.

\section{MONOGAMIA.}

IAS I O N E montana.

viOL A paluftris *) OE D. Flor. Dan. Tab. 23.

- odorata. h.

- canina. $h$.

- montana.h.

- tricolor. h.

- aruenfís miHi f. Viola bicolor aruenfis C B. Varietas praecedentis apud L I N N. **).

- mirabilis ***) h.

IMPAIIEN S Noli rangere.

$$
\text { G Y N A N D R I A. }
$$

ORCHIS bifolia.

- coriophora.

- Morio.

- maf́cula.

- militaris.

a, Galea \& alis cinereis 1 B. HAIL. Hifo n. 1277. Tab. 28.

$\gamma$, militaris Св, Н A L L. bifl, n. 1275. Tab. 30. E 5 $\delta, \mathrm{mi}$ -

*) Ex fylua hercynica attulit D. R V I ING. **) Difcrimen veriusque $\mathrm{V}$, in H A L L. Hif. $n$. 56y. Haec vulgatiffima Gottingae; tricolor au. tcm nonnifi in fylua hercyn. \& ducatu Cellenfi. ***) In nemore montis prope pagumLutielengen. 
$\delta$, militaris maior TOVRN. HALL. Hiff. n。

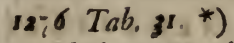

ORCHIS latifolia. Multis varietatibus ludens.

- conopfea.

SA TYRIVM albidum.

OP HRYS Nidus auis,

. - ouata. $\alpha$, bifolia

- a. infectifera. $\alpha$, myodes.

- Monorchis.

SER A P I A S latifolia L IN N. Syfl. nat. Tom。 J. p. 593. n. I. Cf H A L L. Hift. $n, 1397 . T 3 s_{0} 40$.

- $\quad$ lnngifolia Syft. Nat. p. 593 n.2. H A L L. Hifl. n. 12,66 . Tab 39 .

- - grandifinta Syßr. nat. p. sg4. n. 6. H A L L. bi ß, n. 1298 Tab. 4l.

a. latifolia H A L L.

$\beta$, fnliis enfiformibus HALL. rubra S. N. p. S94 n. 7. H A L L. Hi/f.

n. 1299 Tab. 42.

Serapias? - Helieborine bifoliz radice ouali, cucullo fparfo н $\wedge \mathrm{L}$. Comm. Soc. fíent. Gott.

Tom I. Tab 14. p. 3is.

C. Y P RIPE DIV M Calceolus, $h$.

POLYANDKIA.

A R VM maculatum. $\alpha$, non maculatum $h_{0}$ C ALLA palu(ris. **) $\beta$, maculatum.

Clajpis

*) III. HALLERO 3 diuerfae fpecies funt, vt ex numeris quidem iam patet.

**) In ducatu Cellenfi tefte cl. w I L I ICH。 
Selt. 2. Stirpes Spontonteat.

\section{Clafis 21 . \\ MO N O E C I A. \\ MONANDRIA.}

Z A N ICHELI. I A palultris.

CH A R A vulgaris *) L I N N. Sylt. nat. p. 613.

D I A N D I A.

LEM N A ${ }^{* *}$ ) trifuica.

- - minor.

TRIA N D I A.

T Y P H A latifolia.

SPARGA NIVM ereetum.

CAREX ${ }^{* * *}$ ) dioica.

- arenaria f. Carex fpicis in fummo caule congeftis, imis foliolis infidentibus $H A L L$. $H i f .11,16^{6}$.

- lecorina.

- brizoides.

CA-

* Cel. SCHREBER I obferuatio ex cryptogamicis huc rransferri iuber. Nec diffencit cel. OE DER in Enunteratione plant. Fl. Dan.1770. p. 44.

**) In Lemna minori quidem vnice floris partes confpectae, Salicorniae, ve refert auroptes OEDERVS, non abfimiles, fed reliquas fpecies eidem adiungi vult naturalis cognatio. O E D. Enum. pl. Fl. Dan. p. 43.

***) In Caricum recenfione ea libertare vtor, qua folent, qui ftirpium latioris ambirus indices exhibent, vt nimirum fpecies quasdam ex aliorum fide inferam. Grauifima id maxime ill. HA L L E I fiet, qui \& Gottingenfium in Hiftoria Rirp. Helu., locis adeo terrac no. frae fubinde indicatis, rationem habuit. 
76 Set. 2. Stirpes fpontaneda

C A R E vulpina.

- muricata.

- echinata mıні f. Car. fpicis terris echi. naris, glumis lanceolati, capfulae mucrone fimplici h A L L.Hifl,n, 1366. O E D. Dari, T, 384.

- elongata.

- canefcens.

- -

- paniculata.

- flusa.

- pedata.

- digitata.

- mantana *)

- palleficens.

- Pieudo-cyperus.

- diftans.

- - cefpitofa $* *$ )

- - acura. $\alpha$, nigra. $\beta$, rufa.

- veficaria, a, fpicis vicidantibus $\&$ fubfufcie。 $\beta$, fpicis tenuibus remotis. $\gamma$, fpicis turgidis fiauefcentibus.

- - hirta.

- - fpicis maribus vna, plurimis femineis pendulis, capfulis nuato-triquetris, confertis H A L L. Hill. n. 1408. Eft haec line uubio Z I N N. Gott. $\int p . x g$. \& 20.

- - fpica mafcula luprema, fecunda androgyna, femineis feffilibus, copfulis breuirer bifurcatis H A L E. H:R. n. 1398. Visetur $\mathrm{ffe}$ ZINN. Gott. Jp. 2r.

- : foliis cefpitofis breuibus, fpicis confertis petiolis ere?tis breuibus, capfulis ouato. triquetris H A L L. Hifl.w. 138I. Elt Z I N N./P.15.

*) In m. Heymberg.

Ca.

*) Hinc inde in paludofis. 
Carex. - Cyperoides latifulium fpicis feminalibus femimafculis ex longis pedunculis pendulis HALI. Enum. Ji. Helu. $239 . n, 26$. ZINN. $\int p, 16$.

\section{TET RA N DRIA.}

BETVLA alba, h.

Var. pumila za NON I fforia botanica $T$. $3^{2}$.

p 47. h.

- nana.

- Ainus, $\alpha$, glutinora.

VRT I GA. vrens.

- dioica.

PENTANDEIA。

$X$ AN THIVM Serumarium.

$$
\text { POLYANDRIA. }
$$

CERATOPHYLLVM demerfum. MY.RIO) PHY L LVM f́picatum.

SA GITTARI A Tagitrifolia, $\alpha$, litifolia.

$B$, anguftifolia.

POTERIVM Sanguiforba. $\beta$, minor laeuis, $h$.

QVEKCVS Robur. h.

FAG VS fyluatica h.

CARPINVS Betulus h.

C ORYLVS Auellana, $a$, fylueftris $h$.

$$
\text { MONADELPHIA. }
$$

PIN V s fyluefris. $h$.

Var, Pinafter pumilio CL Y s. Pann. p. is. HAL L. Hif. $n, 1660, \gamma$.

- tu Larix, h.

I th _ Abies. h.

SYNGENESIR,

BRYONI A 2lba, h. 


\section{Clalfis 22.$$
\text { D I O E C I A. }
$$$$
\text { DIANDRIA. }
$$

S A L I X triandra.

- vít llina.

- amysualina.

- fragilis.

- Helix,

- $\quad$ rofmarinifolia *)

- caprea. $\boldsymbol{\alpha}$, latifolia rotunda. $\beta$, fuliis oblongis h. - Eadern fed foliis longioribus \& rugofis in Bruitcro **)

\section{TRIA N DRIA.}

EMPETRVM nigrum.

TETRAN D R IA.

V I S C VM albúm، MXRICA Gale.

PENTANDRIA.

HVMVIVS Lupulus. $h$.

$$
\text { OCTA N DRIA. }
$$

pópres tremula $h$.

- nigra.

EN NEA NDRIA.

MERCVRIALIS perennis.

HY DROCHAR IS Morfus ranae.

\section{MON ADEL PHI $\boldsymbol{K}_{\text {: }}$}

IVNIPER VS communis, $\alpha$, ficicofa $b$, T A XV S baccata. h.

*) Omiffa a cl. zinNio, féd notata ab ill HALLER O in Fl. Gott. p. 8.

**) Polt HA LLER VM (Gotfop.q) in folo nata: li legi. 
Sect. 2. Stirpes Spontuneat.

\section{Cla jis 23. \\ P O L Y G A M I A}

MONOECIA.

H L CVS lamatus.

VALA TIA Aparine.

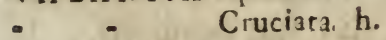

P ARIETARI A officinalis, $h$.

A TRIPLEX haffara.

ACER Pficudo. Platanus. $h$,

- Platanoides h.

- campeftre. h.

D 1 O C $1 \mathrm{~A}$.

FRAXINVS excelfior. $h$.

\section{Clafis 24. \\ C R Y P T O G A M I A *).}

F I I C ES.

E RVISETVM 2ruenfe.

O IHIO GLOS S V M.

O SM V N DA.

A C'ROSTICHVM.

PTERIS.

A SPLENIVM Scolopendrium ( 1 EY ENBERG) b.

- - Trichomanes. h.

- Ruta muraria. h.

POLYPODIVM vulgare. h. - . Filix mas. b.

M V S CI.

-) V.quae de feleqtu fupra p.38. indicaui. Quod ad mulcos \& algas, exfpectata venir I I N Diff. de vfu mufcorum in Amoen. vol. 7. p.370. 


\section{V S C I.}

LYCOPODIVM clauatum.

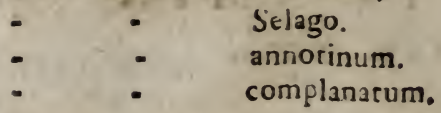

S PH A GN VM palultre. $\alpha$, fquamis cymbiformibus. $\beta$, fqu. capillaceis. FONTINALIS antipyretica. POLYTRICH.V M commune. $\propto$, maius. MNIVM hygrometricum. BRY VM hypnoides, $\boldsymbol{c}$, ramofun ereatum.

- rurale.

$$
\beta, \text { fafciculare. }
$$

H Y P N V M proliferum.

- parietinum.

\section{ALG A E.}

IVNGERMAN IA.

MARCHANTIA polymorpha, a, calyce decem. fido.

$\beta$, calyce oftopartito.

i. I C H E ericetorum.

- tartaricus.

- $\quad$ Caxarilis.

- islandicus. $a$, foliis latioribus.

$\beta$, foliis tenuioribus \& crifpioribus.

- - pulmonarius.

- prunaltri.

- iuniperinus.

- aphthofus.

- caninus. 


\section{Set. 2. Stirpes Jpontaneat. 81}

LICHEN cocciferus.

- rangiferinus, $\alpha$, alpeftris.

$\beta$, fyluaticus,

- plicatus.

t R EMEL L A Auricula.

VLVA.

CONPERVA。

RYSSVS.

\section{F V N G I。}

A GARICVS cantharellus.

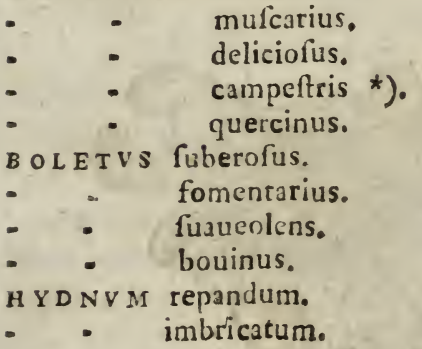

WHAL。

*) Plures fpecies agaricorum, quam I , 2, 3, 4, \& aliorum fungorum efculentorum inferere heic nolo, quum fufficiant dißtae, anceps cibus difficileque digerendus; licet compendiun laboris in delcatu facerent generofiff. A MVNCHHAVSEN Hausvuter Tom, 3. p. 203. 1OH. GESNERI Diff Pbytograph. Pars pract. I p. 47. M ÜL LE R I Efterrättning om Svampe, \& В А T T A K A E Hiflor. fungorum. 
82 Sect. 2. Stirpes Jpontaneac.

BHAL L V S efculentus.

HELVELA.

TEZIZA.

CL A V A R I A Coralloides.

I YCOPERD O N BOuifta. $M V C O R$.

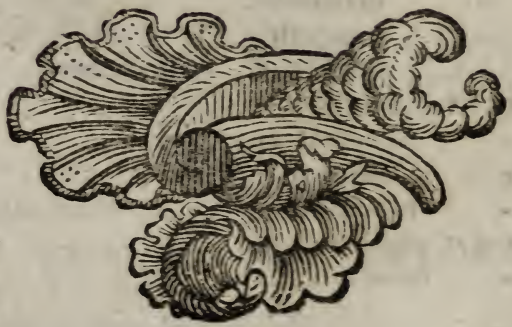

Sectio 


\section{운}

\section{Sectio 3.}

\section{HORTI BOTANICI RATIO.}

Eft igitur ea regionis noltrae vbertas, ve paucis aliis eiusdem ambitus numero plantarum cedat, multas vincat. Et hife quoque acquiefcere liceret, fi fundamenta rei herbariae tantum \& fyftematis vfum addicere volupe effet; quin minori longe copia hifce fcopis fieret facis. Quum vero, quo plures quisque firpes coguitas habeat, eo botanices peritior exiftimetur: botanicorum bortormm neceffitas elucer, in quibus quicquid plantarum per tocum terrarum orbem difperfarum natura produxerit, hic inter exiguos cancellos coarctatum, tanquam ex alta fpecula luftrire eft. Hic plantas inde a prima germinatione ad fruchum vfque maturationem fcrutari fuppetit, \& cognationem earundem, quod vero veterani eft, eruere; hic vel folo acceffu, fub grato amicorum comitatu \& confabulatione \& mutua percontacione, acquiritur plurium longe plantarum notitia, quam peregrinatione alias longinqua, ob moram, fumtus, pericula, valetudinis difpendium, moleftiasque taediofa; hic ignari rei botanicae, 


\section{Sect. 3. Hortus botanicus.}

fcifcitantes de planta, vfu fuo vel noxa famora, quifi ex lexico voti fui mox compotes fiunt, quippe quae contemplatione viuidiorem femper fui, quam defcriptione vel icone, imaginem imprimit. Hic datur miras vegetationis ftirpium \& propigationis leges expifcari; hoitorum colendorum artem, idque fub tanta herbarum varietate tanto plenius a dificere; priustum cuiuslibet ftirpis genium indagare; experimenta in oeconomiae vfum inftituere, paucis quidem in horto fpeciminibus, ne putidi lucri praefectus reus fiat, peragenda, fed fructum repetitione, per multa, feris nepotibus'allatura; hic denque medici difcunt fenfuum exploratione \& affinitate ftirpium abditas virtutes, nifi eruere, diuinare certiffime, \& coniecturas ingeniofe captas experientia fcite, absque praeiudicio, patienterque iterata, vel ftabilire vel repudiare.

\section{Particula 1.}

INITIA HORTIET PRISTINA EIVS C ONDITIO.

$$
\text { 5. } 1 .
$$

Hinc non ad exemplum modo aliarum academiarum, litterariis fuppetiis inftructiorum, fed ex ipfa rei vtilitatis perfuafione mox 


\section{Sect. 3. Horti botan. Hiftoria.}

initio, quum Georgia Augufta conderetur, follicitos tenuit illuftriffimos viros, Regis voluntatem in his terris exercentes, cura, ve botanicus bortus adonnaretur. Traditum hoc negotium praecipue tum temporis b. 10 A N I WILHELMO ALBRECHT, Erfordis verfus finem 3. 1734. ad Prof fionem Anatomiae \& Bot nices admini rsndam euocato. Varii in hune finem vrbis noftrae traclus perluftrati funt. Inter quos primum de ifts, qui olim pharmacopolarum in viu'n cerferat, \& adhuc hodie fub nomine Apothekergarten comnitus eft, dein de alio in fuburbio, die Mafche, quae viduam Commifirii Brauns pofferforem habuit, actum; a quorum veroque vero, ob varia incommoda dein percepta, paullo poft difcefferunt.

Commodum tum vifum fuit pafcuum quoddam fuburbii dieti, aedibus Commendatoris Ordinis equeftris contiguum, amplitudinis perticarum 190 quadr., quod inftar feudi in poifefflione ciuis cuiusdam (Factorem vocant) Frankenfeld fuit; de quo \& poftea, foluta 350 thalerorum fumma, m. Aprili $a_{\text {. }}$ 1738 . emtum eft, accedente paullo poft terrae vicinae artioris ambitus viduae Gallenkampf parte. Fixus igitur \& definitus iam videbatur horti botanici locus effe. Quoni-

$$
F_{3}
$$


86 SeI. 3. Horti botan. Hiftoria.

am vero fubfequente tempore depreffo fitu; \& hieme inundacionibus obnoxio, laborare per-eptum, quod vitium non nifi fumtibus infignioribus emendari poffet, \& facile praeuidebatur, inter breue tempus non fuffecturum plantarum numero: fine vlteriori quadam impenfa derelictus eft \& vrbis magiftratui venditus, eiusque in locum ifts terra, quam iamiam horrus nofter cum adiacentibus eius aedificiis ornat, ceffit.

Sita haec eft ea vrbis parte, quae adhuc nomen Gasbühle feruat, inter portam Nicolai (cuius, poftero tempore cliufae, nomen, quin memoria fere omnino periit; vnde alius magis diffitus limes, nempe porta Albana, fubrituendus ) \& portam Wehndenfem, \& ab hac ipfa non valde remoti. Feudum etiam hic funclus fuit, qui generofifimum IO. GO T T LIEB A fï L O W in Effen. rode dominum, familiam autem. Raufchenplat vufallos habuit, $3: 8$ perticas, \& 6 fere pedes fupra, menfurae quadraticae, vel 3 circiter iugera, amplus, diremtus tum temporis modo in medio exigua terrae ftria 17 perticas cum aliquor pedibus ampla, Böningenfibus heredibus propria. Poftquam vero fundi dominus iure priftino fefe coram eamera feudali abdicaflet, \& vafalli in omnem vlte- 
Sect. 3. Horti botan, Hiftoria. 87

vlteriorem fundi vfum renunciafient, folutis 630 thaleris pro ifta parte, quae Raufchenplatios vafallos habuit, \& 36 thaleris pro illa exili ftria intermedia $\mathrm{i}$ m dicta, Sacrat Regiae Maieftatis clementia in açdemiae nuperrime conditae bona tranfiit. Academiae vero numine illuftrem GEORGIVM GOTTUOB R I CHTER, iam ab incunabulis academiae, quam adhuc ornat, ordinis medici/primarium, follemnibus inueftitirae litteris prouajoilum auguftifimus Rex d. 12 Maii 1739 conftituit; pro quo regio munere fidem confuetis litteris reuerfalibus ill, vir fpopondit.

$$
\text { S. } 2 .
$$

Vita ceffit inter haec cel. A L В R EC H T m. Ianuario a. 1736 , cuius praematura morte haud mediocrem initia rei herbariae apud vios iacturam paffa effent, nifi /ubuenifJet illis, imo cum infigni foenore, ill, AB HALLER, viri, \& patriabotanicis fertilifiena niti, \& tum iam botanica fcientia value inclyti, in hane academiam vocatio, cui iam $m$. Septembri eiusdem anni aufcultauit. Huius fummi viri confiliis apud Curatorem illuftrifimum, incrementis fplendorique academiae fuo aufpicio fundatae intentifitimum; tanto facilior aditus contigit, quo magis ifte perf́picacia \& facundia in rebus horto neceffariis commenF 4 dan- 
dandis, \& ftudio in iis exfequendis, valeret. Confulti \& ad hortum inftruendum alii \& rei hortenfis \& architeconicie periti.

Paullo igitur poft ill. H ALLER I aduentum de terra ad flirpes ferendas idonea reddenda, de fepimento ad animalia furesque arcendos, de hortulano eiusque donicilio, de hybernaculis vaporariis \& inftumentis, de aquae ad rigandàs herbas fuppetiis, de fumitibus" quotaninis in pofterum horto impendendis, ratione quoque commodae partitionis decorisque horti habita, de aedibus denique Profefforis botmices, cogitatum eft; in quibus omnibus etiam poft varia temporis interualla indigentiae horti Maecenatis prouidentia fatisfaclum. Etenim quum compaClum nimis, triticoque repente pertextum, \& inaequale folum effet, etiamfi herbis culinaribus magnam partèm olim feruiiffet \& probae alias notae effet, profundius ligonibus euertere illud, ftercorare, \& iultam planitiem illi conciliare oportuit. Caldarium initio modo exiguum exftructum nec longae durationis, \& quidem illis aedibus, in quibus theatrum anatomicum reperitur, ex aduerfo. Aquarium, vel quo facilius carere poteft hoitus botanicus, fonticulum, inftruere ob defectum aquae fatis altae in vicinia \& difficultatem a- 
Sect. 3. Horti botan. Hiftoria. 89

quaeductuum collocandorum, maximi etiamfi vfus ad alendas aquaticas plantas \& rigandas ftirpes, non licuit; cuius in locum vero in polteriorem fcopum puteus extra fepimentum horti effoffus eft. Lignum pro aedificiis horti neceffariis ex fyluis regiis petitum. Quum maioris ambitus hortus effet, quarm qui primis faltim annis plantis repleri poffer, initio quibusdam proficuum vifum, fuperfluam horti partem colendis, in vfum pharmapolii \& culinae, piantis impendere, eo nimirum fine, ve hortus ipfe fumtus quotannis faciendos fibi compararet. Haud aegre vero conftitit, neque hoc dignitati horti botanici conuenire, nec facile effe fibi ab hortulani, proprii lucri cupidi, perfidia cauere; vt de damno, quod interpellationibus hortulani, fub cultu \& venditione eiusmodi plantarum non vitandis, redundat, nihil proferam. Corruit etiam pro illa, quae Maecenati ineft, fapientia aliud confilium, quod nimirum pro pretio quodam definito expenfae, qualescunque fibi vindicarec horti cultura, ab hortulano procurarentur, quum fufpicio iuftifima effet, ne $a b$ homine iniquiori de priuato potius quam publico commodo difpiceretur. $\mathrm{Vt}$ ne vero defidia vel mala mente peccaret hortulanus, legibus iam tum cautum eft.

$$
\text { F , } 1.3 .
$$




\section{S. 2.}

Et ad haec quidem omnia rite adornanda aliquot annorum fpatium requirebatur; vnde nonhifi a. 1 $739^{*}$ ) ill. A B HALLER prima femina in horto nouo fpargere potuit. Quam moram autem plantaruin, mox undique a viro omnibus botanicis aeftumatifimo \& commercio litterarum inftructifimo conquifitarum, copia abunde refarfit, veque tanto minus grauis effet botanices cultoribus, praelectionibus botanicis \& itineribus frequentibus ad confinia \& a. 17;8. ad Hercyniam *:*) prima vice fufccptis, curauic. Pleraque tum temporis inftituta eadem adhuc hodie integritate perfifunt, etfi vt in iis, quae non a fola voluntate hominum, fed ipfa naturae adiutricis efficacia pendent, accedere foler, tum \& ditioribus fuppetiis exhibitis, varia poft!iminio ad maiorem perfectionem peruenerunr. Quicquid autem mutationum hortus fubituru fit, nunquam illae praefectos horti gratifimi animi officio erga illuftre Hallerianum nomen abfoluent.

\section{S. 3.}

Ita horti initiis leuiter delineatis, prifcis illis

*) V. illuftris Archiatri Regii z I M MERMAN N Loben des Hrn。 v. H A L LE R p. Irs. **) H A L LE R I Hije, fto belut Praef, p. 20. 
illis figillatim defcribendis non amplius immorabor, fed tanquam rem praefentem ea cum recentioribus, quae horto nofiro accefferunt, emolumentis, coniunctim fiftam. Quaje vero per breue iftud tempus, quo mihi horti cura clementifime demandata fuit, in eiusdem vigorem, incrementum \& decus, acciderunt a reliquis diuellere licebit, quippe mihi longe notiora.

Vix iam triginta tres anni, computo ab aduentu ill. HA LLER I facto, poft horti primordia effluxerunt; breue quidem temporis fpatium, fed pluribus mutarionibus, fi praefectos borti mutuo fibi fuccedentes \& horti va riam formam refpicias, obnoxium., Placuit enim Regi eundem virum horti adminiftrationi praeficere, in quem ipfam profeftionem botanicam conferat, nec ve in aliis quibusdam locis fit, alterum munus ab altero feiungere vel praefecturam horti inter profefforem \& alios diuifam ftabilire. Probabile enim erat, eum tanto aptiorem fore ad culturam firpium dirigendam, qui dignofcere fpecies poffit, \& cuiuslibet genium, clima, folum, mores nouerit, vel vi muneris noffe debeat, iunctus quoque aliis botanicis litterarum confuetudine, augmentis horti tantopere fauente, eumque tanto follertioren de bonis horti lo- 


\section{Sect. 3. Horti botan. Hifforia.}

cupletandis \& tuendis futurum, in quem do. minii quafi communio ob conquifitas vndique plantas tranfierit, \& aliqua gloriae, diuitiis \& decore horti acquificae, particula dimanare videatur. Qui huic exfpectationi fatisfacere in horti noft i commodum allaborarunt celeberrimi viri, horum nomina reliquae hiftoriae praemittere e re eft. Fuerunt ifti

ALBERTVS AB HALLER. Fundamenta horti iacta ill. viro deberi iam indicaui, reliqua vero eius de ifto merita nox delibanda dabo Valedixit academise, reuerfus in charam fibi Heluetiam m. Mattio a. 1753. Quae disiunctio ne debilitaret propenfum e. ius in res noftras herbarias animum, praeuertit \& praefidis perpetui focietatis fientiarum munus \& pondus, quod eius confilia apud Maecenatem habent, grauiflimum.

IOANNES GOTTFRIED ZINN. Patuit illi poft difceffum H A L LE I a. 1753 . Profefforis botanici prouincia, quam, licet animo, inter Botanicen \& Anatomen fluctuan. te, tenerctur, commendatifimam fibi habuiffe, docent veftigia, quae adhuc fuperfunt, horto accepta \& icripta cius botanica. Mortuus eft, vita.longiori digniflimus, d. 6. Aprilis a. 1759. Hoft eius mortem 


\section{Sit. 3. Horti botan. Hiforia. 93}

RVDOLPHVS AVGVSTINVS VOGEL, Regis iam Archiater \& Med. Prof. O. qui inter alias, quas ampliat doctrina fua, medicinae partes botanicen pariter in deliciis habet, vicarias operas bocanicas in le fufcepit; quibus vacauit vfquedum

DAVIDES SIGISMVNDVS AVG. B UTTTNER anno 1760 ineunte profefione botanica ornaretur. Praefuit muneri per $y$ fere annos, a quo cl. virum mors d. 20. Nouembris a. 1763. abripuir.

- IOANNES ANDREAS MVRRAY. Quae mearum partium funt, fcire vix attiner. Si quid vero de me gloriari liceat, in hoc gloriam ponam, auditorem olim LINNAEI fuifle, cuius tanquam praefentis admonitoris vultus, ftudium, fides contiuuo oculis meis obuerfatur, etiam adhucdum ab i, fo dilectum \& confiliis adiutum. Quod per plures annos, tam ante Profefforis munus indulgentiflime in me anni 1764 . initio delatum, quam poltea, incitamentis illuftriflimi Maecenacis fuftultus, rei botasicae fudium in hac academia facraui, tanto liberius alacriusque exercere inde a die 3 . Decembris anni 1768 . contigit. Hocce enim factum eft, vt, vacante cathedra botanica, litte- 
94 SeT. 3. Horti botan. Hifforia.

ris gratiofifime exaratis, horti commodis procurandis praeficerer, quas aliae dein d. 23. Aprilis a. 1769 exceperunt, quibus Regis auguftiffimi clementia Profefforis medicinae, nominatim Botanices, ordinarii fparta condecoratum me vidi. Cuiquidem, poft dignitatem, quam ill, ab HALLER illi conciliauic, rite ornandae licet imparem me fentiám: gloriofum tamen femper ducam, ad tanti viri ex. emplum formare animum, \& prouidere, ne mea culpa dedecus in illam aliquod accedat.

Vide iam, quid fub horum pro horto excubiis effectum fit.

\section{5.. 4.}

Fundus in borti gratiam emtus olim fuburbii pars fuit, quod veto nomen poft turrim nuperrime in haud exiguum vrbis decus dirutam, qua ante a reliquo oppido diftinguebamur, plane interiit; ea vrbis plaga reperiundus, quam tam fitus metropolin fpectans, quam vicinia aedis Reformatorum \& hippodromi regii nobilitat. Vtinam \& bibliothecae nouiter exftruendae vicinia frueretur; quid enim gratius \& opportunius, quam fi ex veftibulo eius horti deliciis pafcere oculos liceret, \& is fragrantes fuos halitus fpargeret in ipfa adeo atria Mineruae. 


\section{Sect.3. Horti botan. Hiftoria. 95}

Hic funclus iam initio tam fpatiofus erat, ve non folum plantis fed aedificiis quoque praefecti hortulanique neceflitati \& commoditaci inferuientibus fufficeret. Fauit quoque haec amplitudo ili, ita a reliquo campo dif: pertiendo, vt quum fpatii tum fymmetriae ratio haberetur. Quod factum eft refecta auftrum verfus triangulari parte, extremo autem vtroque verfus orientem \& occidentem integro relicto. Adeptus hac ratione hortus (modo exiguum fegmentum, vix fine menfu. ra confpicuum, dextrorfun eximatur) figrs: ram rectanguli, cuius breuiora latera orienti \& oppofitae plagae, longiora autem auftro \& feptentrioni obucrfa. Longitudine, latere ag. geri contermino, $44^{2}$ pedes exaequat, latitudine verfus occidentem 152 pedes. Deformitas, quae ex protractiori longitudine enafci videtur, non tanta eft, vt pomoeria horti ideo aretare opus effet, idque eo minus, quum apparens dedecus fepe viua vel arboribus recondi poffic. Maiorem moleftiam parit fitus eius quoad magnm partem inter aggerem, qui feptentrionem fpectst, \& verfus orientem fefe incuruat, \& aedificia oppofita ad hortum pertinentia, quoniam eo fit, ve ventus euro \& zephyro fpirante arca quafi recludatur, \& lateribus repercuffus vehementius ftirpes exagitet terramque exficcet; co 
96 Sect.3. Horti botan. Hiftoria.

quoque euenit, vt terra aedificiis vicina diutius, vere appropinquante, gelu feruet ${ }^{*}$ ), \& ftirpes ibidem crefcentes etiam per aefta. tem meridiani folis tepore ferius refocillentur. Sunt tamen extrema horti ab hoc incommodo libera, ideoque tenerioribus ftirpibus alendis aptiora, \&aggeris eleuatus fitus tutelam aduerfus Boream neceffariam ftirpibus largitur. Occidentem qui refpicit horti finis, altero oppolito paullo profundior eft, quoniam, quum hortus inftrueretur, declinitate eiusmodi opus efle ad ficcitatem horti feruandam credebatur; cui vero fini, quum imbribus vehementioribus vel exhydriis non mulctemur, iam fatis fufficit bibula foli natura. Noftra vero terra in argillofam naturam inclinat, fertilis ceteroquin ob diuturnum pro plantis vfum, quippe quae refolutione fur \& deftructione fibimet ipfae alimenta praebent, \& aliquoties repetitum ftercorationem. Cingit hortum ad vtrumque extremum fepes ex Carpino

-) Euidum hoc manifeftius thermometro Fahrenheitiano vidi, fub redeunte hiemis $\mathrm{m}$. Martio a. 1770. (de qua infra fectione 4. fufius) vi. Nempe deliquefcente iterum inde a d. 29. Martii, folis efficacia, niue, etfi difflueret iam infignitcr aedium aufrali purte; fubftitit tamen mercurius ad gr. 27., quin aliquando infra, in appenfo feptentrionali ae. dium parti thermometro. 


\section{Sect. 3. Hosti botan. Hifloria. 97}

pino, topiaria arte tonfa, \& verinque media parte tugurio ex eadem arbore ornata; reliqua latera, exceptis is ftationibus, quas aedificia occupant, fepimentum, ex afferibus conftruetum, munit。

Mature quoque decori horti digeffions eius fecundum artis leges profpectum eft. Primaria, qua in ambulacra fpatiofa \& areas fecatur, fere adill. HALLER I tempora referenda, poft quae cl. BÜTTNERO vifum eft, etfi non perfecic opus, puluinos ad $2 \frac{\mathrm{r}}{2} \mathrm{pe}-$ des reddere anguftiores, ita vt, quum antea duplicem feriem plantarum complecterentur, iam vnicae modo locum dent; Ppatia contra ea puluinis interiecta ampliare. Hac ratione cautum videbatur, ne Atirpes nimis denfe confitae radicum luxurie vel ftolonum petulantiore progerminatione fere mutuo fuffocarent, \& opportunitas maior dabatur fine illata plantis deambulando iniuria tirpes examinandi. Quaelibet area puluino latiori continuo, quem Abietes, Taxi, Iuniperi, Sabinae, Thuyae, Rofae, Ribes, rel., pomiferae quoque arbores in flabelli formam coactse, \& flo. res colorum \& odorum varietate delectantes ornant, circumdatur. Exterior huius margo Buxo veftitus, interior autem maximam partem fepe humili, ex commodis fruticibus, it 
98 Sect. 3. Horti botan. Hiftoria.

Spiraea falicifolia \& opulifolia, Potentilla fru. tefcente, Colutea arborea, Cytifo Laburno. Loniceris variis, Dieruilla, coerulea, tatarica; quorum omnium nullum pu'chriorem eleganria florum \& frondis, nullumque tonfioni obe. dientioren \& brumae patientiorem, noui, quam Loniceram tataricam, quam \& denfitas frondis ramorumque fubitum incrementum \& per fubmerfos ramos facilis propagatio, commendat. Margo vero cuiuslibet arearum puluini, ve plerumque folet, Buxo tonfa, condecoratur, cui equidem lateres costiles, eo praecife fine paratos, ad cingendos puluinos praeferrem, quum radices Buxi vetuftioris fuccum ftipibus ipfis neceffarium confumant, \& tonfio \& Buxi depranatae reftauratio, \& irerata, fi nimis denfe crefcit, eiusdem disiunctio, nouam quotannis operam hortu. lano imponant, vtilius aliis negotiis hortenfibus impendendam.

\section{5.}

Hybernacalorum, fine quibus hortus botanicus the fingi quidem animo poteft, duplex modo genus, vfque ad annum 1708 , adfuit, vtrumque aufro exacte obuerfim.

Horun vnum, frigidius, (Frigidarium vocant) Hefperidum, \&, quae einindem cum hifce 
Selt. 3. Horti botan. Hifloria. 99

hifce caloris grodum requirunt, coeli mediterranei plantas complectitur. Hocque maximum eft \& in eo aedificio adornatum, in quo theatrum anatomicum. Longitudinis eft 60 pedum, latitudinis 20 , \& altitudinis 16 , pauimentoque lapideo tectum. Media parte antrorfum duabus maioribus foribus inftruitur, per quas arbores proceriores transferun. tur, \& ad vtrumque harum latus feneftris duabus. Confuetus vero ingreffus fit per anguAtiorem ianuam parietis pofterioris prope angulum finiftrum. Replent hoc conclaue, ita tamen vt \& antice \& pofterius deambulatio libera fit, per rotam longitudinem, fubfellia lignea, quae e palis perpendicularibus pluribus gradibus conftructa, in quibus ciftae ligneae \& fictilia ita collocantur, ve fpatia ad fummum vfque gradum hinc inde, ambulacrorum inftar, relinquant, tam decoris, quam afcenfus facilioris caufa. Pone haec duo funt furni anemii ex ferro fabrefacti, quos calefacere, nonnifi gelu intenfiori infeftante, opus eft.

Alterum hybernacu'um omnibus reliquis ftirpibus calidioris climatis, quam ve in frigidario perfiftere poffent, deftinabatur. lam a. 1738 . exigum huius generis hypocauftum, ve fupra dixi, paratum \& quidem declinantibus feneftris, quod vero vitio arcis \& fubfel- 


\section{Sect. 3. Horti botan. Hiftoris.}

liorum in primis mala ftructura, quae ob ohliquum palorum, quilus fulciebantur, fitum, pondere tor vaforum in pofteriorem murum preffionem exercebant, iam quinto anno ruinam minabatur; quod ideo moneo, ve alii fimile vitium, quod exiguum initio videri poffet, vitare moileantur; nec fitus huius hypo. caufti commodus hubitus, ve quod oppofitum fibi habuit aedificium elatius folem mert dianum intercipiens.

- Neceffe igitur erat aliud, a. 1745. exftruere, idque extremo horti, quod orientem vergit, propius. Fuitque hoc ex trabibus interpofitis lapidibus aedificatum, 40 pedes longum, Ió autem latum, áccedente pofterius fub eodem tecto, fubfidente verfus pofticum murum, veftibulo 5. pedum, decliues pariter ad gr. 65 . feneftras gerens. Praeter hafce laterum anteriot pars feneftris initio inftructa fuic, quas vero demere $\&$ parietem lapidibus claudere coëgit venti perflantis atrocis. Ita \& area exigus corticibus $\mathrm{co}$. riariorum repleta, quum diuerfum caloren cxpofceret, ablata eft. Alia emenditione indiguit fornax, quae primum fuit fictilis, \& fupra pauimentum collocatus, intrinfecus quoque calefaciendus. Sub qua ftructura quum non calefieri faris polfet hypocauftum, 


\section{Sect.3. Horti botan. Hiforia. 101}

b. 2dFN I I tempore a. 1756. peritia cel. M ï L L E R I, Regi fupremi in re architectonica a commiffi, futuenit, qui furnum alium ferreum fouea effolfa infra pauimentum collocari curauit, ita conftructum, vt extra hypocauftum per Icalas defcendendo focus accenderetur, intra hypocauftum vero eadem tere cum pauimento altitudine canalem emitterer, qui per totum eius ambitum decurrens, fenfim pedetentimque altior factus, in fumarium fefe recepit. Hac ratione tepor conciliatus aequabi is \& commodum vfui euafit hypocau. ftum, adhucdum probandum, nifi \& hoc vetuftatis fata fenfim fubiiffer. - Huic calidiori hybernaculo fucceflit nouum, de qua infra dicum.

\section{6.}

Ad horti bona \& hoc pertinet, quod certum ftabilitumque bortulano ftipendium quotanris foluatur, adeo, fi cum reliquis commodis ipfi conceffis iungitur, largum, yt non cogatur cum difpendio publici officii rem domefticam anxie procurare. Domicilium eius eadem aedificii contignatione reperitur, qua hybernaculum frigidius, feneftracque iftius, quo tanto melius damna auertere poffit, in iplum hortum profpiciunt. Hortuli quoque illi in vfus domefticos dati funt. 


\section{Sect. 3. Horti botan. Hiftoria.}

Ne quid vero eius culpa noxae hortus contrahat, iureiurando, quo ad exordium muneris obftringitur, prohibitum eft.

\section{7.}

Sponte liquet, fruftra omnes hofce fumeus fuiffe impenfos, nifi liberali illuftriffimi Maecenatis indulgentia pecunia fuppeteret, qua alere quotannis inftituta horti liceret, renouare \& refarcire, quae pro ifta rerum omnium inconftantia fenfim conteruntur, augere denique thefauros horti, vt, prout aetate crefcit, \& dignitate \& praeftantia crefceret, \& praèfectus ipfe lorti opportunitate faciendorum inuentorum, ad haec ipfa profequenda in honorem ftationis \& communem vrilitatem, alliceretur. Adfignatum igitur annuum pretium, quo lignum pro foco hybernaculorum, ollse, fimus, arena, pali \& bacilli fulciendis arboribus \& herbis idonei, funes, rel. coemuntur, vitra feneftrarum difrupta reparanzur, \& operarii per aeftatem aluntur. Quodfi vero maiores expenfas defideret horti indigentia, quam quibus ferendis annuum falarium par fit, adeo facilen fefe illuftrifimus Academiae Curator exhibere folet, vt ex alio fonte horti neceffitates fuppleat. 
Sect. 3. Horti botan. Hiforiä. 103

$$
\text { 5. } 8 .
$$

Quum praefente quoque vigile \& cuftode opus effet, aetrficium in praefecti vfum exftat, ita fitum, vt ex eo totus horti ambitus luftrari poflic, \& curari, ne negligentia operarii peccent, vel iniuria vlla ftirpibus inferatur. Quae cum horto vicinia \& hoc emolumentum habet, vt tanto commodius \& exactius culturae operam dare praefectus poffit, \& obferuationibus, quae protractum faepe \& \& per fingulas horas repetitum for utinium requirunt, indulgere. Iunctum hifce aedibus \& tale decus, ve iucunde inhabitetur \& talis ftrutura, quae altitudine $\&$ amplitudine conclauium fefe commendans \& valetudini fauet \& cum litteris familiaritati. Annexas habet auftrum verfus macella rei domefticae praefecii dicata.

\section{9.}

Atque haec funt praecipua, quibus cura ill. HAE.LER 1 eiusdemque in horti adminiftratione fuc:efforum, antequam eidem admouerer, horti commodis confultum eft. De digeftione priftina Atirpium in areis fuis \& earum copia dicturus iam effem, nifi in ifta difficultatem pararet narrationum defectus, in hoc indices ftirpium ab ill. H A L LER O \& cel. Z INN 10 editi otium facerent. Litteris au- 
104 SeEt.3. Horti botan. Hiforia.

tem ill. HALLERO certiorem reddere me placuit, fe olim ftirpes ad leges fyftematis fui difpertiviffe, quss etiam fequi video catalogum horti ab Ipfo manu propria a! 1743 . exaratum. Valde ideo miror, quod ab hoc ordine, qui cognationi plantarum naturali cognofcendae tantopere inferuit, pofteri praefecti, qui tamen auditores magni viri exftitere, deflexerint. Eius praecipue opera faatum eft, vt \& fpontanearum plantarum haud exigusm copiam horrus comprehendat. Reliquae plantae, quas accedens deprehendi, nullum, prout par eft, vel familiae vel regionis felectum produnt, nifi libiricis \& canadenfibus cum conterraneis praerogatiuam adfcriberem, quas \& durior \& brumae patientior vita commendabiles reddit. Arborum \& fruticum, qui fub dio perdurare poffunt, penuriam quandam animaduerti ; quam vero querelam nolim ad porniferas arbores me extendere sliquis credat, quum nec dignitati horti botanici congruat fpeciem ferre macelli, nec prudenter actum videatur, eiusmodi lenociniis gulofos allicere. 
Selt. 3. Horti butan. Hiftoria. $10 \mathrm{~g}$

\section{Particula 2.}

NOVISSIMA HORTIINDE A $A$.

1768. CONDITIO.

\section{1.}

Accedo iam ad illud tempus, quo ego rebus horti praefui. Memorabile hocce non mes aufa reddunt, fed infignis illa, \& incredibilis fere fanctioris facrae Regiae Maicftatis in hac regione Conflisi, illuftriflimi praecipue academiae Curatoris, immortalis MVNCHнAVSI, in hortum indulgentia. quae tanta liberslitate vno ifto anno nuperrime elapfo effulfit, ve dubitem, an luculentiora eius per omnes annos praeteritos documenta exftiterint. Sed innumera praeterea perilluftri \& generofifimo Regis Satrapae, L. B. OTTONI A MVNCHHAVSEN hortus debet, qui pro eo, quo in rem herbariam flagrar, amore, \& pro fumma Eius in eadem peritia, petitionibus meis apud illuftriffimum Maecenatem pondus addere haud grauatus eft, \& confiliis fuis nouorum conatuum moderator adfititit fcientiffimus. Quorum luminum nomen quanta veneratione botanici profequantur, interprete fuo LINNAEO, ftirpe, Muncbbaufia Speciofa nuncupata, nuperrime 
106 Sect. ;. Horti botan. Hiftoria.

declarauit vniuerfus chorus; fanctiflimum vero efto illis, quam diu terra viret!

\section{2.}

Inter omnia nouiter inftituta maxíme neceffarium fimulque fumtuofiffimum byberna: culum eft ; fine cuius adiumento nec potuit thef urus femel acquificus feruari, nec nouorum augmentorum fpes concipi. In antiquo enim illos calidioris climatis plantis deftinato, trabes feufim p'urimam partem computruerant, feneftrae compagibus fuis hiantes pluniae ventoque tranfitum concedebant, fumusque ftirpibus funeftiflimus, fpirante in primis Borea, per rimas canalium vndique penetrabat. Anguftia practerea laborabat prae numero plantarum tanta, ve ob halitus copiofos marcefcerent mulsae plaitae \& aphidibus coccisque foedarentur. $\Lambda$ ccedit, quod, quam duo modo in vniuerfum hactenus hyberracula fuppeterent, non poffet commoda partitio 1tirpium fieri, fed fuccofae mix tim cum ficcioribus feruarentur, \& aliis plus, aliis minus iufto, caloris impertiretur. Sumtus igitur ad aliud aedificandum non detrectauit illuftriffimus Maecenas, fed variis peritiffimis viris in confilium adhibitis, celeberrimo м ̈̈ L L E R O, rei architectonicae Commiffa. sio primario, cuius eximiam in arte fua dex- 


\section{Sest. 3. Horti botan, Hiftoria. 10?}

teritatem tot antea aedificia comprobarant, totam aedificii rationem exfequendam tradidit; quam exfequutus perite \& alacriter.

Hocce nouum exfiructum eft diftantia 4 pedum ab aggere, qui contra boreale frigus commodam tutelam fubminiftrat, auftro directe oppofitum, \& domunculie illi ex aduerfo, qua aedificium praefecti \& illud, in quo theatrum anatomicum eft, connectuntur; quo fitu \& fymmetriae horti \& praefeci vigilantiae confulitur. Damnum, quod ex mala praecedentium hybernaculorum ftructura emerfit, vitia quaedam docuit euitare in nouo ifto. Fundamentum ideo firmum $\&$ ad 6 pedes vfque fub terra profundum ex lapide calcario in vicino $\mathrm{m}$. Heymberg fracto pofitum, cui innituntur lapides quadrati altitudinis 2 pedum. Totum vero aedificium ita diuifum eft, vt anterius duo conclauia exftent, quorum alterum finiftrum plantis calorem mediae naturae defiderantibus fiue iftis ex capire bonae fpei \& regionibus extra tropicos, alterum dextrum plantis maximum calorem pofeentibus $f$. iftis in zona torrida deftinatur, poftice veftibulum fecundum totam eius longitudinem decurrat. Tectum ex tegulis hamatis conftat. Muri ex mero lapide ruditer fracho coagmentari, veftiti tamen exterius late- 


\section{ros Sect.3. Horti botan. Hifforia.}

re coctili, \& in maius decus hinc inde in an. tas prominentes; pofterior, vt tanto efficacius boreae vis auerteretur, craffior, fcilicet ad $2 \frac{x}{2}$ ped., reliqui 2 ped. modo craflitiem con. ftituunt. Tota eius, murorum fimul ratione habita longitudo 64 pedes, latitudo 30 ped. exaequat, Anterior facies modice inclinat fupra arcum formans, cuius extimus margo a folo 28 pedes diftat. Pofticus autem murus aggeri proximus 9 modo pedum altitudinem habet. Pauimentum ex laminis lapideis laeuigatis ex lapicidina Heyınbergenfi petitis ftratum eft, \& ad 2 pedies fupra horti folum eleuatum. Fenefris, Belgatum exemplo, declivis fitus datus eft. Sub iftis autem de prae. ftantia declinantis \& ereai fitus difcidiis, quorum illi folaris caloris intenfitas fauere, aduerfari vero videtur fpatii difpendium, op. portunitas-maior frigori, vento pluniaeque penetrandae exhibita, \& niuis cadentis onus; tutifimum vifum eft, altitudinem folis fub folftitio hyemali, in definienda feneftrarum inclinatione, pro norma vti. Graduum igi, tur 75 fere decliuitas parieti feneftrato data eft *). Media parte fores ex duabus alis fe.

ne.

*) Opus nempe eft in bybernarulo bene frueto, ve planum feneftrarum radiis folis, folftitio hyberno (d. 31. Dec ) emicantibus, fub angu. 
Sect. 3. Herti botan. Hiftoria. \&og

treftratis conftantes factae funt, ad transferendas modo proceriores plantas, aperiendae. Arcus margini tedi vicinus ex afferibus ligneis ftructus eft feneftraque rotunda media perforatus. Reliquis feneftris indita funt, quo acceffus radiorum fo! is tanto liberior fit, vitra albiffima, \&, tam huius quam pluuiae excludendae caufa, imbricatim, inftar tegularum tecturum, absque fulcris transuerfilibus pofita. Secundum longitudinem autem bacillis fir-

man:

io resto obuerfetur. Quare inclinatio fene. ftrarum, altitudinem folıs hiemalis a $90 \mathrm{gr}$. fubrtshendo, defunitur. Ex obferuationibus cel, $M$ it $L L E R$ I noftri altitudo folis tum tem.poris Gotringse gr. is aequat ; vnde \& angulus parietis feneftrati gr. 75 conflituere debet. - Eadem ratione iufta feneftrarum vaporariorum inclinario indagatur, modo altirudo folis fub rolltitio acfiuo (d. 21 . Iunii; quam horum vfus aeflate, prout hybernaculorum, hyeme fiat) quae Gotringle $\sigma_{3} \mathrm{gr}_{0}$ aequat, pro bafi calculi ponatur. Hocce po. fito feneftris vaporariorum noftrorum decliuitas 28 gr, conceffa eft. - Si deflectendum ab hac norna efle aliquis exiftimet, praeftate viderur, angulum inclinationis $f_{e}$. neftrarum gradibus qurobusdam augere quam minuere, eam praecipue ob catufam, vt ne calore aëreque bumido intra arctum nimis fpatium reclufo plantae contabefcant. Quam regulam \& nofmet ipfi, tam in hybernaculo quam vaporariis, in vfune vertimus. 
110 Seit.3. Hurti botan. Hiftoria.

mantur, ex quibus ftyli ferrei prominent, quibus quadrae vitreae fulciuntur. Duae feneftrae mobiles funt, fupra affixae ad aëris renouationem, qua humiditate tepore iuncta, fub finem praecipue Aprilis, initioque Maii, inualefcente, opus eft.

Sequitur iam, ve de fructura aedificii \& ratione interna agam; quod dixi ftirpium caufa in duo conclauia effe diuifum, idque quidem per parietem, anterius ianua ad dimidium feneftrata inftructun. Vtriusque eadem altitudo eft, fcilicet anterius a tecto ad pauimentum, $18 \frac{1}{2}$ pedum, ad pofteriorem autem murum 14 pedum. Ne vero angulus pofterior tecto fubiectus neceffarium ftirpibus teporem fine frualu vllo abriperet, tedti dimidia pars verfus pofticum murum decliuis euafie, ita, ve ad latera hybernaculum interne trapezium referat, cuius latus fupremum $\&$ infimum parallela funt. - Cuilibet conclaui furnus ineft, quadratae figurae 5 pedum, ex lateribus coctilibus coa gmentacus, \& fupra lamina ferrea tectus, tam profunde collocatus, ve fuperior eius fuperficies pauimenti planum exaequet, \& a fouea, cui immergitur, vndique pedem vnum, quo tanto liberius calorem fpargat, diftans, extrinfecus denique ca. lefa- 
lefaciendus. Canales veriusque furni vnit commune fed fepto disiunctum fumarium.

Calidiffimum bifocauftum (Bark - ftove, Caldatium) 27 pedes longum occidentem ad latus refpicit, qui fitus nubis faltem a'tero verfus orientem aptior eft, quippe qui Euro, ficcitate \& ffrigore molefto, nimis pacet. Furnus angulum pofticum lateris oricatalis occupar, ex quo canalis varie flexus latitudinis 16 poll. quadr. emergit; Hic primum intra hypocaufum prope parietem laminis ferreis opertus fenim afcendit, dein tribus ductibus hinc inde forma ziczac factis prriete poftico fefe recondic, tecius ibidem antice tegulis cenuioribus planis. Arridet in primis Anglis *) canalis haecce in poftico muro fedes, a quibus tamen in eo apud nos difcelfum eft, quod fepta ductuum intermedia non vbiuis eiusdem latitudinis fine, fed ve fumus eo minus fuo curfu retardetur, cuneum forma referant. Mediam huius hypocaufti partem occupat fouea rectanguli in formam lapidibus obuallata, altitudinis 3 , latitudinis 5 , \& longitudinis 12 pedum, germinationi \& vigori praecipue plantarum ex regionibus inter tropicos fitis dicata, quibus ita optime vide-

curc

*) V. in m I L e R I Gardeners Diefionary Ed. e. isones ad atriculos Girentionse \& Stoves. 


\section{Iia Sest.3. Horti botan. Hiftoria.}

tur confuli, ve primum ftrato ramulorum ficcorum ad humidum fuperfluum imbibendum, dein corticibus coriariorum, repleatur, qui in eo praeferendi fimo, quod, mitiorem licet modo fotum concipiant, eundem tamen diutius longe leruent; nifi vtriusque mifcelam praeftantifinam arbitreris. Pone fuueam iftam fubfellia aliquot grdduum collocantur.

Alterum bypocaufum, mitiorem calorem alens (Dry-ftove, Tepidarium), longius eft, fcilicet 33 pedum, \& otientein ad latus finio ftrum refpicit. Furnum habet poftice oppofito angulo. Canalis huius decliui fitu per totum conclauis ambitum decurrit, remotus tamen ita a feneftris, vt prope iftas via libera maneat, the canalis calo pedibus moleftiam facefiat. Amplitudo eadem eft, quam defcripfi, cui id tamen addendum, quod furfum per inceruallia ad 6 pollices vfque ampli. entur, eum in finem, vt calor retineatur in hifce diuerticulis diutius Ad faciliorem vero fumo circuitum conciliandum, qui alias $\mathrm{fa}$. cile per rimas penetrat, canali prope furnum 3 pedum fubter pauimento profunditas data, \& trium rurfus pedum altitudo fuper eodem prope fumarium, fub quo tractu fenfirn pes detentimque afcendit. - Supra ifte laminis ferreis tegitur. Subfellia \& in hoc hypocaufto inftar 
inftar amphitheatri ftructa funt; praeter quae tam in hoc quam in altero hypocaufto pone feneftras afferes fuis ferramentis impofiti ad fictilia fuftentanda occurrunt.

Per vefribulum, quod indicaui pone hypocaufta reperiri, fcalis ad oftia furnorum defcenditur, ibidemque lignorum neceffiria ftrues pro foco feruatur. Lumen vero per feneftram, muro poftico inditam, incidit.

Loco valuarum lignearum, quibus olim hybernaculi feneftrae contra frigoris vim \& tempeftates opertae fuere, aulaea lanea denfa tor, quot feneftrae, texta funt, quae \& melius frigus auertunt nec tantum in feneftras pondus exercent, \& commodius longe tractari tempeftateque orta velocius demitti poffunt. Plerisque in hortis, vbi ifta adhihentur, conuoluta poft vfum vides fuper feneftris propendere; quae vero deformitas vituta fpatio pone arcum anterioris parietis relicto, intra quod fupra cylindros ligneos \& trochleas fub tecto funium ope retrahi \& demitti poffunt.

Media marginis anterioris tecti parte vexillum ferreum proftat affabre factum \& vel minimo vento aufcultans, ve ventorum ratio $\&$ in plantas efficacia inde cognofci poffit. 
114 Sect. 3. Horti botan, Hiftoria.

\section{3.}

Non exiguos quoque fumtus vaporaria ifta 4 noua fibi vindicarunt, ex afieribus quernis craflis coagmentata, quoorum fingulorum tota longitudo 2 I pedes aequat, latirudo 7 . Quoniam vero hoc ligni genus, ob durationem reliquis tamen praeferendum, humiditate $f e-$ fe incuruat, \& compagibus fuis foluitur: quodlibet vaporarium ex tribus arcis compofitum. Media harum in quolibet vaporario paullo altior eft, in duobus vero tam alta, fcilicet ad $4 \frac{x}{2}$ pedes antice \& 6 pedes poftice, vt \& Atirpes proceriores, quae continuum fere teporem requirunt: nec praegnantis terrae adiumento carere poftunt, femina in iis maturare queant. Et hae quidem tam antrorfum quam furfum feneftris inftruuntur; reliquae omnes modo furfum, numero 6 in quolibet vaporario, directione modice decliu *). In quauis arca media parte bacillus inter parietem anteriorem \& pofteriorem infixus eft, eo in loco, quo feneftrae fefe contingune, in canalis formam excaustus, vt pluuialis aqua penetrans per anterius orificium effluere poffit. Collocatavero vaporariorum bina, vnum ante aiterum, ad vtrumque hybernaculorum latus.

Stra.

*) V. quae de inclinatione feneftrarum fupra (Sect. 3. Part. 3, in nota S, 2.) monita funt. 


\section{Sect. 3. Horti botan, Hiforia. is}

Stragulae, quibus feneftras operimus, ex arundine \& ftraminis medio ftrato parantur, quod vtriusque connubium praeftar ftragulis ex folo vel ftramine vel arundine factis; quum iftae, etfi denfiores, laxae nimium fint, hae vero onere vitra gratient, nec calori feruando tam opportunae.

\section{4.}

Eandem, quam hybernaculum nouum \& vaporaria, Juftentacula noua occupant aream, quibus ftirpes exoticae, redeunte aeftiuo tepore, horti inftar penfilis imponuntur. Fuerunt haec vndique antea ad latus ambulacrorum difperfa, vnde vero operafior euafit translatio, nec merita potuis vigilantia damnum rarifimis ftirpibus a male moratis illatum arceri. In nouis iftis, loco palorum e ligno terrae infixorum, putredini autem nimium obnoxiorum, afferibus, qui ollas gerunt, la. teres coctiles calce conferruminati pro fulcimento funt.

\section{Sed non hifce acquieuit gratiofa Mrece-} natis in hortum beneuolentia, verum mulcis aliis notis cumprobatam fefe exhibuit. Deerit nobis hucusque conclaue, quo lignum pro foso, fenefrae \& itragulae vaporariorum, in-

$$
\mathrm{H}_{2} \text { Atru- }
$$


116 Sect. 3. Horti botan. Hifloria.

Atrumenta \& vtenfilia feruarentur, \& quo varia opificia ex ligno horto neceffaris parari poffent. Vnde non mirum, quod aeris iniuria vel imprudentiori in variis latibulis fuppellectilis hortenfis occultatione multa fuerine corrupta, longioris alias durationis futura. Qua in re vero quoque precibus meis fatis. factum, affignata huic fini domunculae, quae aedificiis maioribus horti interiacent, parte.

$$
\text { 5. } 6 .
$$

Inftrumentorum \& vtenflitum hortenfi. um, vt ploftellorum, raftrorum, gutturniorum, ligonum, fcalarum, afciarum, ferrarum, furcarum, forficum, amphorarum rel. nouus quoque apparatus conceffus, vitiato nimirum priftino omnino fere. Inter vtenfilia commemoranda dolia pro feruanda aqua in hybernaculis, ciftae quernae rotundae, quae quadratis duratione antiftant, in vfum arborum peregrinarum \& Itirpium grandiurum, vt \& ollarum fictilium infignis copia. Plurimae harum \& quidem minorum, quas coëmimus, quadratae figurae funt, quae ideo praeferenda, quod ollae, fub ea forma fefe mutuo contingentes, tepore vaporarii tanto melius refosillari poffunt, \& fpatii in vaporariis tam fumtuofis parfimoniae inieruiunt (in noftrorum nempe quolibet ol- 
lis 312 locus eft ), tum \& quoniam radicibus amplius longe fpatium, quam rotundae, concedunt.

$$
\text { 6. } 7 .
$$

Sepes viuse ciuum, ornatui quidem fauentes, raro tam denfae fiant, ve animalia minora arceri poffint, neceffe erat, vt occidelstem verfus, vbi peregrinus hortus alluit, Jepimento, palis afferibusque ftructo, muniretur; quod iamiam factum effe, non inter exigua horti emolumenta referendum.

\section{8.}

Ita \& fortunate euenit, quod, quum nobis aquaria ad rigandas plantas deeffent, horum loco practerits aeftate canales ex laminis ferreis, ad colligendam aquam pluuialem, quae omni reliquo aquarumgenere praeftantior, tecto aedificiorum fubfternerentur. Suppofita hifce ampliora dolia terra ad marginem fere vfque recondita. Etenim putealis aqua, qua antea vfi eramus, prour in vniuerfum fere Gottingenfis, tanta tophi copia impraegnata exftitit, ve crufta denfa terra ollarum fenfim obtegeretur; vnde facile colligitur obturatione pororum per lapideam materiam neceffario alimento plantas orbatas fuiffe.

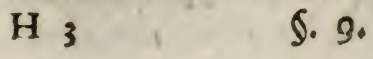


118 Sect. 3. Horti botan. Hiftoria.

\section{S. 9.}

Nec reticere conuenit expenfas ad cotrparandos hacillos (Etiquettes) erogatas, quibus ftirpium per areas confitarum limites definirentur, \& hae ipfae numeris aliisque neceffariis fignis mux dignolcerentur. Et ifti quidem ex ligno querio non fecto fed fifo fabrefs cti funt, dupares magnitudine, ira vt maximi perennibus ftirpibus, minores annuis, in areas transferendis, minimi plinti in ciftis \& ollis feruandis tribuerentur, diuerfi quoque pro iufta proportione latitudime fupra in vniwerlum latifimi. Quorum omnes \& linguli colore commodo, non decoris modo led \& durationi caufa obdueti funt; fab tanta plantarum copia tanto fumtuofiores. Vtilitas auזem huius inftituti paullo poft ex $\S_{0} 13$. vlterius patebit.

\section{10.}

Inter tot alia maioraque, quae horto noftro seftate praeterita contigerunt laeta \& jucunda, leuiora habenda funt, quod dealba-. tum fuerit hybernaculum frigidum, quo ipfo non tantum elegantize fed \&, reflectione radiorum folis t nto viuaciori, plantarum vigori confultum eft: quod ambulacra horti, arena sparfa, pluuiofa etiam tempeftate deambula. tionibus opportuna fint reddita, quod prae- 


\section{Sect. 3. Horti botan. Hiftoria. IIg}

ter definitam horto pecuniae fummam alia adhuc, fub tanta laborum hortenfium copia 0 perariis erogata fuerit, vt alia taceam.

Abfit tamen, ve ad leuiora referrem, quod nouis litteris de annuis pro horto expenfis illuftriflimus Maecenas certiores nos reddiderit, \& renouato legum vigore profpexerit, ne illicita herbarum cupiditate vel ioco vituperando horti diuitiae \& decus aliquid noxae repeterent.

\section{1 I.}

Equidem vero ne tanta in hortum munificentia male collocata videretur, iam fub aufpicium noui muneris varia tentamina feci; quibus, quum vilitati, tum decori, \& futuro horti vigori ${ }^{*}$ ) bene cupiui; de quibus iam rationem reddam.

Mutata noftro tempore mirum in modum hortorum iuftuendorum ratio, \& quum antea de fymmetriae rigore, de ambulacris in rectam lineam producendis, de foli planitie, de tonfis arboribus \& fepibus maxime fuerint folliciti: iam ad Chinenfium guftum varietsti

* Lustilité, la propreté, er la prevayance fulcra ifta funt, quibus perilluftris auftor libri, der Housvater, totam rem hortenfem fuperftuit. 
120 Sect. 3. Horti botan. Hifturia.

in primis ftudetur, ne fimplicitate torpeat animus, \& vincula naturae omni arte pulchriori imponere, \& calamiftro torquere eam, nefas exiftimatur. Quum vero fimul legis inftar effe debeat, in quoliber horto finis, cui deftisatur, memorem effe, isque in horto botanico copia praecipue diuerfiflimarum itirpium, or ine commodo \& facili vfu, contineatur, \& fpatio quoque, quantum fieri poteft, parcindum fit: culpam potius quam laudem incurrerem, fi ambulacra in ductus ferpentinos flexiffem, loca areis deftinata in cefpites virides vel luculos mutaffem, planitiem in monticulos collesque eleuafferm, aliisque modis mori feculi, inter Europaeos Anglis nominatim familiari, litaffem. Pergens contra ea in iam incepto tramite, decus horto iam ante me tributum nouis infitutis \& diuitias femel partas nouis fupplementis augere, quantum in me fuit, annifus fum. Quibus vero conatibus non vno anno fatisfieri poffe, quilibet, vel me non monente, perfpiciet. Plures quoad areas \& ambulacra mutationes mutata hybernaculi recens exfructi ftatio iniunxerat, ad quod, medio fere in horto conditum, tota eius partitio exigi deberet, vt ne lymmetriae defectu decori, quo pretiofum hocce aedificium nitet, aliquid decederet. Ambulacra igitur varia in puluinos, hique in 


\section{Sect. 3. Horti botan. Hifforia. 121}

ambulacra commutati. Qui inter priftinos difpares antea menfura fuerant, hofce aequandos \& Buxo cingendos curaui. Ad nouos parandos gramen caninum terra profundius eruta fuffocare oportuit. Arbores indigenae, hinc inde in horto per ipfas adeo areas antea difperfae, pone fepimentum horti translat ae funt, vt, etfi minime fpernendae, locum concederent rarioribus, quas America feptentriona!is alit. Inch atas circa areas fepes produxi vlterius, eoque fine ad continuandum fequenti anno opus ramos fruticum tempeftine fubmerfi, quoniam eiusmodi fepes tam ad tuendas contra ventos plantis, quam ad excludendos maleuolos exinium commodum praeftant, vnde \& in pofterum portulis inftruentur. De luculo ex americanis arboribus, ve luniperis, Populis, Tulipifera, Mefpilis, Prunis rel, ad extremum horti orientale inftruendo in pofterum cogitabitur.

\section{12.}

Aliud negotium iniunxernt neceffaria ad fyftematis normam ftirpium perennium fub dio crefcentium transpofitio, quae tanto difficilior erat, quum ineunte iam vere, vbi multae nondum germina emiferant, perficienda effet, nec vlli harum neque diftantia definita neque index competcret, multae contra ea eiusdem fpe- 
122 Sect. 3. Horti botan. Hiftoria.

ciei pluribus in locis occurrerent. Iucunda tamen ad radicum cognofcendam naturam, \& valesudini fauens ob reficientes halitus, electrica forfitan materia foetos, quos terra recens effoffa fpargit. Decem fere amni effluxerant, quod vni eidemque fedi affixae remanferint, vude won potuit non eneruari fenfim terra, \& radices multae, fuccofae alias, euaferant lignofae, adeo, vt fub effodiendum ipfe ligo frangeretur \& media parte putredine confumtae exifterent, quod in Rheo Rhabarbaro, Laferpitio latifolio aliisque multis apparuit. Hac quoque transpofitione opus erat ad luxuriandi, quin extra puluinos, vitium mulcarum coërcendum. Ita vero rem peregimus, ve effoffae radicis truncus, fi adeffet, vel fibrae ad apicem amputarentur, tum demiffa ea in foueam manu vel ligone paratam, terra apprimeretur, moxque fulco circa plantam facto, ve fubfifteret paullum aqua, rigaretur. Hocce leuidenfi artificio contigit, vt reluctante licet tempeftate praeteritae aeftatis frigida, inicio fic$\mathrm{ca}$, dein hanida nimis, omnes fere, quod poft transpofitionem aegrius alias primo anno fit, laetifime florerent, ftaturam Spectabilem nactae.

Ita \& opus fuit plantas perennes hybernaculorum in alias ollas, vel ciftas transponere. Sua. 
Suadebat hoc confumtio per moram fubtilioris humi partis, a qua nutritio \& vigor plantae dependet, \& radicum nimium augmentum \& incrementum, quod tantum fuit, ve e. g. in Phoenice dadylifera \& Haemantho puniceo ipfa terra furfum adigeretur, \& ollae, eciamfi craffae firmaeque, vi fefe expandentium radicum difrumperentur, in ciftis autem fi. brillae, vbicunque poffent, latera ligni putrefcentis perreptarent。

\section{13.}

Id porro mihi datum exiftimaui, ve plantas tam perennes quam annuas biennesque ill a LINN É fy/temati conuenienter difponerem, \& cancellos ipecierum bacillis adpofitis definirem. Infcripti hifce funt numeri, qui ill. A L I N NE' Species plantarum Ed. 2, $\&$ quidem paginam \& numerum fpeciei, refpiciunt, \& characteres varii, quibus mox durario ftatioque commoda elucet. Iisdem fignis Atirpes in ollis germinantes ante transplantationem, \& quae in hybernaculis fermantur, capfulaeque feminum, notatae. Ita v. c. infcriptis characteribus \& numeris $\Varangle \mathrm{d}$. $531 \cdot 3$. the Rheum palmitum, plantam nimirum perennem fub dio perdurantem, indicare facile cog. nofcitur. Non mihi fed Botanices Profeffori Hafnienfi, cel. OEDER, cuius beneuolenti- 


\section{Seff. 3. Horti botan. Hiftoria.}

ae tot a lia debeo, \& quem adeat, qui compendia in colendo horto botanico in vniuerfum difcere cupit, compendiariam hancce, auditoribus fimul fructuofifimam, ftirpes defignandi rationem, tribuo. Huius enim ope negotio operofo catalogos quotannis confcribendi fuperfedere licer, quum Linnaeanae fpecies loco caralogi fint, fub transplantatione ex oilis in areas vel translatione ftirpium in hybernacula nouimus, quis cuilibet fit locus, quis caloris gradus, affignandus; ita \& in ftirpibus fignificandis parcitur tempori \& fcriptioni pr lixáe, (cui parfimonize, quan. tum ftudendum, nemo, fub tanta herbarum \& negotiorum copia luculentius perfpicit, quam qui horto butanico colendo admouetur, omni praecipue adiutore deftitutus.) quando vel alii a nobis plantas defiderant, vel nofmet ipfi aliorum auxilio indigemus; \& botanices cultoribus commodiffimum compendium fuppeditatur, ftirpes paullo ante in praelectionibus demonftratas in animum reuocandi. Plantae, poft editionem Specierum a L I N N A E O defcriptae, vel in Syftematis naturae Editione 12, fiue in Mantiffa vel in Appendice tertii eiusdem voluminis, pari modo notantur; ita \& lineola vna vel altera numero praemittitur, $f i$ in eadem libri pagina pluries idem numerus occurrit. Hybernacula defig- 


\section{SeCt. 3. Horti botan. Hijtoria. 125}

nantur characteribus fr, t.c. \& ftatio fub dio littera $d$; duratio plantarum confuetis notis

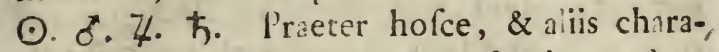
ceribus nonnullis vtor, pro plantis nondum cognitis fatis, botanicis, a quibus miffae fuerint, nctandis \&c. quos, quum a cuiuslibet arbitrio dependeant, adpingere nolo. Stirpes annuas cum biennibus LIN N AEI exemplum fequurus combinaui, licet moleftum fit, quod hae ipfae fecundo modo anno flores emittant; vnde, quando area annua recens inftruenda, haice per tempus in alium locum collocare oportet, repetendas rurfus pro fyftematis ordine, ve ne, fi permaneant ibi in fecundum vfque annum fixae, fyftematis feriem turbent.

\section{'5. 14.}

Semina autem cuiuslibet ftirpis, a qualicunque etiam patria prouenerit, fub recto in ollas primum ferere opportunum fuit. Eo enim prohibetur, ne ifta per ventum fub fa. tione difpellantur, vel fata pereant, vel alienis locis emergant. Quae naturae funt eiusmodi, ve vaporarii tepore non indigeant, horum ollae fub feneftris tantummodo contra aeris iniurias feruantur. Reliqua vero calidioris climatis femina in vaporaria collocantur, ve tepore fimi equini vel corticis coriariorum 
126 Sect. 3. Horti boian. Hifloria.

germinatio acceleretur. Per hocce artifi ium quoque vacat, femina maturius terrae committere, quod alias fub dio, ob frigidiores quin gelu interdum obnoxias nockes, vix ante medium Aprilem apud nos licet, ino fae. pe ferius fieri debet; vnde vero iufto breuius maturationi feminum tempus relinquitur. Poftquam vero germina digiti circiter longitudinem adepta fuerint, \& fenfim aëri adfueuerint, excuffa ex olla eandem fubuertendo, terra, hanc vna cum planta in definitum areae horti locum immifimus, ve fponte dein fpatium repleri poffet. Teneriores ob clima calidius plantas, in altiora vaporaria vel hybernacula, vt libere procrefcere poffent, transtulimus.

\section{§. 15.}

Non inficior tamen difficilem effe rem moleftiaeque plenam in digerendis plantis $\int y$ fematis, qualecunque fuerit, ordini fele adftringere, quin lubens largior, fumma eam accuratione abfolui nunquam poffe. Etenim germinandi tempus non omnibus idem contingit, fpariaque in areis vacua pro germinaturis ftirpibus, quum incertum fit, anne femina effoeta fuerint, aegrius relinquimus. Differunt quoque nimium plantse quoad terram, fationem, calorenque neceffarium. Multo-

que 
Sect. 3. Horti botán. Hifioria.

que minus arbores fruticesque exilibus plantis commilcere licet, quum ne proccriores quidem ftirpes herbacese, quippe quae vimbra nocent \& nutrimentum auide nimis hauriunt, humilioribus impune interferuntur. Multas tamen difficultates impiger labor vincit; \& tam in itineribus botanicis quam in horto in. numeris fere, aquaticarum adeo exemplis, didici, quod plantae exiam extra ftationes a natura praefcriptas fatis commode degant. Nec probibent recentes quolibet anno accelliones huic difpofitioni indulgere, quum, quod ad annuas pertinet, nouae firpes antiquis fub fatione facile interferantur; perennium vero vigor \& integritas requirat, ve omni triennio vel quadriennio transferantur, fub quo negotio, quae eo interuallo arceffere, ftirpes excipi a reliqua ferie poffunt. Vtilifimam etiam fub minori perfectione, quam atringere ipla vetat rei natura, hanc digeftionem exiftimo, quum ad fyftema tamen addifcendum \& comparationem multorum generum \& fpecierum conferat; \& fic fine mora planta examinanda reperiri queat.

\section{§. 16.}

Semina vero ita difponere nihil prohi. bet, itaque difpofui iam ineunte munëre nume. rofiflima ifta mihi mixtim relicta, incipiens ab an- 
128 Sect. 3. Horti botan. Hiforia.

no 1768 \& tum, regrediendo ad praecedentes, vfque fere ad annum 1760 , ex cuiuslibet anni congerie ea felegi, quae inter pofteriores meffes non obuia erant; nominum ab hortulano adicriptorum loco characteres fupra fignificatos \& nomina Linuaema addidi. Optima vero feruandi femina ratio videtur in capfulis chartaceis effe, quum arca plures in loculos divifa hoc incommodum pariat, ve fub eius motu vel agitatione ex vno loculo in alterum facile femina tranfiliant, \& ciftulae ex lamina ferrea vel ligno factse uperculoque tectae, iacturam temporis, quando femina eximenda funt, pariant. Chartaceae capfulae id quoque conmorlum habent, quod femina indita \& adhuc humida aëris libersliori acceffu ficcari melius queant.

\section{17.}

Communem hortis fortem \& nofter expertus eft, quae faepe ne vlla quicem arte vitari poteft, quod plantae multae perierint, non dico earum modo, quas ill. HAL LEK v $s$ \& b. Z INNIVs indicibus fuis confignarunt, fed harum quoque, quae poftea in poffeffione eius fuiffe ipfe teftis fum. Cuius interitus pars in defectum commodorum hybernaculorum coniicienda, qui in caufa fuir, ve multae calidiorum regionum ne germinare qqui- 
Set7. 3. Horti botan. Hiftoria. 129

quidem poffent, multo minus eo calore foueri, quo opus habuerunt, aliae ruif.s an. guftia hypocaufti, \& ftirpium fuccofarum \& parciori lucco praeditarum fub eodem tecto connubio exftinguerentur. Aft plerarumque ex hilce difpendium refarfic apparatumque priftinum bane mulcis nouis auxit futorum infignis in hortum heneuolentia, quibus eximiam non feminum modo fed \& viuiradicum, ramorum depactorum \& integrarum ftirpium, copiam acceptam refero; quorum igitur memoria faftis horti noftri gratiflima femper erit。 Nominandus inter holce primum

Perilluftris \& generofifimus L. B. отто A M ÜNCH II A V SEN, Satrapa Regius \& Dynafta in Schwöbbern, qui iam dudum fauentifimum herbariis muneribus horto fefe praebuit, nouo vero prae1tantiflimarum arborum fruticumque, praecipue Americae borealis, quibus hortus eius Schwöbberanus abundat, obfrictifimum fibi me reddidit. Operam miffionis in fe fufceperat peritifimus oeconomiae vir, $1 \mathrm{~A}$ C O B 1 , perillu. ftri viro a fecretis.

Reliqui ill. \& cll. viri, hanc ob rem a me laudandi, funt: 
330 Sect. 3. Horti botan. Hiftoria.

A N D R EAE, Pharmscopola Hannoueranus, Chemiae hiftu. riaeque naturalis fcientia inclytus, qui adiumento haud exiguo, a me autem ob modeftiam eius hic reticendo, in neceffariis horti inftruendis fuit.

RETRVS IONAS BERGIVS, Hiftoriae naturalis \& Pharmaceutices Profeffor Stockholmienfis, qui Bidentem fuam acmelloiden, aliasque varias rariores dedic.

IOANNES IACOBVS DICK, Paftor Spie-

- zenfis in pago Bernenfi, qui varias alpinas patriae fuse mifit.

ALBERTVS AB HALLER, Praefes Reg. foc. fcient. Gott., cui ill. viro, hortum a fe infructum continuo adthuc amore profequenti, copiam feminum rarifimorum debeo.

CAROLVS A LINNÉ, Eques, cuius opem hac in re non defuifte, facile ad coniiciendum eft.

CHRISTIANVS GOTTLIEB LVDWIG, Medic. Profeffor Lipf. \& Decauus perpetuus, qui, praeterquam numerofis femi- 
Ssct. 3. Hurti botar. Hiftoria.

minibus, hortum multis Mefembryanthemis \& Craffulis ditzuit.

GEORGIVS CHRISTIANVS OEDER, Bocanices Profelfor Hafuienfis. Maximo omnium feminum numero ad plura centena vfque, quae inter muitae nouiffime detectae ftirpes, me donauit; $\mathrm{cl}$. z o $E \in A$, Demonftracore horri Hafnienfis, auxiliatrices manus prsebente.

IOANNES FRIDERICVS POTT, Medicinse Practicus Brunfuicenfis, qui memor priftinae cum horto familiaritatis, rarioribus variis fubuenit.

1. P. DV RO 1, Praefectus horti Harbeccenfis, qui, arboribus \& fruticibus ditiffimus, perill. \& generofiff. a VEL TH E IM polfelforem haber. Huius igitur generis ftirpium eleguntifimarum femina multa ab illo obtinui.

10 AN NES CHRISTIANVS DANIEL SCHRERER, Mec'. Doctor, iam in A. cademia Erlangenfi Med. \& Oecon, Profeftor, qui graminibus pretiofis praeter quam aliis plantis eximiis adfticit.

$$
\text { I) } 3 \text { Rा: }
$$


132 Sect. 3. Horti botan. Hifforia.

FRIDERTCVS GABRIEL SVLZER, Med. Doctor \& practicus Gothanus, qui fruticum horti numerum auxit.

IOANNES TAVBE, Regis $M$. Britanniae medicus, qui prima feminum mifforum guudia excitauit.

Subiungendus eft frater ADOLPHV $S$ MVRR A Y, arti falutari operam nauans, qui fymbolam horti reftaurandi attuliffe glo. riofum maxime repurat. Vt taceam propenfum amicorum praefentium bor tulanorumque in me animum. Ne vero foris arcefferem, quae intra proprios muros continentur, exitineribus botanicis vndique petii plantas terrae gleba exfeclas, qua in re iuuanda non fatis comieum alacritutem laudare poffum. Varias quoque nec fpernendas plantas horti vicini fuppedicarunt. Silentio vero praeterire nefas effer, quod noua hoc ipfo anno a muitis eorum, quos laudaui, viris praeftantifimis munera herbaria confluxerint, quos igitur conftantes perpetuosque auforum noftorum fauto. res venerari oporter. 
Sect. 3. Hurti botan. Hiftoria. 133

$$
\text { 5. } 18 .
$$

Hifce exoptatiffimis fuppetiis accefliones firpium factae funt vno anno numerofifimae, quarum, exclufis fpontaneis plantis, nec aliis, quam quae vel certe floruerunt vel viren. te herba fpem futuri floris excitnnt, receptis, nomina ian fignificabo; eo nimirum fine, vt aliorum defectus ex noftris fupplere quẹamus, noftra rurfus inopia fitutorum beneuolentia fubleuetur. Nouae \& fub mea horti adminiftratione introductae, litteris inclinstis indicabuntur. Paucitatem ita diftinctarum vereor potius quam copiam ne mirentur celeberrimi nuperrime dicti viri, longe plurimarum a fe mifarum confcii, Nolo aliquid vitii feminibus infuiffe fufpicari : fed in eam potius, de qua \& alii botanici litteris conqueruntur, ae. ftatis praetericae (de qua infra vlterius) afperitatem, frigidam, ventofam, humidam, maximam culpam coniicio, quae germinationi \& incremento maxime aduerfa, \& feminum maturationi inferta fuit, cuius vlterius perficiendae caufa multas adeo plantas in hybernacula autumnum verfus transferre oportuit. Intere rim omnes \& fingulae adhuc per hyemem feruatae, quarum annuse aegrius fpem aliquam relinquunt, biennes autem, perennes \& frutefcentes eam adhuc alunt, vtquae fero fac-

$$
\text { I } 3
$$


134 SeEt. 3. Horti botan. Hiftoria.

pe germinant. Perennium vero \& frutefcentium, quae primo anno flores emittere plerumque re cufant, eas modo indici infero, quae herbam protuicrunt eandemque plurimam partem adiuc virentem, relictis quibusdam fpeciminibus lub dio experimenti caufa, in hybernaculis feruant; vnde non dubito, certis illas horti ciuibus adfcribere. En igitur catalogum.

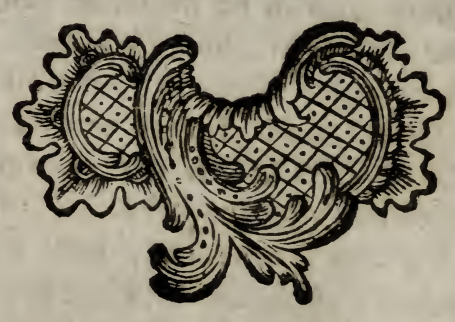


Sot. 3. Horti botan. Stirpes.

\section{PLANTAE HORTENSES A. 1769.}

\section{Cla fis 1 . \\ MON A N D R I A.}

MONOGYNIA.

CANNA indica.

A MOMVM Zingiber.

BOERHAA VIA diffura.

$$
\because \quad \text { fiandens. }
$$

CORISPERMVM hyffopifolium.

BLITVM copitatum.

$$
\text { fquarrofum. }
$$

- 09 virgatum.

$$
\text { D I AND R I A. }
$$

IASM INVM officinale.

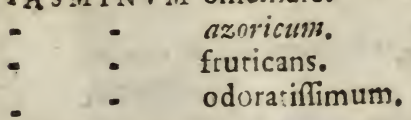

OLE A europaea. $\alpha$, ramis teretiufculis:

- anericana L IN N. Mant. p. 24.

SYRINGA vulgaris.

perfica. $\alpha$, foliis lanceolatis.

$\beta$, foliis diffectis.

VERONICA fibirica.

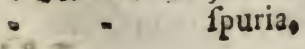

I 4 VE- 
136 SeCt. 3. Horti botan. Stirpes.

VERONICA maritima.

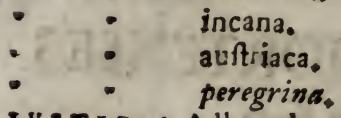

I V I I I A Adhatoda. incana. auftriaca. GKATIOLA officinalis. VERBENA mexicana.

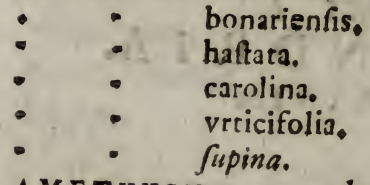

A METHYSTEA coerulea. ZIZIPHORA copitats. - tenuiar. MONARDA fifulor. - didyma. ROSMARINVS officinalis:

SA L V I A officinalis. $\alpha$, maior, flote coeruleo.

- pomifera. $\beta$, fi. albo.

- Horminum. $\alpha$, coma violacea. $\beta$, tubra.

- - fylueftris.

- nemorofa.

- verbenaca.

- clandeffinso

- difermas.

- hifpanica.

- verticillata.

- aegyptiaca. Mantop. 26.

- Sclarea.

- argentea.

- Aethiopis.

- ceratophylla; 
Seq. 3. Horti botan. Stirpes.

T RIGYNIA.

P\& PE R pellucidum

In hoc vnicum nifillum indiuifum eft.

$$
\text { TR I A N D R I A. }
$$

MONOGYN1k.

VALERIAN A rubra.

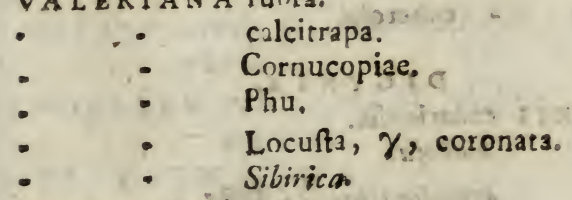

c N $\Xi \cap R \vee M$ tricoccum.

MELOTHRIA pendula.

POLYCNEMVM aruen $\int e$.

CR OC V s fatiuus. $\beta$; vernus. Varietates, rec, $\mathrm{Co}^{\circ}$ lores, plures.

$I X I \wedge$ cbinenfis.

GLADIOLVS communis,

I R IS fufunn.

- germanica.

- fambucina.

- fqualens,

- pumila. a,flore purpureo. $\beta$, fl. purp.coeruleo.

- foetidifmina.

In meis exemplis caulis non vniangulatus, fed anceps, altero angulo obtufiori. Petala reflexa verfis bafin rugnfa. Reliqua, fiue ere\&., quae breuiora \& anguftiora, tubum ad bafin formant exiguum, fupra apertum, qui dein is laminam lanceolatam, margine rugo. fam, ampliatur. Infra petals iunctim nectarism leuiter ventricofum conftituunt, ex quo 
138 Sect. 3. Horti botan. Stirpes.

extrinfecus liquidum exfudat, in faccharinam fubftantiam pellucidam concrefcens inflar guttarum. Folią nonnifi fricta foetent, Dạturae odore aemula.

I R I S fibirica.

- graminea.

C OMMELINA communis.

- - africana.

- $\quad$ tuberola.

\section{I G Y I A.}

PHALARIS canarienfis.

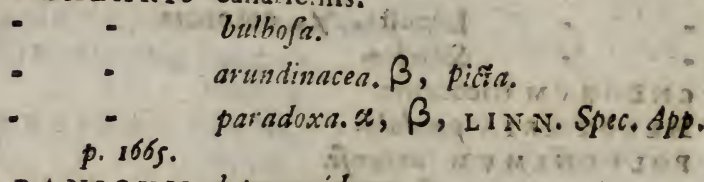

P A N I C V M alupecuroideum.

- italicum.

- Corus corui?

- - filiforme.

- - capillare.

- - miliaceum.

A L OPECVRVS monjpelienfis.

A G R OS TIS indica.

\section{paniceus.}

A I R A /picata.

MEI I C A ciliata.

B RI Z A minor.

altifima.

$\therefore$ - virens.

- maxima.

CYNOSVRVS aegyptius.

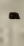

-

- indicus. cornconus: atriets.

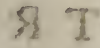

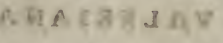




\section{SeEt. 3. Horti botan. Stirpes.}

Spiculae omnes \& fingulae pendulae fenfim $\mathrm{f}$.

unt, primumfupremae, dein inferiores,

BROMVS diflacbyos.

AVENA fatiua.

LAGVRVS oulatus.

E L Y M V S pbiladelphicus.

- fibiricus.

- canadenfis.

SECALE cereale, $\alpha$, hybernum. $\beta$, vernum.

- - orientaie.

HORDEVM vulgare, $\alpha ; \beta$, coelefle.

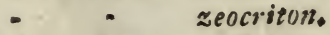

TR I I I C M seftiuurn.

- hybernum.

- turgidum.

- polonicum.

- Spelta.

TRIG Y N IA。

MOLLVGO frieta.

$$
\text { I E T } \underset{\text { MONOGYNIA. }}{\text { Clajis A }} \text { N D R I A. }
$$

CEPHALANTHVS occidentalis.

DIPS ACV S laciniatus.

SCABIOSA alpina.

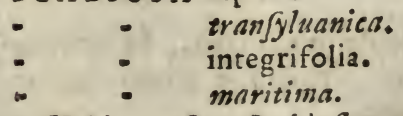

Habitu refert Scabiofam pappofam. Nam folia inferiora ouato-Ianceolata integra, fuperiora pinnatifida, fuprema linearia integra. Setae etiam in medio flore apparent, quae vero in Scabiofa maritima funt paleae fetaceae, in 
140 Sect. 3. Horti botan. Stirpes.

Scabiofa pappofa radii calycini. Ita \& in Sc。 maritima calyx communis corollis longior $f_{0}$ liolis latioribus. Vix dici poffunt flores ra. diantes, nam laciniae corollularum radii e. jusdem longitudinis, nec magnitudine fati differunt a corollulis difci.

se ABIOS A fellata.

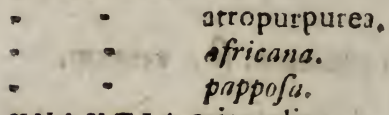

K NA V T I A orientalis.

SPERMACOCE tenuiot.

A S PER V LA aruenfis.

G A L IV M glaucuru.

laeuigata. Mant. p. 38 .

CRVCIANEL L A anguftifolia.

KV $V$ BIA tinetorum.

monspeliaca.

CALLICARPA americana.

PLANTAGO maior $\gamma$, rufea, fluribus in fpica difpofitis C. B.

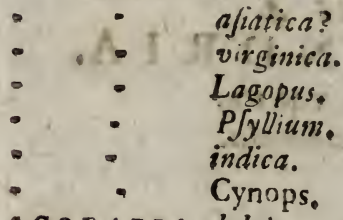

SCOPARIA dulcis.

Folia in fupremo caule modo terna, in inferiori eius parte oppofitil, vtrobique ouato- lanceo: lata, incifo- ferrata.

SANG V I SORBA officinalis.

$$
\text { media. }
$$

EP I ME D IV M alpinum. COR N V s alba. Mant, p. 40. PTELE A trifoliata. 
Sett. 3. Horti botan. Stirpes.

LAEA GNVS anguftifulis.

RIVIX a humilis。 $\alpha$, canefcens

- uctandira.

DI G Y N IA.

HY PECOV M erectum.

\section{Clafis 5 . \\ PEN T A N D R IA. \\ MONOGY IA.}

HEIIOTROPIVM PGruuianum.

Quoniam difcrimen fpecierum huius generis a florum in primis is fructus diuerietse peten. dum, quae quaelibet fpecies, quas hortus poffider, in hifce fingularia habet, exponam.

In dista fpecie exftant fpicae tres vel qua. tuor. ex. plaribus punftis prodeuntes, pollicares, reflexse. Corolla tubo breuiffimo glohofo, limbo amplefimo, odnro, albido. Semina fubglobofa 4 diftincta, prominentiae cylindraceae intermediae affixa.

indicum.

Spice vnica (rariffime duplex) palmaris, termin lis caulis \& tamorum, aliquando lateralis rami, apice modo reflexa. Tubus cornllae longiftimus, cylindraceus, nec prout in reliquis giobolus, albus, limbo cocruleo. Semina mox duo, mox tria, mox quatuor, magnitudinis inacqualis, \& fi plura, quam dun, teliqua abortiua funt. Fertilia funt o. uata, acuminata, extus torulofa, cortice fucecofo veftita, bafi nonnihil connexa.

\section{europacum.}

Spicae binae in extremis caulis \& ramo. rum, bipollicares, ex communi puncto emer . gentes? tatifime folitariae, nifi ex defectu nu.

tri. 
14: Set. 3. Horti botan. Stirpes.

tritionis, quae fi adlint, ex alis prodeunt. Corolla alba, tubo globolo. Semina quatuor nuda, aequalia, ouata, extus coruexa, corti. ce fuccolo glabro inltructs, interius, vi ne. funtur, per angulum prominentem in duo plana diuita absyque cortice.

HELIOTROPIVM angiospermUM MIHI. Vid, in. fra Defcr. rarior.

A NCHVSA tinctoria.

CYNOGLOSSVM cheirifolium.

PVLMONARIA fibirica.

SYMPHY T VM officinale, $\beta$, flore rubro.

CERINTHE mainr. tuberofum,

ONOSM A fimpliciffima.

BORAGO officinalis.

- indica.

Caulis ramofus, hifpidus, ad exortum foliorum \& ramorum gibbus. Folia lanceolita, am. plexicaulia, fcabra, inferiora oppofita, fuperiora ramorum alterna. Rami pacentes, ul. terni. Peduncu'i breues, vniflori, cєrnui, 2 xillares. Folia calycina cordato - fagitrata, iunctim quinquangularia, hifpida. Curolla alba, calyce paullo longior.

Similis Bor. indicae. Sed planta tota robuftiot \&altior, Coulis craffior, magis diuifus, fetis rigidis fragilibus hipidus. Folin periolata, longe latiora \& nuata, magis hifpida. Pe. dunculi non vnifori, fed nultiflori, divifi, \& fere racemofi, ficci, rubri, pedicells cernuis, Folia calycina Ianceolata, non tam confpicuos angulos formantia, rubra, albis pilis 
pilis notats. Cornlla eiusdem fere longitudi. nis ac calyx, fordide alba.

I YCOPS IS veficaria.

ECHIV M italicum.

variegars.

violacemm. Mant. p. 42.

De difcrimine inter hoc \& Ech, vulgare in primis agicur. Addoigirur quaedam Mantiface. Color herbae gratius viridis, non tanta hiriuties, pili quoque teneriores, nec bafi tuberculati. Flores quidem spica colliguntur, fed breuiori, nec tam compa?ta. Color horum conftans, nec primo die ruber, led femper pallide cue. ruleus. Staninum diuerfa longitudo, ita vt vnum longifimam corollae partem aeyuet, reliquae oppofica eius parte -vel maiores vel minores fint.

- $\quad$ creticum.

NOLAN A proftrara.

A NDROSACE feptentrionalis.

PRIMVL $\Lambda$ veris. $\%$, acaulis. Varietates plures.

Auricula. Var. plures,

CYCLAMEN europaeum.

I. Y I M ACHiA Ephemerum.

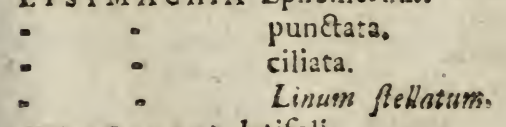

A N AGALI Is latifolia.

PLV M B A O zeylarica.

PH L OX maculata.

- diuaricata.

CONVOLVVLVS Scammonia.

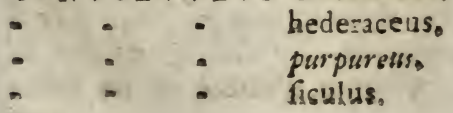


144 Sect. 3. Horti botan. Stirpes.

CONVOLVVLVS lineatus.

- - Cnntabrigica.

- - - tricolor.

IPOMAE A Quaro:lit.

- coccines.

- triloba.

POLEMONIVM coeruleum.

CAMPAN V A Medium.

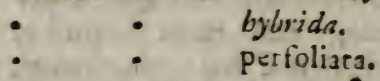

SA M OL V s Valerandi, $\beta$, africanus,

COPFE A arabica.

LON ICER A Caprifolium.

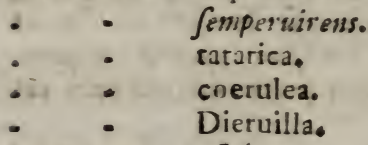

MIR A BILIS Ialapa.

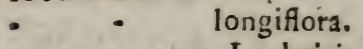

VERBASC VM Lychnitis.

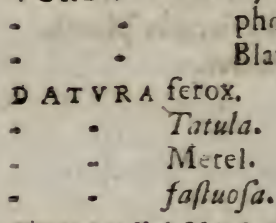

AiYOSC YAM YS albus.

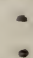
aurcus.

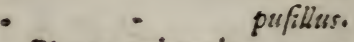

Planta palmaris, annua, Canlis obliquus, fro. gilis, indiuifus, pilis longis notatus. Folia inferiora integra, lanceclata, fuperiora ob. longa, dentata, alterna, parce pilofa; petioli longitudinis eiusdem. Pedurculi breues in extimo caule, quorum quilibet ex ala folio 


\section{Sect. 3. Horti botan. Stirpes. 145}

rum duorum oppofitorum prodit. Calyces fpinoli angulati. Corolla lutea calycis longi. tudine.

NICOTIANA Tabacum.

- - ruftica.

- - paniculata.

A TR OPA phyfulodes. glutinofa.

PHYSAL IS fomnifera.

SOLA NVM guineenfe.

flexuofa.

Pfeudo-capficum.

rảdicuns.

bonarienfe,

aetbiopicusm.

tuberofum.

Lycoperficum.

nigrum, $\gamma$, villofum.

$\varepsilon$, virginicum.

Melongena, $a$, fructu albo.

$\beta$, luteo. $\gamma$, violaceo.

- tomentofum.

c APSICVM annuum. Varietates plures pro fru. Etus figura diuerfa.

I. Y C I M afrum.

- europaeum.

R HAMNVS alpinus.

$\begin{array}{ll}-\quad & \text { Alaternus. } \\ -\quad & \text { Iuiuba } \\ \text { Ziziphus. }\end{array}$

PH Y L IC A ericoides.

RIBES rubrum.

HE DER A qunquefolis.

VITIS vinifera.

K 10 


\section{Set. 3. Horti botan. Stipes.}

VIT Is lacinio $a$.

I A GOE CIA cuminoides.

Characterem floris fruktusque eximie ill. A I No

$\mathbf{N} \mathbf{r}^{\prime}$ (in gener. $p l$ ) definiuit, herbse autem pa rio um in Speciebus omilit, ve folet in generibus vnie ca modo fpecie inftructis; quem praecipue defca ctum in vniuerfum vtinam refarcirent ampliori defcriptione botanici hortis ditioribus praefecti. - De Lagoccia efto fequens. Caulis ramofiffimus, idque iam ad balin. $R a$ mi inferiores diftantia femipollicis geniculum formant, ex quo ramus oblique afcendit. Folia quaedam radicalia, pieraque caulina ; pinnata, infra ramos vaginantia, alterna, pinnis fubrotundis, oppofitis, confertis, feffilibus, oblique inferts, tripurtitis, laciniis incifis, mucronatis, fuperiorum foliorum la ciniis indiuifis, Pedunculi terminales, diuaricati, filiformes, flcxuoli, bis vel pluries parti$\mathrm{ti}$, in diuaricatione vlcima foliis binis oppofie tis fuffulti.

ACHYRANTHES lappacea.

CEL OSI A argentea.

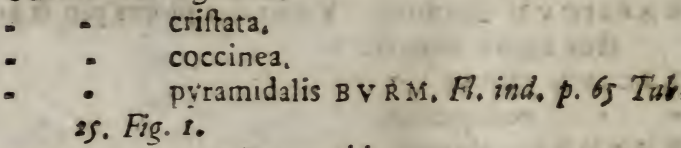

II LEC E BRVM Paronychia.

$\checkmark$ IN CA maior. ar abicum, Mant. P. st.

- mea.

NERIVM Oleander.

D I G Y N I A。

CY NANCHV M acutum. A POCY N V M androfaermifolikm, 


\section{Sest.3, Horti botan. Stirpes.}

A SCLEPRVS fyriaca. $\beta$, exaltata,

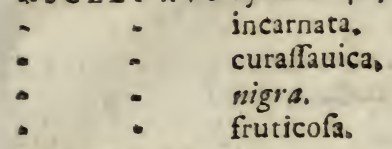

BET A vulgaris.

- Cicla. Syft. nat.p. 195.

SALSOLA Kali.

- - fruticor3. Sp.pl. El. 2. p.j24.

TRIA NTH MA monogyna. Manto $p, t_{p}$ GOMPHR AEN A, globola. BOSE A Yeruamora. HEVCHERA americans. PHYLLIS nobla. ERYNGIVM planum. BVPLEVRVM odontiles. TORDYLIVM apulum. - fyriacum。 CAVCALIS dawioides. DA v C v muricatus. $\propto$, A MMI maius. SEL I N V M Monsieri. PEVCEDANVM officinale, $\beta$, italicks? C RITH MVM maritimum. I I GVS I ICVM Leuifticum. A NGEL I C A Archangelica。 SIVM Sifarum. 
$\$ 48$ SeCt. 3. Horti botan, Stirpes.

sis o N fegetum.

- canadenfe.

B V B ON macedisnicum.

COR IANDRVM fatiuum. SC A N D IX odorata.

- $\quad$ Cerefolium.

- auftralis.

I MPER A T Ò I A Oftruthium.

SESEL I glaucum.

S MY R I I Olufatrum.

A NETH V g giaueolens.

- Foeniculum.

PI MPI NEL L A Anifim?.

A PIVM Petrofelinum.

- graueolens. 3 , dulce.

T RIG Y IA.

R H V S Coriaria.

- giabrum.

- Vernix.

- radicans.

- Toxicodendrum.

- Cotinus.

VIB VRNVM Tinus.

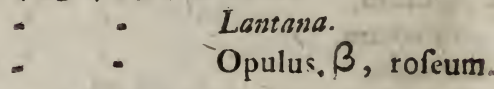

S A M B V C V S nigra. $\gamma$, lacuniata.

STAPHYLEA pinnata.

- - trifolio.

TAMARIX gillica.

T E L E P H I V M Imperati.

PHAR NACEM Ceruiana.

B ASELL A rubra.

- alba.

, PENTAGYNIA.

STATICE Loimonium. 


\section{Sect. 3. Hortibotan. Stippes. $\quad \mathbf{1} 49$}

L 1 N $\mathrm{M}$ vfitatifimum. $\beta$, fatiuum.

C K A SSV L A coccinea.

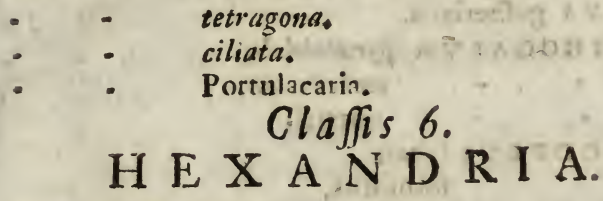

MONOG Y I A.

BROMELIA Ananas.

TR A DESCANTIA virginians.

H A EMANTHVS puniceus.

G A L A N THVS niualis.

N ARCISSVS poëticus.
- Tacetta.
- $\quad$ lonquilla.
- - Pleudo-narcifjus.
PANCRATIVM caribaeum.
C $R I N V M$ africanum.
A MARYL $L$ is formofiffima.
$A L L I V A 1$ ampel nprafum.

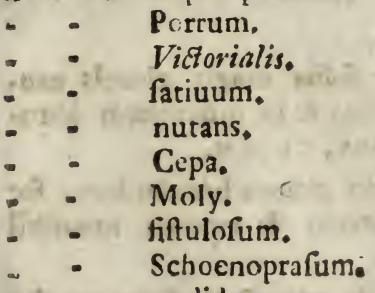

Li I Y M candidum.

- bulbiferum.

FRITILLARIA imperialis,

Var. Corona imperialis folio vario T O VR N.

Inflit. P. 372.

K 3 , ER I० 
150 SoCt.3. Horti botan. Stirpes.

FRITIILAR IA Meleagris. 4 , purputea variega. ta C. B.

ER YTH RO NIVM Dens canis.

I V I I P A gefneriana.

ORNITHOGALVM pyramidale.

-

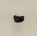

A SPHODELVS luteus.

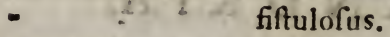

A NTHEKICVM reuolutum. V. infra Dejcr. ras.

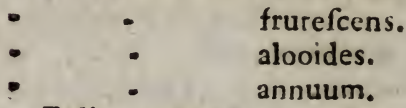

Folia canaliculata fune \& fubulata.

A SPARAG VS officinalis. $\gamma$, altilis.

POLIANTHES-tuberofa.

HYACINTHVS orientalis.

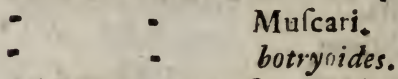

ALETRIS capenfis, $V$, infra Defcr. rax.

Y VCCA gloriofa.

- - draconis.

AL O Ë perfoliata.

$\alpha$, - caulefcens foliis magis glaucis caus. lem amplectentibus \& in mucronem obtusfiorem definentibus, $C O \mathrm{MM}$.

$\xi$, - caulefe. foliis glaucis breuioribus, foliorum parte interna \& externa nonnihil fpinofa, с ом м.

4, - caulefc. foliis glaucis caulem amplea Etentibus, С ом м.

$\lambda$, - maculata fpinofa maior, DILI.

$y,-$ mitriformis lpinofa, D IL $L_{0}$ 


\section{Sect. 3. Horti botan. Stirpes. 151}

$\xi$, - fuccotrina anguftifolia fpinofa, flore purpurco С O M.

$0,-$ humilis.

A L O E variegata.

- difticha. $\alpha$, foliis linguiformibus patulis diftichis, L I N N.

$\beta$, - folio triangulari \& verrucis albicantibus ab veraque parte, comm.

$\delta,-$ foliis planis coniugatis verrucofis, caule \& flore corallii colore, MARTY N.

- fpiralis.

- vifcofa.

- pumila $\delta$, arachnoidea.

- Vuaria.

A G A V E americana.

Var. Aloe americana; muricata, foliorum margine luteo. R I S L E R I Hort. Carlsrub.p.3. HEMEROCALLIS flaua. fulua,

D I G Y N I A.

AT RAPHAXis vndulata.

\section{TRIGYN IA.}

RV M E X Patientia.

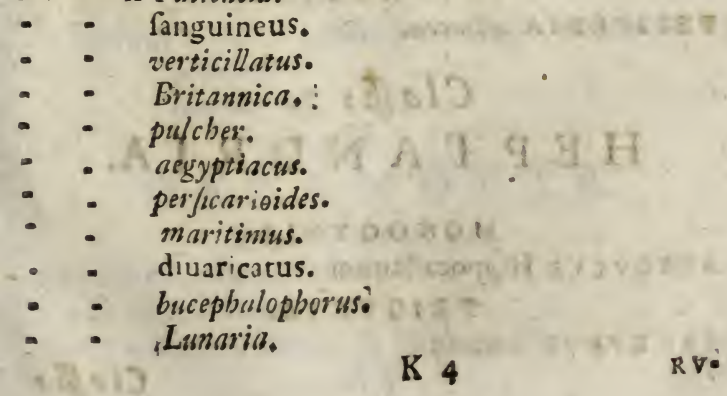




\section{Seet.3. Horti botan. Stirpes.}

RVM EX veficarius.

- - fcutatlos.

- Spinofus.

Caules ex vna radice, eaque annua, plures, diffuli, teretes, fulcari, dodranrales; ramis paucis, breuibus, alternis. Folin corilatoouata, vil oblonga, vix lagitrat3, obrufa breui acumine, pullide viridia, flaccida, reno. $f a$ petiolata, radicalia numcrofa, caulina pau. ca, alterna, remota. Petzoli longi, tupraca. naliculati, infra obialete fulcatı, foliis paullo breuiores. Flores monoici. Mafculini fupe. rius liri, pedunculo communi, qui folio pro. ximo obuercitur, inferti, racemofi. Horum calyx triphyllus, patens, foliolis ouatis, obtufis; corolh peralis tribus anguftioribus, obtufis, patentibus. Stamina is eiusdem lon. gitudinis, filamentis antheras aequantibus. Femin feffiles, axillares, verticillati fere. Calyx monophyllus, rugofus, laciniis reflexis, fpinolis ; cotolla tripetala, pecalis erectis, acutis; germen vnicum, triquetrum; ftyli tre reflexi, breuiffmi ; figmata totidem pe. nicillata.

TET RAG Y NIA。

PEIIVERIA alliacea.

\section{Clatis 7. \\ H E P T A N D R I A.}

MONOGYNJA.

AESCVLVS Hippocaftanum.

T.R IG Y N IA.

SAY R.YR YS cernuUs. 
Sect. 3. Horti botan. Stirpes.

\section{Clafjis 8 . \\ O C T A N D R I A. \\ MONOG Y I A.}

TROPAE OLV M minus, $\alpha$, Hore fimplici. $\beta$ A.pleno. maius.

OENOTHERA biennis.

-

-

FOL'YGON VM frutefcens.

pumila.

T I G Y IA.

virgininnum.

orientale.

diuaricatum.

tataricum.

- Fapopyrusn.

CAR D I O S PERM M Halicacabunk.

Cla fis 9.

\section{E N N E A N D R I A.}

M O N O G Y N IA.

L A VR $\mathbf{S}$ nobilis.

T RIG Y N IA.

R HEV M Khaponticum.

Rhabarbarum.

Varietas foliis anguftioribus magis vndulatis,

- palswatum.

- compactum.

Cla fis Io.

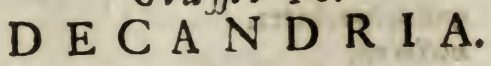

MONOGYNIA.

SOPHOR A alopecuroides.

C A S I A marilardica.

D I C I A N Vs albus. fl. rubro, slbo,

K 5

$R$ V* 
154 Sect.3. Horti Uatani. Stirpes.

RVT A graucolens, $a$, fylueftris maior. $\gamma$, hortenfis latifolia:

MELI A Azedarach, $\alpha$, fl. coeruleo.

ZYGOPHYLL V M. Fabago.

TR $1 \mathrm{~K} V \mathrm{~L}$ V S tereftris.

\section{I G Y N I A.}

S AXIFRAG A Cotyledon, folio'longiori $\alpha$, 2 . cuto. $\beta$, obtufo м 1н1.

- - vmbrofa.

- - rotundifolic:

MITEL L A diphylla.

GYPSOPHILA S xitraga. Sp.pl。 Ed, 2, p.58\%. SAPONARIA oricntalis.

DIAN THV S barbarus.

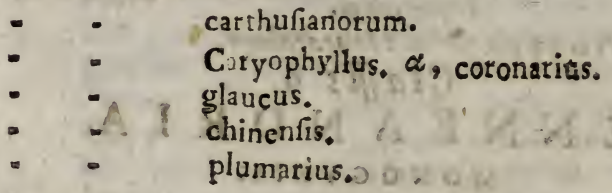

C V C V B A L V S bacciferis.?

$$
\text { T R I G Y N I A. }
$$

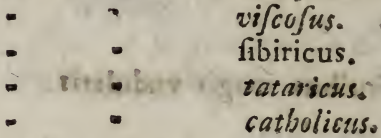

SI L E E anglica.

- - lufitanica.

- guinqueuulnera.

- - "nocturria.

- paradoxi Sp. pl. p. rízz.

- - fruticofa.

- viridiflora.

- gigantes. 
Sect. 3. Horti botain. Stirpes. Iss

SIIEN E conoidea.

- conica.

- Behen.

- noctiflora.

- antirrbinas.

- cretica.

- Armeria.

A RENARIA peploides. $G A R I D E L L A$ Nigellaftrum.

\section{PENTAGY NIA.}

C OTYLED ON Orbiculata.

SE D VM Anacampferos.

- Aizoon.

- flellatum.

- bifpanicum.

OXAL is corniculata.

A GROSTEMMA Coelirofa.

coronaris:

L YCHN IS chalcedonica.

Vifcaria.

CER A S T I M dichotomum.

Plurima exempla vix dichotomism caulis prodiderunt; alią vero fatis manifeftam. Planta tenella, hirfuta, vifcofa, fefquipalmaris. Cau. lis decumbens, atticulatus, geniculis tumidis, Folia oppofita, lanceolata, feffilia, Calyw corolla quadruplo longior.

DECA G Y N IA.

PHYTOLACCA oftandra.

- - decandra.

- - icofandra.

D O D ECA A ND R I A.

MONOGY NIA.

PEGANVM Harmala. 
156 Sect. 3. Horti botan. Stirpes.

Nitrania Schoberi. Vid, infra Defript,rar. eticon.

POKTVLACA oleracea.

$T R I G Y N I A$.

RESED A vndata.

-
-
- librca.
- Plbytcima.
- odritata.

E VPHORBI A canarienfis.

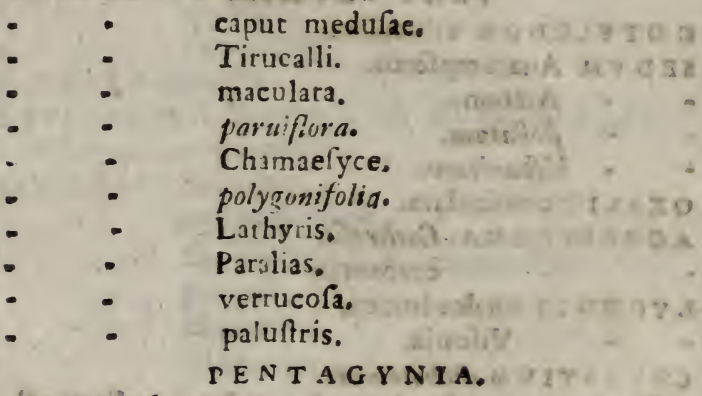

GLINvs lotoides.

DODECAGYN IA.

SEMPER VIVVM arboreum.

$$
\text { I C O SA N D R I A. }
$$

C A C I V s tetragonus.

- $\quad$ hexagonus.

- pentagonus.

- grandiflorus.

- flagelliformis.

- Itriangularis.

- Opuntia. 
C A.CTVS Ficus indica. ? $7 \mathrm{P}$ (

- Tuna.

- coccinilifer.

- curaffauicus.

- Pereskia.

In Cakti fpecicbus difcernendis licet, quum flo: res apud nos rarius erumpant, alia nulla no. ta, quam quae caulibus \& articulis ineft, fuperfit: dolendum tamen, quod haec tantae inconftantiae obnoxia fit. Quod ad Cereos. vidi numerum angulorum mirum in modum variare, ita vt in vno codemque trunco, bac in re fuperior $a b$ inferiori eius parte differret, nec numerus angulorum in furculis cum angulis trunci conveniret. Par in Opuntiis quoad figuram articulotum \& f finarum diuerfitas obtinet. Nam quidam eiusdem Ipecici, quin in eadem planta, articuli oblongi, alii breuiores, yuaedarn ferae craflae, longae \& folitariae, aliae anguftiores, breuiores \& congeftae, appz: rucre.

THILADELPHVS coronarius.

MYRTVS communis. $\propto$, romana.

$$
\gamma \text {, italica. }
$$

PV NICA Granatum.

nana.

A M Y G D L V S Perfica.

$$
\text { communis. }
$$

PR VNVS Padus.

- virginiana.

- Laurocerafus.

- Mabaleb

- armeniaca.

- Cerafus. Varietates plures.

- domeftica Item. 
158 Sect. 3. Horti botan. Stirpes.

\section{G Y N IA.}

CRATAEGVS coccinea.

$$
\begin{aligned}
& -\quad \text { Crus galli. } \\
& \text { T RIGYNIA. }
\end{aligned}
$$

SORBVS domeflica.

$$
\text { IENTAGYNIA. }
$$

MES P I L S germanica. $\alpha$, folio non ferrato C B.

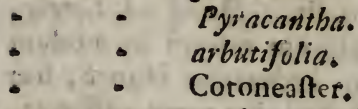

PYR V S communis. Varietates plures.

- Malus. Irem.

- Cydonia.

TETRAGONIA fruticofa.

MESEMBRYANTHEM VM nodiflorust.

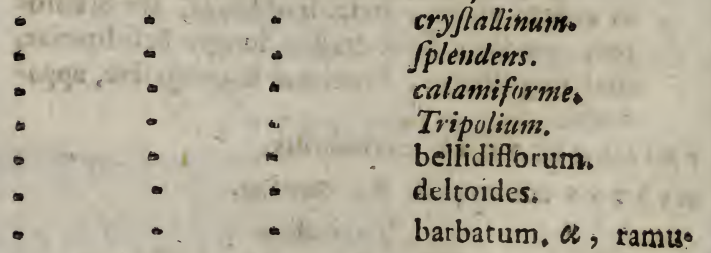

lis prolixis, $\gamma$. humile, foliis maioribus.

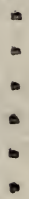

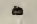

-

๘

$\rightarrow$

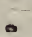

- bifpidum.

vncinatum.

acinuciforme. veruculatum. glaucum. corniculatum,

$a$, foliis longioribus.

B fol, breuioribus. 
MESEMBRYANTH EMVM linguiforme. $\alpha$, folio falprato $\gamma$. fol. anguftiori.

SPIRAEA falicifolia. pugioniforme.?

Var. $\beta$, flore albo, foliis angultioribus. bypericifolia. opulifolia.

\section{P O I Y G Y N IA.}

ROS A pimpinellifulia.

- villofa.

- centifolia.

- canina. Fl, pleno.

- alba.

- lutea; caule aculeato, foliis pintratis, foli. olis ouatis ferratis vtrinque glabris, pedunculis breuiffimis mI t. Dict. Ech. 8. n. $\boldsymbol{\pi t}$. Audtore grauifimo L. B. a $M V N C H H A V a$ SEN (Housvater so. Th. $z$ St. p. $2 ; \sigma, 389$. ) hanc rofain, in hortis haud infrequentem, a R. Eglanteria fegrego, cuius varietas (V. $e_{\text {。 }}$ gr. Z I N N. (Gott. p. 14') vulgo habetur.

- virginiana, M I L L. Cf. Hausz, loc, citop. $88 y_{0}$ FRAGARIA vefca. Var. fatiua.

DOTENTILLA fruticofa.

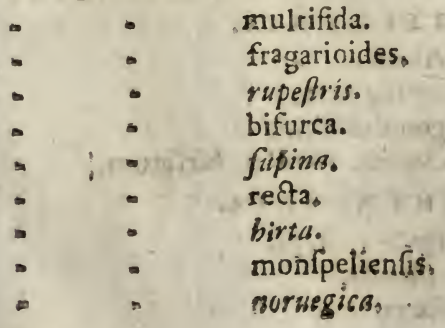


160 Sect. 3. Horti botan. Stirpes.

GEVM virginianum.

- vrbinum. Var. Caryophyllara cinadenfis foliis acutioribus flore luteo ms ori. I v S S.

- riuale. Var, fl. pleno.

$$
\begin{aligned}
& \text { Cla } \sqrt{25} 13 . \\
& \text { PO L A N D R I A. }
\end{aligned}
$$

CAPPAR IS fPinolis,

CHELIDONIVM maius, $\beta$, foliis quernis,

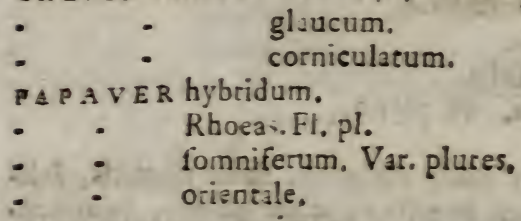

$A R G E M O N E$ mexicana.

Cis I vs ledifolius.

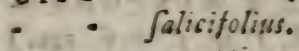

- aegyptiacus.

CORCHORYS Olitorius.

birtus.

D I G Y N I A.

PAEON1A officinalis. $\alpha$, femina. $\beta$, mafcula,

- tenuifiliz.

TRIG Y NIA.

DELPHINIVM Aiacis.

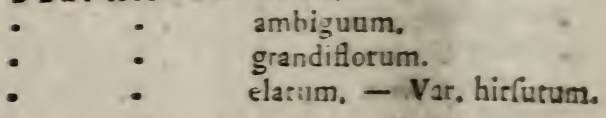

PEN T A G Y I A.

AQVILEGIA vulgaris, flo plo.

- - canadenlis,

NIGE L L A damatíena. 


\section{Sect. 3. Horti botan. Stirpes. 163}

NIGELLA fatius.

orientalis.

P OLYGYNIA。

ANEMONEHepatica, Fl,pl.

- Pulfatilla.

- coronaria.

- virginiana.

CLEMATIS Viorha.

recta.

integrifolia.

THA I I C T R V M minus.

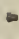

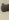

$A D O N$ Is vernalis.

fibiricum.

aquilegifolium.

RANVNCVLVS afiaticus.

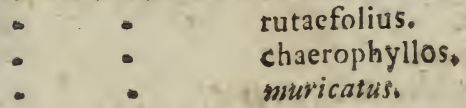

I SOPYRVM fumarioides.

HELLEBORVS hyemalis.

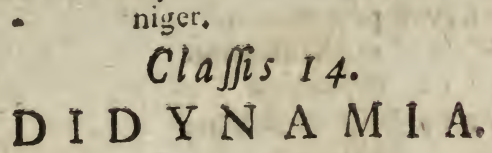

G Y MNOSPERMIA.

TEVCRIVM Chamaepitys،

- fruticans.

- Marum.

- hircanicum.

- virginicum.

- Scordium (V. Catal. Spont.)

- lucidum.

SA TVRE IA montana.

- hortenfis. 
162 Sect. 3. Horti botan. Stirpes,

H Y S S OPV S officinalis.

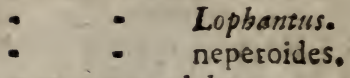

NEPETA violacea.

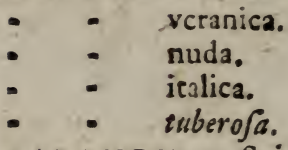

LAVA D I A Spica.

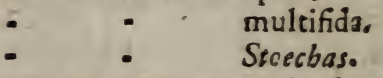

SIDERITIS canarienfis.

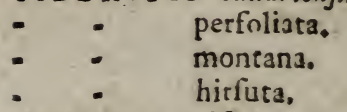

I ENTHA crifpa.

- Pulegium.

PERIL L A ocymoides. S. N. p. iss.

IA M I M garganicum.

S T ACHY S cretica.

MARRVBIVM peregrinum.!

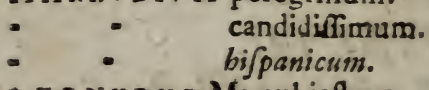

LEONVRVS Marrubiaftrum.

- fibiricus.

PHOMIS fruricofa.

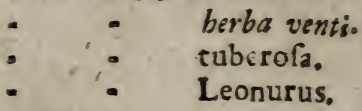

CLINOPODIV M vulgare. $\beta$, segyptiachis.

OR IG ANvM Maiorana.

THYMVS Serpyllum. 6 , folis citri odore,

- vulgaris.

MEL IS S A officinalis.

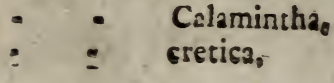


Sect. 3. Horti botan. Stirpes, 163

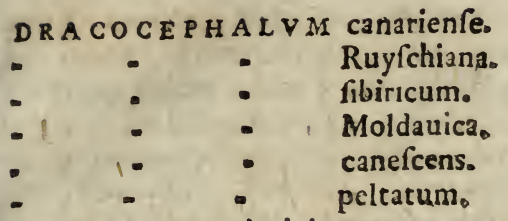

HOR M I N V M virginicusm.

- Ci м v M album Mant. p. 85.

- Bafilicum. $\alpha$, maíus.

$$
\gamma \text {, maculatum. }
$$

- - minimum.

SCVTELLAR IA orientalis.

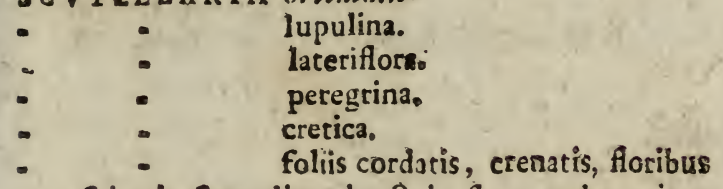

fpicatis fecundis, bracteis flore multo mina: ribus, Z IN N. Gutt. p. 3g3. B. 4.

PRVNELLA laciniata.

PRASIVM maius.

\section{A NGIOSPERMIA。}

C H E L ON E glabrn.

$$
\text { obliqua. S. N. p. } 408 .
$$

A NTIRRHIN VM tripbyllum.

Variat nonnunquam folis binis, etfi terna confantiora funt, idque tam in vno codemque, quam diuerfis exemplis. Radix fibrofa, annua. Coulis flaccide affurgens, tires, fragilis, femioedalis, ex coalitu iunctorum foliorum obfolete nodolus, infra rubefcens, glaucus. Folia ouaro-nblonga, fefflia, obtura, inferins in caule mox uppofica, mox ternata, fuperius : L. 2 
16. Seq. 3. Horti botan. Stirpes.

vbi furculi ex alis emergunt, alterna, fuprs vix neruofa, infra quinqueneruia. Flores folitarii ex alis fummi caulis, iuncto plurium fitu quali fpicati, fubpedunculati. Calyx monophyllus, fed profunde in lacinias quin. que, lanceolatas, patentes, fubacutas, tubum corollae aequantes, diffectus. Corolla bilabiata, vt in congeneribus, labio fuperion pallide rubro, inferiori ad palatum croceo, tubo ab vna parte ftriis rubris, ab altèra, quae in calcar eiusdem longitudinis ac corolla producitur, colore ex luteo rubro, pilto.

ANTIRRHINVM purpureum.

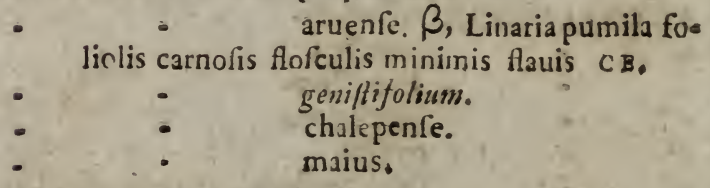

MARTY NIA annua.

SCROPHVLARIA Scorodowin.

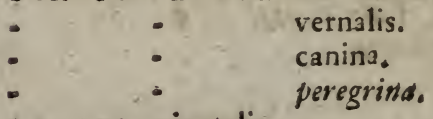

CELSIA orientalis. vernalis. canina. peregrinta.

DIGIT ÁL IS lutea.

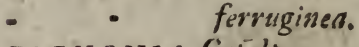

BIGNONIA Catalpa.

- femperuirens,

LAN $T$ A N A aculeata.

C A P R ARIA bifora.

BR OW ALL A demiffa. DODARTIA orientalis.

VITEX Agnus caftus, $\alpha_{\text {, foliis anguftioribus; }}$ ACANTHVS mollis. 
Sct. 3. Horti botan. Stirpes. 16;

\section{Clafis 15.}

\section{T E T R A D Y N A M I A.}

\section{S I I I C V L O 5 A.}

MYAGRVM perfoliatum.

VELLA annua

IEPIDIV M perfoliatum.

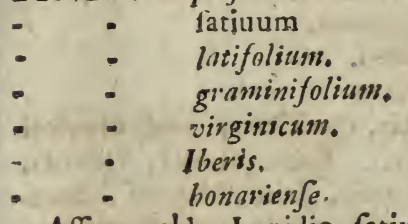

Affine valde Lepidio fatiuo, a quo nee latis certe ftaminum numsro diftinguitur, quem \& hic, prout iam cel. CRANZ (Cruciformes p. 85.), licet DILLENIVS binarium primus adfcripferit, fenarium obferuaui. Tenera planta, caulibus procumbentibus varieque fle. xis, \& foliis pinnato - multifidis inftructa.

TH L A S P I peregrinum. faxatile.

C OCHLEAR I A officinalis.

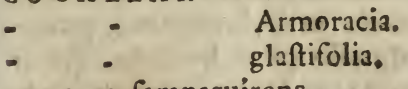

IB E K I S femperuirens.

Armoracia.

- vmbellata.

- amara.

A L. Y S S V M incanum.

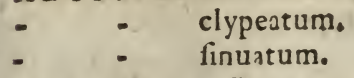

PELTARIA alliacea.

BIS CV TELL A auriculata.

I V N AR I A rediuiua. didyma. 
166 Sect. 3. Horti botan. Stirpes.

\section{SILIQVOSA.}

RICOTIA aegyptiaca.

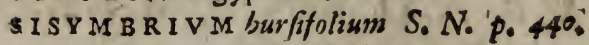

$\begin{array}{lll}- & - & \text { polyceratium. } \\ - & \text { - } & \text { arenofum. } \\ - & \text { orientale. } \\ - & \text { - } & \text { barbareace } \\ - & \text { friefiffimums. }\end{array}$

CHEIR A THV S Cheiri.

Nimium affinis Cheir. maritimo; vnde vberiori defcriptione opus. Rudix annua, fibrofa. Caulis infra proftratus, dein obliquus, flexu. ofus, fubteres, pilis rigidis adpreffis fcaber, dodrantalis, fragilis, ramis alternis patentio bus. Folia alterna, ouato-lanceolata, ple. rumque obtufa, in petiolum longum definentia, margine fabra, \& hinc inde ferrata, vena intermedia infra prominente. Flores in fummitate ramorum, quorum calyx ad bafin alternis foliolis manife?te gibunfus, \& conicus fere. Petalorum vngues calyci aequales, albi ; laminae obcordatae, fupra rubellae, infra pallidiores. Stamina in finu vnguium recondita. Siliquae adpreffis pilis hirfurae, fubulatae. - DILLEN II (Hort. Eltbam, Tab. 347. f. 178.) icon meis plantis fimillima, prae teryuam, quod folia magis oblonga depingat. Emarginata folia non, vt L I N A E V S, inueni. incanus. - trifis.

- - littoreus.

- - tricufpidatus.

Y ESPER IS triftis. matronalis. Fl. pl. 
UESPER IS africana.

$A R$ A B I alpina, $\alpha$, caule crecto fimplici, $\beta$, caule diffufo.

- canadenfis.

- pendula.

- Turrita.

B RASSI C A orientalis.

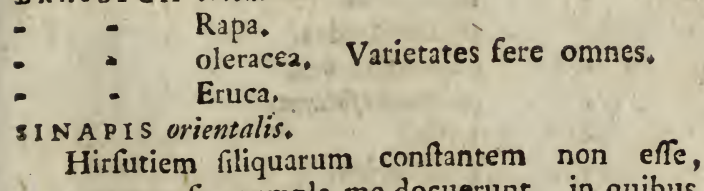
numerofa exempla me docuerunt, in quibus glabrae, etfi caules \& folia inferiora omnino hifpida erant. Vereor, ne non tuto fatis ab aruenfi diuellatur.

- loesigate.

- erucoides.

- chinenfis. Mant.p. gs.

a PHanvs fariuus, $\alpha$, Radicula. $\beta$, niger.

$\gamma$, chinensis oleiferus.

B N I A Erucago.

- orientalis.

- Cakile.

- negyptinca. S. N. Tom, 3. p. 23r.

Is A TIS tinetoria. $\beta$, fatiua.

C R A M B E hifpanica.

CLE OM E pentaplylla.

- $\quad$ dodecandra.

Clafjis '16.

$M O N$ A DE L P H I .

PENTANDRIA.

HERMANNIA alrhueifolia.
-
hyffopifolia.
L 4.
D E: 
168 Sea. 3. Horti botan. Stirpes.

\section{DECA N DKIA.}

GERA NIVM inquinans.

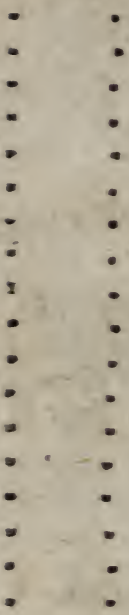

caculatum.

gibbofum.

zonale.

vitufolium.

capitatum.

alchimilloides.

odorstifimum.

coriandrifolism.

trite.

mofchatum.

malacoides.

gruinum.

ciconium.

mactorhizam.

phaeum

bobemicum.

caroliniansm.

foiricum.

POLYANDRIA.

SI D A fpinofa.

- alba.

- rbomibifolia.

Mea exempla fuerunt annua, fpithamaea, Cow lis intruifus pubefcens, vifcidus. Folia bre. viter peciolata, ouato-rhombea, ferrata, Stipalae feraceae, ad quarum bafin fpinae duae mutica, breulfimae. Flores lutei, magnie tudine florum Sidse capitatae.

- cordifolia.

- paricalata.

- Abutilon.

- indica.

- crilpa. 
SID'A criftata. $\alpha$, caule erecto, $\beta$, caule procumbente, ora foliorum fufca.

\section{- capirata.}

- anguflifolia MIL L. V. Defcript, rar.

NAPAEA dioica.

A I T H A E A officinalis.

\section{- Ludwigii. Mant. p. 98.}

$V t$ planta, gratiam cognomine prae fe ferens, melius cognofcarur, yuaedam addere ill. A LINNE' defcriptioni licebit. Omnibus haec fupra teram partibus, praeterquam foliis, hifpida, fed pilis raris, in caule faepe fafciculatis. Caulis fimplex, eredus, periolis alternis, femiteretibus, foliis triplo longioribus. Fulia feminulia ouata, radicalia indiuifa, laxe dentata, caulina palmata, tri-quinque-feptenuloba. Stipulae dujé lancenlatae. Flores in meis exemplis vel folitarii vel bini, pedunculati. Calyx externus, plerumque oftophylluss, internus pentaphyllus, vterque, internus praecipue, hirfutifimus, Corollae color elbus.

A L CE A rofea.

ficifolia.

M A L y A tumento $a$. annericana.

- peruuiana.

i. limenfis.

- capenfis, $a$, groffulariae folio minori, $\gamma$, fcabrofa.

- caroliniana.

- paruiflora.

- masritiana.

- verticillata, 


\section{Sect. 3. Horti botan. Stirpci.}

MALVA crifpa.

- aegypria.

L A V A T ER A arborea.

- : $\quad$ olbia.

GOS SY PIV M berbaceum.

Radix attenuata, lignofa, fibras numerofas fpargens, annua. Cotyledones duae, reniformes, fenfim figura dimidiati infundibuli in petiolum longum definentes. Caulis tripcdalis, erectus, reres, ve tota herba, pubefcens, inferius brenus \& leuiter rimofus, fuperius punktis nigris confperfus; ramis axillaribus, folio fubfrato vix longioribus. Folia alterna, petiolo duplo breuiora, quinqueloba, tomentofa, venis productioribus, dum tenera funt, odora. Petioli teretes, tomentofi, verlus infertionem folii inflexi, ad bafin gibbofi \& craffiores, patentes. Stipulae ad exortum petiolorum \& pedunculorum duae, lanceolatae. Pedunculi petiolis bieuiores, ramei. Calyx duplex, quorum externus monophyllus, dum adhuc clauditur, triqueter eft, dein patens, tripartitus ad bafin fere vfque, lacinris cordatis incifis corolla dimidio breuioribus, punctis nigris confperfus; internus cylindraceus, altero triplo breuior, ere\&tus, quinquepartitus, laciniis breuibus ohtufis, pariter punktatus. Corolla monopetala, tubo breuiori, limbo quinquepartito patente, laciniis obtufis, ad la. rera crenatis, pallide flaua, in fundo rubicun. dis maculis 5 notata, decidua. Stamina pluri$\mathrm{ma}$, filamentis in pyramidem coalitis. Piftil. lum vnum, eiusdem longitudinis. Germen fu.

pe. 


\section{Sel?. 3. Horti botan. Stirpes. 171}

perum, ouatum. Stylus filiformis. Stigmn quadruplex. Capfula fubtrigona, acuminata, triualuis, trilocularis. Semina ouata, in qunuis loculo circiter tria, altera parte conuexa, altera magis plana, lanae tenerrimae immerfa.

H IB IS C V S fyriacus.

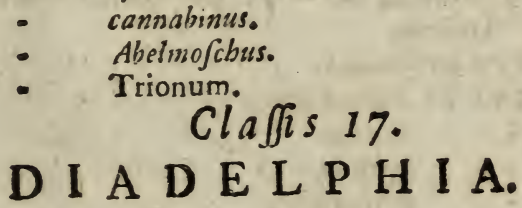

HEXANDRIA.

F VMARIA femperuirens.

- capnoides.

- ficata.

- capreolata.

- clauiculata.

- veficaria.

DE C A N D R I A.

ER'YTHRINA Corallodendron. $\beta$, orientalis.

SPARTIVM iunceum.

GE N IS T A canarienfis.

$A M O R P H A$ fruticofa.

C R O T A L A R I A laburnifolia.

ON ONIS alopecuroides.

- vifcofa.

- $\quad$ ornithopodioides.

L V P I N V S albus.

- $\quad$ hirfutus.

- luteus.

PHASEO IV S vulgaris. $u$, flore albo, $\beta$, fl. rubro. lunotus. 
172 Sect. 3. Horti botan. Stirpes.

PHASEOLVS vexillatus.

radiatus.

DOLICHOS finen/is.

- - Lablab.

- - vnguiculatus.

- lignofus.

pis V M fatiuum, $\boldsymbol{\alpha}_{0}-\gamma$, fine cortice duriore.

- Ochrus.

O ROB V S latbyroides.

LATH X R V S amphicarpos.

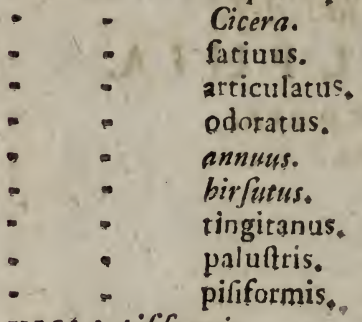

vici A pififormis.

- benghalengis.

- lutea.

- bybrida.

- peregrina.

- narbonenfis.

- Faba, $\alpha$, maior, $\beta$, minor.

ER V VM Lens, $\alpha$, minor. $\beta$, maior,

- - monanthos.

- Eruilia,

CI CER arietinum,

CYTISVS argentea.

ROB I I I P Peud-acacia.

- Caragana.

- : frutefcens. 
174 Sect. 3. Horti botan. Stirpes.

tus, indiuifus. Folia pinnata quadri . ad fexiuga cum impari, foliolis lanceolatis, birfutis, petiolo paullo longiora, patentia. Stiprulae fetaceac. Flores capitati, breuiter pedunculati. Calyx quinquepartitus laciniis fetaceis, pilis atris diftinitus, Corolla calyce longior, vix fefe aperiens, purpurea. Siliqua cordata, furfum carinata, complicata, adpreffis pilis hirfuta. - In hunc quadrat Altragalus hifpanicus filiqua epiglotridi fimili, flore, albo minor HE R M. Hort. Lugd. bat. I. con 7 , potius quam 75 , etfi HERMANNI flos fuic albus.

AST R A G V L V S finicus. Mant. p. v93.

BI SERKVLA Pelecinus.

P SORALEA pinnata.

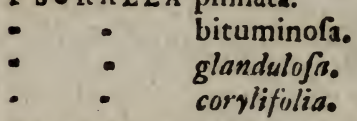

T R IF OLIVM Mel. coerulea.

- $\quad M$. indica, $a-\delta$, floribus \& fi. liculis minoribus.

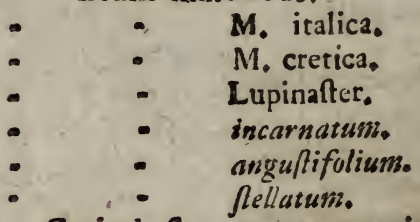

Capitula florum ante eruptionem in ftipulis vefi: cularibus latent, eleganter venofis \& marginatis, quae \& poftea formam bemifphericum Ieruant.

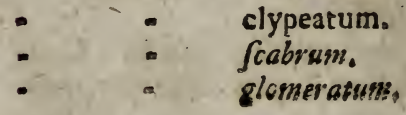

Res 


\section{Sect. 3. Horti botan. Stirpes. 175}

Radix perpendicularis, tenuis, ad latera fibrofa; Coulis teres, proftratus, ramis alternis paten. tibus; ex quibus alternation emergunt petioli longi, canaliculati, flipulis duabus ad bafin coalitis, acuminatis, 1triatis, petiolum vaglriantibus. Folia ternata, foliolis obouatis, primum integris, dein ciliate ferratis, acutis, vel obtufis cum acumine. Capitulum florum axillare, fubferfile. Calyx monophyllus compreffus, ftriatus, quinquepartitus, laciniis las tis, acuminatis, rigidis, vicinas reliquorum florum mutuo ampleitentibus. Vexilla alba ex calyce, fetae inftar obtufae, eleganter prominent, conduplicata, calyce duplo longiora, inter quae alae lanceolatae, quadruplo breuiores, adpreffae, \& carina eiusdem longitudinis. T R I F OL I VM refupinatum.

\section{LOTVS maritimus.}

$$
\begin{aligned}
& \text { - filiquofiss. } \\
& \text { - cotragonolobus. } \\
& \text { - angugutliffimus. } \\
& \text { - arabicus. Mant. p. zop. } \\
& \text { - ornitbopodioides. } \\
& \text { - racobaers. } \\
& \text { - cytifoides. }
\end{aligned}
$$

TRIGO NELLA polycerata.

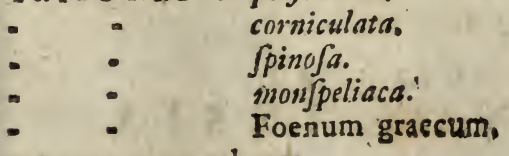

MED I C AGO arborea.

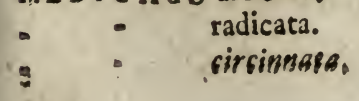


176 Sect.3. Horti botan. Stirpes.

Stirps, etfi iam C. BAvH I No cognita, curatiotem delcriptionem videtur exigere ; \& prae. cipue, quibus notis a Med. radiata differdr, indicandum. Tota planta pubefcens, folia gerit cuneiformia inregra inferius fimplicis, luperius pinnata, pinnis numeri inconftantis, alcerutro latere faepe deficientibus, \& in op: pofito minoribus, iisque alternis pinna impari mox feffili, mox petiolata. P'rominet foliorum fuperticies ad exortum pilorum, itave tu• berculata appareat. Stipulae nullae, Flores in extremis ramorum plerumquc terni, rariffi. me bini. Legumen craffius, magis rotundum, vix margine dentatum.

MEDICAGo lutiua.

- polymorpha. ee, orbicularis. $\beta$, fcu. tellata. $\gamma$, tornáta $\delta$, turbinata. $\delta$, intercexta. $\zeta$, muricata. $\eta$, arabica. $\downarrow$, rigidula. $\mu$, minima. $\nu$, Iaciniata, Et aliae varietates a LI No NAE O nondum receptae.

\section{Clafjis 18 .

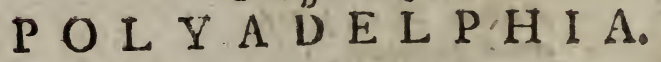

ICOSANLRIA.

CITRVS Medica.

- Aurantium.

POLYANDRIA。

HYPERICVM hircinum.

$$
\text { SY Cla Jis I9. }
$$

GEROPOGON glabrum.

TRAGOPOGON orientale. 
TRAGOPOGON porrifolium.

Picroides.

SCORzONERA hifpanica.

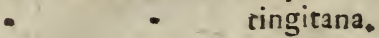

- - Picroides.

PICRIS Echioides.

SONC HVS paluftris.

- $\quad$ tenerrimus.

- - fibiricus.

I A C T V C A fatiua.

- Scariola.

HI ERACIVM aurantincum。

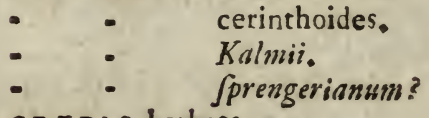

CREPIS barbata.

cerinthoides.

$$
\begin{aligned}
& \text { - } \quad \text { rubra. } \\
& \text { - } \quad \text { alpina. } \\
& \text { - pulcbra. } \\
& \text { - Rhirica. } \\
& \text { - Rhagidioloides, Mant, p. 108. }
\end{aligned}
$$

HYOSER IS lucida, loc. cit.

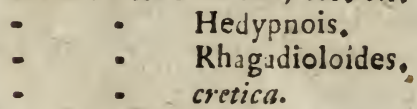

SERIOLA aethnenfis.

L A P S A N A communis, Var, foliis crifpis.

- Z Zacintba.

- Stellata.

- Rhagadiolus.

C ATA N A NCHE coerulea. lutea.

C I C H OR IV M Endiuia.

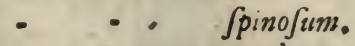

SCOLYMVS maculatus. 
178 Sest. 3. Horti botan. Stirpes.

A RCTIV M perfonatum.

SERRA TVLA coronata.

C ARDV V lesscograpbus.

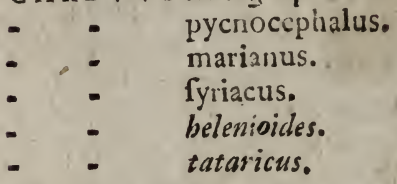

C N I C V S cermutus.

- Acarna.

ONOPOKDON arabicum.

CYNARA Scolymus.

CARTHA M V tinetorius.

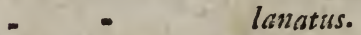

S PILANTHVS oleracea Syf. Nat. T. 2 p. $534^{\circ}$ Bidens Acmelloides, e ER G. Vet. Ac. Handlo 1768 p. 245 . Tab. 7.

BIDENS frondofa.

- pilofa.

C A C A L I A Anteuphorbium.

- Kleinia.

EVPA TOR I V M cannabinum.

- - aromaticum.

AGERATVM Conyzoides.

C HRY SOCOMA Linofyris.

SA N T O I N A Chamaecypariffus.

Var, fl, pallidiori $\&$ foliis profundius vitidibus,

$$
\text { POLYGAMIA SVPERFIVA. }
$$

TANACET VM vulgare. $\beta$, crifpum.

- Balímita.

ARTEMISIA Abrotanum.

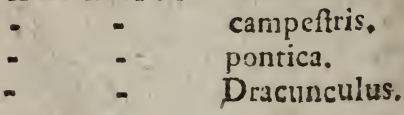


Var. folin inndoro. Artemifia lini folio hirfuto A M M. Rutb. 147.

G N A PHAI, I V M Srocchas.

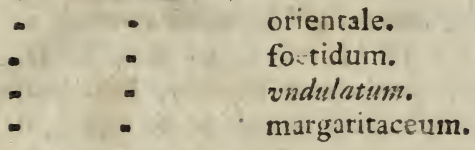

XERANTHEMVM annuuin, $\alpha$,

CONYZA laxatilis.

ERIGER ON graweolens.

- - bonariense.

Radix flexuofe perpendicularis ad latera fibrofa, annua. Caulis angulatus, firmus, hirfutus, fupra ramofus. Fotica alterna, lanceolata, hirfuta \& mollia, liffilia, inf riora dentatoincifa, fuperiora integra anguftiora \& fere linearia, verfus bafin vndulata, vena media prominentiori \& hirfutiori. Flores in fummo caule \& ramorum extremis, pedunculis vnifloris \& bifloris, alternis. Calyy pubefcens, Flores paullo minores quam in Erigero 2cri, maiores quam in $\mathrm{E}$. canadenfi.

SENECIO bieracifolius.

$-\quad: \quad$ diuaricutus.
$-\quad \therefore \quad$ glaucus.
$-\quad$ elegans.
$\quad \quad$ Doria.
ilicifolius.

A STER tenellus.

- - ericoides.

- linifolius.

- acris.

- nouse angliae.

- cordifolius.

$M 2$ A = 


\section{SeCt. 3. Hurti botan. Stirpes.}

A S TER annuus,

- indicus.

- mutabilis.

Hoc LINNAEI nomen infero ob ciratam ab ipfo HERMANNi (Hort. Lugd. Bat. p. 65 . Tab. $6_{7}$ ) defcriptionem \& iconem, etfi pro. pria ill. viri defcriptio (Spec. pl.p 12,o.) in plantam non omnino quadret, viquae itti folia ferrata \& calyces fquarrofos tribuit. Certe eft HERMANNi ( $l o c$. cit ) After nouae Belgiae latifulius panicularus, f rribus faturate violaceis \& H ALLERI Sclidago. Sp. 1 . Flos, G $s t$.p. $4^{60}$ - Percnnis, floret excun. te Ofobri, vt igitur ex maxime ferotinis fit. Caulis tripedalis, ereetus, teres, firmus \& verfus radicem fere lignofus, infra calami anferini vel cygnei cruffitie, hine inde rimofus ideo. que fcaber, \& faturateruber, verfus fuperior fenfim gracilior, glaber \& vel viridis vel ftriis rubris maculi que noratus, fuperiori dimidio paniculatus; ramis paniculae patentibus, ereEtis, friktis, alternis, vndique caulem pyra. midalem in forman ambientibus, axilaribus. Folia integra, exceptis crenis nonnullis obloletis, raris, lato-lanceclata, faturate viridia, hine inde ad marzinem rubicunda, glauca, venofa, exprominente cofta ad bafin gibbofa, fu. periora amplexicaulia, inferiora verfus bafin anguftiora, palmaria, latitudinis fefquipollicaris, alterna. Flores terminales caulis \& ramorum, mox folitarii, mox plures. Pedunculi fquamofi, fquamis linearibus acutis confertis, diftantibus. Calyx ouato-cylindraceus, imbricarus fijuamis quinque ordinum, lanceolatis, fubadpreffss. Corcliae difci her. 
Sect. 3. Horti botan. Stirpes. 181

hermaphroditae, tuhulofae, planae, flauae; radii femineae, ligulat 20 pluresqne, linesres, initio conuolutae, dein medio eleuatiores, apice vix confpicue tridentatae, patentes, violace. ae. Receptnculsm alueolatum, nudum. Pappus pilofus.

A S TER noui belgii.

Afteri priori tam fimilis, vt facile confundatur. Perennis pariter, florendi autem tempore paullo prior. Conulis obfolete fulcarus, pallidius ruber, non ita ereftus, fed inordinate flexuofus, corymbofe ramofus, ramis diuaricatis valdeque diuifis. Folis figurae eiusdem, rariffine ferratura folitaria notata, margine, fi digitus verfus bufin ducitur, fcabro, -fuperficie pilis inconfpicui, afpera. Flures magis folitarii, paullo minores, pedunculis longis, fquamofis, flauefcentibus infidentes. Calyx fquamis diffantibus 5 ordinum. Corollae difcus luteus, radius pallide coeruleus, reuolutus.

- macropbyllus.

- chinenfis.

SOLIDAGO canadenfis.

alriffima.

- caefia.

- flexicaulis.

- lanceolata, Mant. $p$ 814.

I N V L A Helenium,

- $\quad$ odora.
$-\quad$ Oculus Cbrifli.
- $\quad$ indica.
- falicina.
crithmoides.

CINER ARI A geifolia.

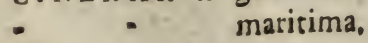


CINER A R I A amelloides.

DOKONICVM Pardalianches.

HELENIV M autumnale.

BELLIS pcrennis.

T A GE TE $\$$ patula.

$$
\text { d. flore fiftulofo: }
$$

erecta.

C HRY SA N THEM V M coronarium.

MATRICARIA Parthenium. Fl. pl.,

argenten.

COIVIA artbenoides V. Defor. rar.

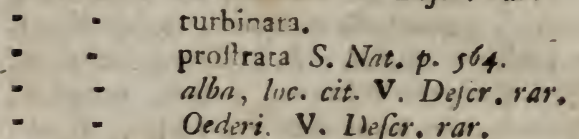

A N ACYCLVS valentinus.

A NTHEMIS Cota.

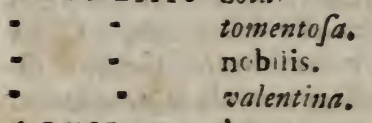

ACHILIEA Ageracum.

- puhefcens.

- inodora.

Plunta tenera. Caulis fulcatus, fimplex. Folic alterna, feffilia, laciniata, ad apicem tripartita, laciniis fubulatis. Flores, terminales, cun. ftant ex capitulis cylindraceis aggregatis, pe. dunculatis, fattigiatis. Capitula meros flof. cuios tubulofos continent, fuffulta fquamis ca* lycinis, obrufis, imbricatis.

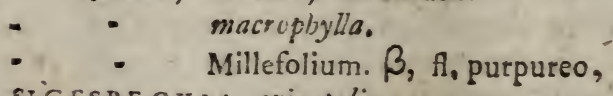

SIGESBECKIA orientalis.

Z I N I A paucifinra.

- multiflora. 
Sact. 30. Horti botan. Stirpes. 183

VERBESI NA alata.

Acanella.

B V P H THA M V M frutefcens.

grandiflorum.

- Helianthoides.

POL YGA MIA FRVSTRANEA.

HEL I A T T V S annuu:

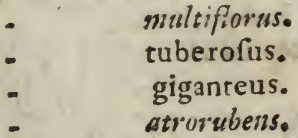

RVDBECI A laciniata.

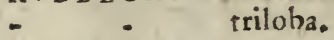

COREOPS IS coronata:

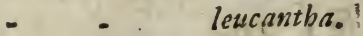

CENTAVREA Crupina.

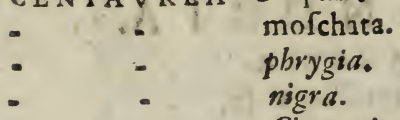

- Cineraria.

- - argentea.

- $\quad$ Scabiola.Var.fl.flauo,ochroleuco.

- $\quad$ Stocbe.

- - glaftifolia.

- $\quad$ Soncbifolia.

- - $\quad$ - beridis.

- - eriophora.

- $\quad$ melitenfis.

- - falmantica.

P O LYGAMIA NECESSARIA:

CALENDVLA aruenfis.

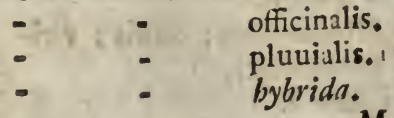


$1 \$ 4$ Sect. 3. Horti botan. Stirpes

C ALEN D VLA nudicaulis.

ARCTOTIS triflis.

- - afpera.

ER I OCEPHA L V S africanus,

F IL A Go acaulis S. N. p. 580 .

MICROP V S fupinus.

POL Y GA IA SEGREGATA.

SPHAEBANTHVS indicus.

ECHINOPS fphaerocephalus.

- Ritro.

- - frigofus.

MONOGAMYA.

LOBELI A Cardinalis.

IMPATIEN S Balfamina.

\section{Claffis 20. \\ G Y N A N D R I A.}

T R I A N DRIA.

SISYRINCHIVM Bermudiana.' $B$.

PENTA NDRIA.

PASSIFL O K A foetida.

$-\quad$ incarnata.
coerulea.

ARISTOLOCHIA Clematitis.

POLY A D R I A.

A R V m Colocafir.

CALL A aethiopica.

\section{Cla lis 21. \\ MO N O E C I A.}

T R I A N D R I A.

z E Mays. Var. granis albicantibus; flauis; viridibus; variegatis; rubentibus.

TRIPSACVM bermapbroditum.

AXYRIS amarantboides.

T E. 
Sect. 3. Hortibotan. Stirpes. 185

\section{TETRA N DRIA.}

B E T V L A nigra.

- Alnus americana MIL L. A M N N H. Hausv. s Th. I St. p.II4.

B v X v s femperuirens. $\boldsymbol{c}_{2}$ arborefeens. $\beta$, fuffruticof 2 . VRT ICA pilulifera.

Dubium de fpecie ipfe mouit cel. OEDER, qui eiusdem femina mific. Nam, fimillima Vr. ticae Dodurtii, cui LIN NAE Vs (Sp.p. 139;) tribuit folia ouata fubintegerrima, prout $V p$. ticae balearicae folia cordata ferrata, \& caulesl petiolosque purpurafcentes. Sed in meis exemplis quaedam folia ouata, alia cordata: quidam caules \& perioli purpurafeentes, alii non. An fequentes notse confances \& propriae, aliis diiudicandum relinquo \& fururac confiderationi. - Folia ad bafin obliqua ita, ve alcera parte magis promineant; verius bafin \& apicem integra, in reliqua parte fer. rata finubus obtufis. In adultioribus foliis margo coarftatur, vt conuexa appareant.

$$
\begin{aligned}
& \text { - } \quad \text { - Dodarii. } \\
& \text { - } \quad \text { niunabina. }
\end{aligned}
$$

MOR V S alba.

$$
\text { - nigra. }
$$

PENTANDRIA.

$X \wedge N$ TH IV M frumarium.

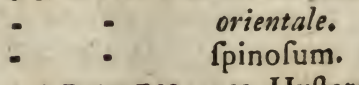

PARTHENIVM Hyfterophorus.

I V A frutefcens.

A MARANTHVS oleraceus. 


\section{Sect. 3. Horti botan. Stirpes.}

A MARANTHVS tricolor.

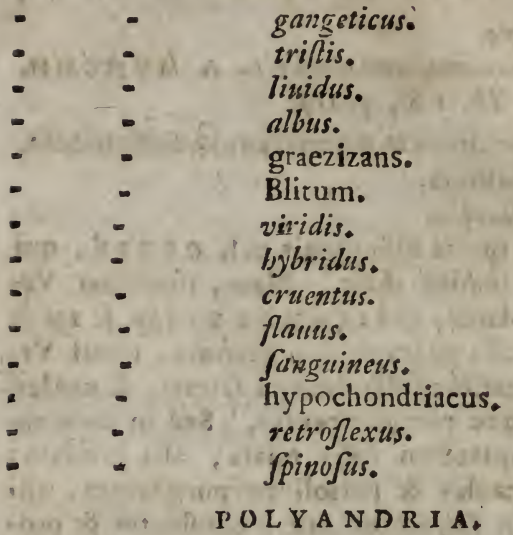

THEL IGONVM Cynocrambe.

POTER IV M bybridum.

I V GL A N S regia.

- $\quad$ alba.

I L T A V V occidentalis.

\section{MON A DELPHIA.}

p I N v fylueftris. Var. Mugbo Hall. Hif. n. 1660: B. s co pol I Ann. 2, p. 6s.

- Strobus.

- Picea.

THVYA occidentalis.

- orientalis.

CVPRESSVS femperuicens.

- - Tbyoides.

ACALYPHA virginica.

R I CiNVS communis, a, vulgaris.

$\beta$, caule rutilante: 
Sact. 3. Horti botan. Stirpes. 187

S Y N GEN E S I A.

MOMOR DICA, Balfamina.

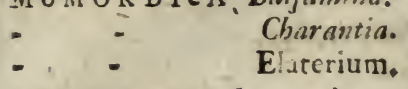

C VCVR B I T A lagenarin.

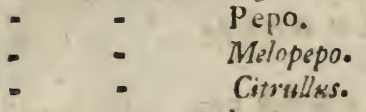

CVCVMIS propherarun.

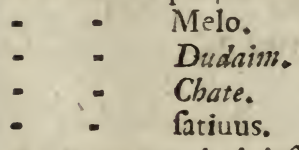

BR YO IA lnimioja.

S I C $Y$ O $S$ angulata.

$$
\begin{aligned}
& \text { Clafis } 22 . \\
& \text { DI OE C I A. } \\
& \text { DIANDRIA. }
\end{aligned}
$$

S A L I X labylonica.

- incubacea.

TET RANDR IA:

H I P OPHAE Rhamnoides.

MYRICA cerifera.

TENTANDRIA.

PISTACIA Terhinthus.

- Lentifcus.

S PINACIA oleracea.

CANNABIS fotinl.

H E X A N D R I A.

SMILAX afpers. $\gamma$, toliis angultis,

$\because \quad=\quad P \int$ eudo. Chima. 
188 Sect. 3. Horti botan. Stirpes.

$$
\text { OC TANDRIA. }
$$

POPVLVS alba.

- nigra. Var. italica.

- balfamifera.

KHODIOLA rolea.

EN NRANDRIA.

MER C VRIALIS annua.

D ODE A N DRIA.

MENISPERMVM canadenfe.

MON A DELPHIA.

IVNIPER VS barbadenfis.

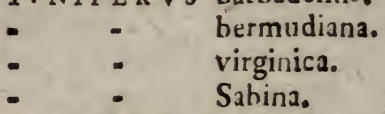

EP.HE D R A diltachya.

S Y N GE N E IA.

RVSCVS aculeatus.

- Hypogloffum.

- racemofus.

G Y N A N D IA.

C I V I I pulchella.

$$
\begin{aligned}
& \text { Cla Jis } 23 . \\
& \text { P O Y Y G A M I A. } \\
& \text { MONOECIA. }
\end{aligned}
$$

CE LT IS aufralis.

VER A T R V M nigrum.

HOLCVS Sorghum.

CENCHRVS racemofus.

- - echinatus.

v A L A N I A Aparine. Var. Cemine Coriandri facharati PARKINS.

PARIETARI A lufitanica. 
Sect. 3. Horti botan. Stirpes, 282

ATRIPLEX Halimus.

fibirica. hortenfis. $\boldsymbol{u}$, pallide virens.

$\beta$, rubra.

A C E R Negundo. MIMOSA pidica.

- glauca.

DIOECIA.

GLEDITSIA triacanthos.

FRAX IN VS americana.

POL Y OECIA

CER A T ONIA Siliqua.

FICVS C3rica.

- benghalenfis.

\section{P A L M A E.}

PHOENIX daEtylifera.

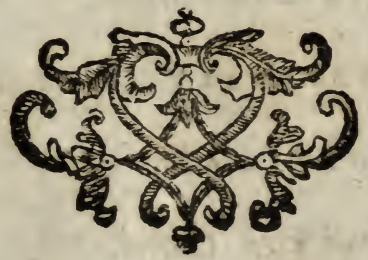


190 Sect.3. Horti botan. Stirpes.

:

$$
\text { Particula } 3 \text {. }
$$

DESCRIPTIONES STIRPIVM ALIQVOT RARIORVM.

Sunt hae

I. NITRARIA Schoberi.

2 ALETRIS copenfis.

3. ANTHER I C V M reusolutum.

4. HELIOT R O PIV Mangiofpermum.

5. S I D A anguftifolia.

6 ASTRAGALV s ecbinatus.

7. C O T V LA albr.

8. cotvla Oederi.

9. COT V L A ant bermoides. 
Sect. 3. Horti botan. Stirpes. IgI

\section{I.}

\section{NITRARIA Schoberi *) IINN.}

N I T RAR I A L I N N. Spec. plant. pag. 638. E I V S D. Monographia in Nou. Comment. Acad. Scient. Petropol. Tom 7. p. 309, Sqq. E Icon, Tab. 20.

Non minus memorabile iucundumque botanicis eft, plantam raram florentem videre, quam aftronomis, in tranfeuntem per folem venerem inquirere polfe. Piget,enim operae, ftirpis fterilis faepeque incognitae cultui, impenfae; \& vnicus flos non raro coniungit ftirpes, vt primum videntur, diffimillimas, qnin genera integra \& familias. Sponte igitur liquet, quanta voluptate aeftate praeterita affectus fuerim, quum floribus ornatam ftirpem intuerer, quae inde a generofiff. H ALLER I tempore in poffeffione horti quidem fuit, fed nec fub huius illuftris viri nec fuccefforum celebrium adminiftratione flores protrufit, aeque \& alibi in votis botanicorum fallendis tenax. Inde euenit, vt per plu-

res

*) Ex promtuario Hannouerano (Hannou. Magaz. $N$. of Aug. a 1769 ) hanc commentationem infero, fed typographicis vitiis purgatam, \& hinc inde au\&tam \& mutatam, lingua, ve fponte apparet, diuerfa. 
192 Sect. 3. Horti botan. Stirpes.

res annos, quin a fummi ordinis botanicis, vel omnino non, vel infufficienter modo, determinari poffet. De frutice loquor, quem ill, a L I N é Nitrariam Scboberi vocauit. Haec quidem nec infigni florum venuftate vel amueno odore fele commendat, nec vfu, quantrum hucusque innotuit, valde confpicuo. Sed politiores noftro tempore pierorumque mores funt, quam vt ea modo naturae dona probarent, quae vel famem exftinguant, vel fenfibus lenocinentur, vel opibus augendis inferuiant, indeque pretium ob. feruationibus ftatuerent. Primum, quum erumpere inciperent flores, negotium in deferibenda planta collocabam, ad comparationem dein cum defcriptionibus aliorum auktorum accedens. Qui idem ordo \& hic pro norma erit.

Indicare vero iam $a b$ initio fas eft, me vnicum modo exemplum coram habere, id: que in olla reperiundum; quae ftatio non poteft non directionem plantae \& crefcendi modum nonnihil perturbare. Et hoc ex praeci: puis incommodis eft, cum cultura plantarum in vafis, coniunctis. Stirpes enim, procumbentes alias, vi bacilli adpofiti \& vinculi inieSti in erectum fitum coguntur, quam vim in jpfum adeo incrementum \& humorum propulfionem effectum exferere haud abfimile eft. 


\section{Deforiptio.}

Stirps $2 \frac{1}{2}$ pedes alta.

Radix lignofa, rảmofa.

Truncus fruticofus, pedalis, craffitie digiti exigui, cortice cinereo, fcabro, rimolo, veftitus.

Rami duo primarii, cortice eiusdem naturae obdlucti, fubdiuifi in ramulos numerofos, alternos, furfum oblique conuerfos, ad exitum foliorum tumidos \& qquamula breui, obtufa, interftitia foliorum intrante, (ex gemma priftina relidua, ) inftructos, glabros, albidos \& multis punctis \& lineolis nigris notatos, fpinam in extremo, poftquam exaruerunt, referentes. - Ex directione ramorum iam fufpicabar, fupinum fitum in natali folo plantae effe proprium, poftea aliorum obferuatis de eo certior faEtus. Et quod ne truncus quidem plantae fibi relictae competat, ex quibusdam non inconfipicuis abfcifforum ramorum reliquiis palam fuit. Vt igicur iam ad radicem copiam ramorum energere liquidum fit.

Gemmoe compreflae, acutac, ex fquamis copio- 
194 Selt. 3. Horti botan. Stirpes.

fis acutis, tenuibus, imbricatis \& per iṕa quoque foliorum interftitia enatis, intra quas folia tenella coaceruata plura, quim quae poftea radiatim prodeunt, concaua, iam initio Martii in hybernaculo apices fuos protrudentia.

Folia ex eodem puncto, absque refpectu diftantiae extremorum bina, quod maxime vulgare eft, terna vel quaterna, ramea, alterna, radiatim diuaricata, feffilia, lineari lanceolata, bafi anguftiora, fed verfus apicem latiora, crebrius acuta quam obtufa, \&, vbi anguftiora, hamo furfum directo exili inftructa, integerrima, auenia, nitida, fuccofa, pollicem circiter longa, nec fupra 2 lineas lata, furfum flexa; dum adhuc virefcunt, decidua. Ex axillis ho. rum prodeuus fubinde folia alia 3 vel 4 , quae facile errorem in numerando creare poffunt.

Pedunculi in extremis ramorum duo, quorum vnus terminalis, alter ex axilla folii penultimi prodit, teretes, virides, mu tifar iam, plerumque bifariam, dinifi, hinc non perfecte racemofi, afcendentes, foliis fere aequales. - In mea planta 8 ad 9 modo sami floriferi erant. 
Flores erecti, 3 ad 7 , vel feffiles, vel breuiter pedunculati.

Calyx fùccofus, monophyllus, quinquepartus, laciniis erectis acutis cum petalis alternantibus, corolla quadruplo breuior, viridis, perfiltens.

Corolle pentapetala, infera, alba, petalis 5 , lanceolato-linearibus, patentibus, reflexis, cymbiformibus, ad apicem fornicato-hamofis (hamulo in floribus nondum expanfis manifeftiori) \& ibidem viridibus.

Stamina Is, ereeta, corollae aequalia; filament is fubulatis, albis; antheris luteis, oblongis, bilocularibus.

Piftillum 1 , ftaminibus aequale; germine conico; fylo nullo; ftigmate bifido.

Fructus: drupa ouato.oblonga, intra quam nux acuta, trilocularis - Hanc fructus delcriptionem ab aliis mutuari oportet, quoniam apud me ante maturitatem vel decidit vel exaruit.

Pertinet igitur Nitraria ad Dodecandriam Monogyniam LI.NNAE I; maximamque cum 


\section{Sect. 3. Horti botan. Stirpes.}

Pegano, quod pariter perpetuo 15 ftaminio bus inftruitur, cognationem habet. Satis vero vtraque planta calyce \& fructu inter fe differt.

Adeft in horto \& alius frutex, alteri iam delineato valde fimilis, qui \& pariter per multos annos florum expers exftitit. Non audeo tamen illos fub vnam eandemque fpeciem redigere. Eft ftirps fefquipedalis. Ex fignificatis fupra indiciis coniicio \& hunc pro. ftratum olim habuiffe caulem, licet dein cultura erectus euaferit. Diuifio ramorum eodem ordine perficitur, \& cortex eiusdem na. turae eft. Plurima folia ex eodem puncto bina, terna, quaterna, prodeunt, quaedam folitaria. Memoratu autem dignum, ea dimidio fere breuiora \& eadem proprortione latiora effe, quam in altera ftirpe, iam ad bafin latiora, plerumque obtufa, vel obtufa cum acumine non furfum fed deorfum flexo, magis congefta, pallidiora \& quafi glauca, mature autumno, fed non antequam flósefcant, decidua.

\section{Animadurviones.}

Vtraque facile. floribus deficientibus, pro Lycio, in prinis afro, haberi poffet. Nan $\&$ in hoc folia ex vno puncto emergunt, eandem figuram \& faporem quoque falfum ha. bent, \& cortex pariter in ramis tenellis albus. 
ScI. 3. Horti botan. Stirpes.

Hoc quidem Lycium aculeis inftructum, quibus Nitraria defituitur, fed huius tamen rami aculeos mentiuntur, quibus cl.LE R C H E adeo fibi imponeré paflus eft. Rara funt extra Pini genus foliorum communi puncto emergentium exempla. Prout vero ipfi petalorum hamuli memorabiles: ita fingulare eft, fimiles, féd alius parumper figurae in multis foliis, animaduerti. Equidem, fi hamulos iftos in apicibus calycis animaduerterem, nouum discumentum inde communis foliorum \& calycis ex cortice originis peterem. Quam ipfam ill. A LINNÉ (Ämoen, acad. Tom 6.p. 333) \& argumentis \& obferuationibus ftabilire annifus eft. Inter alia exempla Mefembryanthemum barbatum citat, quod in apice calycis easdem fetas ac in foliorum extremis gerit. Et m!hi Calla aethiopica ad hoc confirmandum aeque apta videtur, in cuius foliis \& foliorum vagina eundem mucronem, in quem fpatha definit, praeterito vere obferuaui; vt alia exempla taceam. Sed nec ipfa Nitraria huic rei aduerfa videtur, verum eidem ftabiliendae vlterius conuenire, quum maculae virides ad apicem petalorum vero fimile reddant, quod in ipfa petala fubftantiae corticis pars intrauerit.

- Flores medio iam Iunio confpicie $N_{3}$ ban- 
198 Sect. 3. Horti botan. Stirpes.

bantur, fed claufi adhuc \& globofi, fupremis arefcentibus \& deciduis. Intra quodlibet petalum ftamina duo tum inuoluta erant, reliqua quoad partern petala diftenderant. Quoniam vero ob friggidam tum \& pluuiofam tempeftatem explicatio florum nimis lente fuccedebat: hanc verfus lunii finem in vaporario alto accelerabam. Vnde fecundo iam die multi flores aperiebantur, fuccedentibus poftea reliquis. Fuit Nitraria frutefcentium prim a, quae folia, eaque adhuc viridia, autumno a. 1769 , amifit, idque factum medio Septembri; nec dubium id in vniuerlum quotannis contingere.

\section{Synonyma.}

Nomina diata firpis noftrae refpiciunt ftationem, qua crefcit, \& inventorem fuum, impigrum olim botanicum D. GOTTLOB sc, HOBER, itineribus fuis in Ruffiam, Afracanum \& ad fluuium Tarak vfque inclytum, qui exiftimationem dubio procul fuam contra cel. IO. GEORGII GMELIN (Flar. Sibir. Vol. 2 p. 239) exprobrationem tuitus effet, modo opus eius, Memorabilia Ru/fico - afiatica inferiptum, quod manu exaratum poffidet Academia fcientiarum Petropolitana, \& index eius plantarum (Vegetabilia circa Petropolin, Mofcuan E in eius territo- 


\section{Sef. 3. Horti botan. Stirpes. 199}

vio foonte crefcentia ordine alpbabetico a. 1736) qui iam in manibus ill. $L$ I NNAE 1 eft, publicam lucem afpexiffer $s$ C н о B ER v $S$ eam derexit primus vna cum aliis herbis falfis prope offiin mitrariam Aftrach nenfem; meminicque iam GMELINVS (Fior. l. co) variarum ab ifts obferuntsrum partium. Prolixiorem vero eiuidem obferuatoris defcriptionem multos annos poftea cl. LERCHE ( Nou. Comment. ac. Petrop. Tom. 7 p. 28) fuppeditauit, in qua tamen generis charater defectu laborat.

Calace fructu nigro nomine GMELIN v $\sin$ A M M A N 1 A N O opere (Stirp. rarior. imper. ruth. icones $E$ deforiptiones p. 178. $n$. 256.) plantam quandam defcribit, a fe iplo ad lacum falfum lanifcham Sibirize inuentam; \& dein in Flora fua (Fl. Sibir. Vol. 2. p. 237 Sqq.) fub nomine Ofvirdis folits obiufis, quae denominatio tum temporis LINNAEO in vfu fuit Proxime dicto loco, fimillimam iudicat illi, quam SGHOBER V S in codice manu frripto Memorabilia Wolgae funii) Nitrariam dixit. Non licuit vero illi, nec per propriam nec fociorum eius in rimandis ruthenicis naturse thefauris indaginem, cl. S T E L LERI fcilicet, qui plantam, in deferto Vrunfuicenfi vel Orongoenfi a fe repertam, Elaeagni fpeciem (El. bumilem barbae louis folio, fructu 
racemofo minori dulci nigro) reputauit, \& clo IERGHEI, qui plantam Aftracani vidit, extra dubium omnino ponere, an Nitraria cum altera praecife eadem effet; nemini enim horum conrigit, florentem eam videre.

Quin \& ego de hac ipfa re duhitare incipio, duas tam fibi fimiles horti noftri plantas comparando; quas tamen maxime probabile eft fpecie, vel varietate faltim, inter fe differre. Et hac quidem fententia obfirmor icone G M E L IN I (Flor. Tab. gs), quam delineatam illi STELLERVS fuppeditauerat, quae maiorem longe fimilitudinem cum ftitpe fecundo loco a me defcripta, quam cum altera habet: quum e contrario icon ill. L I NNAE I (Nou. cumment. Petr. Tom 7. Tab. 10.) cum priori magis longe congruat. Quam incertitudinem labes porro defcriptionum botanicorum Rutheniae fuftentat.

Nihilo 'tamen minus ill, A $L I N N E^{\prime}$ Vo trumque vno nomine comprehendit, vt ex prolixiori eius Nitrariae in N. Comment. Pctrop. (loco faepius sit.) defcriptione \& Editione 2. Specierum plantarum p. 683. cognofcitur. In Horto VPfalienfir p. 295 edito a. 1748 , quum flores eius nondum vidiffer, Ofjridem foliis obtufis vocauit, quoniam 
Sect. 3. Hurti botan. Stirpes. 2CB

G MELINO apud AM MAN N VM Cafiae fpecies (genuS TOVRNEFORTII a LINNAEO autem Ofyris dictum) vifa, \& plantis divicis annumerauit. A. 1753 (Diff, Demonfrationes plant. recufa in Amoen. acad. Tim 3.p. 409.) decandram effe ex cognatione cum Zygophyllo coniecit. Editione vero 1. Specierum a. 1754 . p. 1022. animaduertens iam errorem prae nimia confidentia commiffum, Nitrariae modo in nota ad Ofyridem fine vlteriore determinatione meminit, \& in Generibus plantarusn eiusdem anni filentio omnino pratterjit. Floribus autem poftquam eius Nitraria a. 1758 inftrueretur, facile conftitit' eandem $O$. fyridem non effe, fed proprium genus, quod in Commentariis Petropolitanis vna cum totius ftirpis characteribus \& in Generibus plant. a. $176 \%$. p. 602. accuratiflime definiuit.

\section{Icones.}

Conuenit exacte cum mea planta \& de. fcriptio praeftantiffima ill. A LINN É \& icon in Cummentariis nuperrime dictis fuppeditata, quae pofterior tamen neque calycem integrum neque fructum delinestum fiftit, quicquid de reliquo de fynonymis additis fit fentiendum.

Icon GMELIN I Florae adiuncta fru- 
202 Sect. 3. Horti botan. Stirpes.

cum delineauit ouatum, quam quidem figuram ob germen conicum non exfpectaffem; \& quicquid ibidem aculeos refert, nihil, practer ramos aridos, eft.

D v h A $\mathrm{M}$ c (Traité des Arbres or Arbuftes Tom 1. p. 131.) duas Cafiae fpecies fiftit, quarum aleri fynonymon $A M M A N N$ I adpofitum eft, quae vero, iudicio ex icone floris fructusque lato, pro vera Nitraria nullo modo haberi potest.

In Icone, quam ego ipfe pingendam curaui, adiecta vna \& altera pars repraefenta. tur a reliquis cel. viris non delineata. Scilicet

fgura 1. fiftitur ramus naturali magnitudine \& directione refectus, foliis floribusque inftructus.

fig. 2. calyx a tergo vifus, cui pedicellus ex infertione plurium florum tuberculatus adnectitur.

fig. 3. petalum, cuius hamofa pars finifrorfum fpectat.

fig. 4. germen, quod poft delapfum pe. talorum paullum increuit, intra calycem. 
Sect. 3. Horti botan. Stirpes. 203

\section{Cultura.}

Florum defectus in caufa fuit, quod tantis tenebris ftirps tam diu obuelata fuerit. Huic quoque tribuendum videtur, quod in tam paucis hortorum indicibus recepta occurrat. Vix enim arbitror tam raram hortorum botanicorum incolam effe. Queritur ill. A L INNE' (Amoen. aiad. Tom 4. P. 67.) per 20 integros annos in Suecia floribus caruiffe. Et in horto Vpfalienfi (N. Comm. Ac. Petr. Tom 7. $p$. 316.) quicquid caloris, ftationis \& terrae mutatione tentaretur, plus quam 10 anni tamen effluxerant, vfque dum ill. A L I N N É florum eruptioni, perfundendo plantám aqua falina, fubueniret. Quod ipfum artificium, exceptis plantis marinis, omnibus reliquis veneni inftar eft, ad quod vero tentandum \& Statio plantae natalis, \& fapor foliorum eum excitauerat- In horto Gottingenfi autem ne hocce quidem adiumento opus fuir.

$$
\text { vfus. }
$$

An vfu quodam infigniori praeftet, huc vfque non conftat. Paucis modo narrat $\mathrm{cl}$. $\triangle \mathrm{DAN} S$ ON (Familles des plantes Tom 3. $p$. 441.) fructus in cibum adhiberi; qua auctoritate nixus, non refert. Miror vero, quod, folo fuo natali, non ad Sodae praeparationem ftirps impendatur, quae, quantum ex fapo- 


\section{SeCt. 3. Horti botan. Stirpes.}

re iudicare licet, aeque huic fini apta vide. tur, ac variae Salicorniae, Salfolae, Cheno. podii fpecies. Neglectus huius caufa vtrum in parciori iufto prouentu collocanda, an ditiori ex aliis plantis falfis reditu, quarum in Ruffia haud exigua vbertas, prout cel. M oD E L numinatim de Chenopodio maritimo refert, illud Aftracani pro Soda vfurpsri, haud dixerim. Nec conftitusm, an potius eadem ofcitantia fubfit, quae alibi quoad Triglochin maritimum, Atriplicem Halimum \& Portulacoiden \& fpecies quasdam Anabafeos obtinet. Spes vero eft fore, vt cl. F A L C K \& cl. s AMVEL GOTTLIEBGMELIN, qui ad antecefforis fui affinisque gloriam merito fuoadfpirat, in hifce declarandis nobis, ex itineribus fuis reduces, fatisfaciant.

\section{ALE-}


Seff. 3. Horti botan. Stirpes. 205

\section{2. \\ ALETRIS capenfis LINN.}

ALETRIS acaulis, foliis lanceolatis vndu. latis, fpica ouata, floribus nutantibus LiN N. Spec. plant. p. 456.

Peculiare genus ex charactere Aloës \& Hyacinthi compofitum. F A B R I C. Hort. Helmfad. p. 23.

Aletris capenfis Lo, plenius defcripta in 10. B V R M. Flor. Capenf. Prodrom. p. 10.

Habitat in promontorio bonae fpei.

Bina huius plantae exempla poffidet hortus, ex femine culta, quae poft moram 10 circiter annorum flures emiferunt. Alterum procerius omnibusque partibus vegetius \& perfectius, vtpote, ad germinationem promouendam, initio ftatim vaporarii cepore adiutum; alterum exilius, in caldario modo feruatum. Illud integro menfe prius quam hoc floruic, fummum nempe vigorem initio Decembris a. 1769 . habens, floresque quosdam illibatos vltra menfem adhuc retinuit, quae tandem femina fua medio Aprili a. 1770 . maturarunt, ex quibus, paullo poft terrae commir- 


\section{Sect. 3. Horti-botan. Stirpes.o}

miffis, intra fefquimenfem noua germiná enaca. Ob colendi modum diuer um in leuioribus momentis difcrimen exftitit; quod idem vero manifeftius docet, 'quid naturae, quid arti, tribuendum.

\section{Descriptio.}

Radix bulbofa, bulbo globofo, tunicato, fub: tufco, emittens deorfum fibras numerofas craftiores, longas, albas, ex quibus fibrillae copiofifimae, flexuofae, hirfutae, ad latera horizontaliter prodeunt.

Folia radicalia 6 , duplicis ordinis, quorum intimum anguftiflimum, reliqua duo latiora, extima tria latifima, expanfione inter fefe alternantia, fcapo dimidio breuiora, ouato- lanceolata, ad bafin anguftiora, ibidemque violaceo-maculata, canaliculata \& fuccofiora, fenfim ad palmam vfque latiora \& planiora, canaliculo tamen fuccofo ad apicem fere fefe exferente, duplicato-vndulata, Atriata, obtufa, fcapum amplectentia, profunde viridia.

Scapus intra folia oblique furgit, initio incuruus, dein erectior, bipedalis, ad bafin pollicem dimidium craffus, fenfim fefe anguftans, 
Sect. 3. Horti botan. Stirpes. 207

ftans, teres, parte florifera angulatus, maculis denfis violaceis notatus, glaucus.

Spica, to fupraque floribus conftans, quae, dum nondum expanfa, primum ouata, dein pyramidalis, bracteis imbricatis flores recondentibus inftruitur; verfus florendi tempus inferius lixior euadens; \& forefcens fefquipalmam longa tresque pollices lata: foribus initio erectis, poftea pendulis. - In minori exemplo 20 modo flores numeraui.

Bracteae fingulis ad exortum pedunculorum duae: quarum inferior in flore nondum expanfo appreffa, in perfecto autem flore diftans, corolla dimidio breuior, cordatoacuminata, pillide ex rubro viridique colorata; fuperior breuior, fubulata, dilure viridis, femper patula; vtraque marcelcens. - Bracteae fupra in ficica comam quafi formant, quoniam intra fupremas multi flores effoeci latent.

Pedunculi conferti, breuiffimi, fefquilinese longitudinis, teretes, cernui, - Inferior fpice pars primos flores expandit, fuccedentibus dein fuperioribus, qui omnes 
208 Sect. 3. Horti botan. Stirpes..

gratifimo fpectaculo, prout perfectioni propiores, dependere incipiunc.

\section{Calyx nullus.}

Corolla monopetala, infera, tubulofa, fubangulata, tres fere pollices longa, duss vero lineas lata, inodora, ad maturitatem fere fructus, quo (inftar calyptrae mufcoruin) difrumpitur, perfiftens. Tubo parum incuruo, verfus extremum oblique ampliori, albido, maculis carnei coloris diftincto; limbo erecto, linea paullum longiori, in inferioribus floribus vel octofido, vel, quod crebrius, feptemfido, in fuperiuribus omnibus floribus fexfido, quando marcercere incipit, fefe claudente, laciniis ouatis medio paullum prominentibus \& viride pictis, apice obtufo callofo, margine pallide rubro. - Et haec quidem ex exemplo maiori: in exiliori' conftans fere limbi in 6 lacinias diuifio.

Stamina florum inferiorum vel octo, vel, quod frequentius, feptem, (qui numerus vero non refpondet numero laciniarum corollae) rariflime, $v t$ in fuperioribus omnibus, $h$. e. plerisque, in vniuerfum fex. Filamentis tubo corollae per duas tertias ad 
Set7. 3. Horti botan. Stirpes. 200

fundum vfque infertis, ad inferius latus corollae reflexis, prope marginem limbi fefe terminantibus, fubulatis, ad bafin liberae partis carneo colore tinctis. Antheris totidem oblongis, didymis, incumbentibus. Polline fiauo. - In humiliori planta omnes flores, excepto vnico heptandro, hexandri erant.

Pifillum vnum, ftaminibus parum breuius, ad idem, quo ftamina, latus declinatum. Germine fundo corollae infixo, oblongo, trigono, trifulco. Stylo fubulato, ftriato. Stigmate obtufo.

Cápfula ouato-oblonga, ad bafin obtufa, apice acuta, bipollicaris, trialaris (monftrofa fabrica interdum fexalaris), venofa, fexualuis, fubinflata, columella dimidia furfum diffiliente, trilocularis, apice liquidum tenax dulce ante maturitatem fecernens.

Semen in quouis loculo plerumque vnum, interdum duo, quae fi adlunt, alteruter reliquorum vacuus eft; obouatum, teres, ad latus feffile, bafi columellae affixum, arillo nigro nitente obductum, hilo albo, monocotyledon, coriaceum, includens corculum cylindricum apice erumpens. 
210 SeCt. 3. Horti botan. Stirpes.

\section{Animaduerfrones.}

Hexandris L I N N, annumerare ftirpem nemo dubitabit, quum id fuadeat potior florum numerus, etfi numerus ftaminum fenarium interdum excedac. Nom procliuis valde in luxuriandi vitium eius natura eft, cui quaed m plantae non vnice prae foli fertilitate, fed \& priuata quadam de caufa magis obnoxiae. Fuit in hac planta flos, cuius fauci fpurium petalum adnatum, fuitque alius, ex duabus quafi corollis conflatus, in quo numeraui vndecim ftamina, duosque ftylos 8 : vndecim limbi lacinias; in alio rupfus duplo craffior folito fuit ftylus, fupraque fiffus.

Foliis maxime refert Haemanthum puniceum, a quo vero ftirpem defcriptam effe diuerfam emergente fcapo ftatim cognofcitur, vtqui non ex latere, fed media herbae parte prorumpit. Scapus autem floribus ornatus proxime accedit ad Aloën Vuariam ( C O MM E L. Hirt. Amft. Tom. 2. p. 29. Tab. 15.) cui veros e в A (Thel. Tom. I. Tab.19. Fig.3.) hinc inde bradeas adpinxit. Haec nimirum non minori copia florum inftruitur, pendulorum pariter, eiusdemque figurae.

Multa flos fructusque cum generibus, Aloës, Hyacinthi, Aletris, Polyanthes, haben. 


\section{Sect. 3. Horti botan. Stirpes. 211}

bent communia, quaedam tamen fibi peculiaria. Inter quae praecipue refpiciendum duco ad coroliae tubum incuruatum, ftaminum infertionem ad latus corollae eorundemque \& piftilli inflexionem, fructus denique figuram, angulosque productiores \& trialares. Singulum horum tanti effe momenti vt generis characterem efficiat, plura aliorum exempla decent. Ita e. c. incuruacus corollae tubus inter diffinctionis notas Lycopfidis \& Phlocis reponitur. In Pancratio ftamina neEtario inferuntur; in Aphyllanthe \& Polyanthe fauci corollae; in Aloë receptaculo. Et quod ad directionem eorum attinet, in Crino, Atropa, ftamina inter fe diftant; in Phyfalide conniuent; in Hemerocallide \& Alftrömeria declinant. Ve de vi fructus in difcernendis generibus nihil dicam. Quo plures autem eiusmodi fingulares notae in plantae flore frucluque confipirant, eo iuftius pro fingulari genere habetur.

Non commode igitur cum aliquo dictorum generum combinari ftirps mea poteft.

Aloës fpeciebus initio videbatur adiicienda, tam ob corollae quam fructus fimilitudinem. Et quoniam inter hafce proxime accedit ad Aloën Vuariam: quaerebatur anne

$$
\mathrm{O}_{2} \text { haec }
$$


212 Seat. j. Horti botan. Stirpes.

haec a reliquis Aloibus diuelli poffet, \& cum defcripta firpe confociari ; tanto magis, quaps Vuaria multa ab aliis Aloibus diftincta, animaduertente iam b. T REW (Comm. Nor. 1744. P. 322. 375. Tab. 2. Fig. 8.) habeat, \&, i praeter florem \& habitus externi ratio haben. da fit, contra naturam videatur, ftirpem membranaceis foliis infructum cum tot aliis fpeciebus, quae carnofa gerunt, coniungere. Sed in toto genere Alö̈s \& in Vuaria quoque (docente praecile ill. TRE w l. c.) ftamina receptaculo, non vero corollae, inferta.

Hyacint bo in apice germinis tres pori nectariferi funt, corolle limbus reflexus \& cap. fula fubrotunda; defcriptae nihil nectario fimile, limbus erectus \& capfula oblonga, trialaris.

Aletris characterem effentialem pofuit ill. A L I N NÉ (Gen. pl. Ed. 6 p. 170. Sy/f. nat. Ed. $12 p .24 \%$ ) in rugora \& farinacea fere corollae fuperficie, quae vero in deferipta planta glaberrima eft. Vnde non aufus fuiffem LINNAEI nomen in fronce praefigere, nifi iple ill, vir, defcriptione iioneque mea illi mifla, me de eo litteris d. 1 4. Febr. : 770. certiorem feciffet, fimul faffus, fe Alztrin capenfem nunquam viuam vidife, \& characterem ipfius generis correctione opus habere. Equidem ce!. B V R M AN N I (loc. cit.) defcriprio. 
ptione iam ante conieci, ftirpem meam eo a LINNAEO nOmine infigniri; nam ipfe nulla fynonyma citat. B RRMANVS autem declinationis ftaminum, etfi piftilli, mentionem non facit. Reliquarum duarum Aletris $(S y / t$. nat.) fpecierum, (quibus duas alias B V KMANN V S addit) fares viuos quidem exami. nare mihi non contigit: conferendo vero icones COMMELIN I cum mea ftirpe valde diuerfos inuenio. Nam in iftis corollae tubus rectus, \& limbus profunde diffectus laciniis reuolutis, \& ftamina bafi laciniarum non medio tubo adnata, depinguntur.

Cum Polyantbe iequitur iam comparatio, inter quod genus \& floris plantae, de qua agitur, partes haud exigua obtinet cognatio. Vtraque ftamina corollae inferta habet, tubum, etfi diuerfo gradu, inflexum, capluam in mulcis fimilem, ve vulgaria pluribusque liliaceis communia reticeam. Disiungi vero iubet corollae Polyanthes figura infundibuliformis, limbus infignior putensque, \& antherarum infignis quoad ftamina magnitudo.

In difficili hoc cafu nolo temeritatis me reum facere, fed ill. LINNAEI erit, definire, verum peculiare genus tirps defcripta contituat, an inter reliquas Aletris fpecies in pofterum permaneat. 
214 Sect. 3. Horti botan. Stirpês.

\section{3. \\ ANTHERICVM reuolutum}

L I N N.

AN'THERICVM foliis planis, fcapo ramofo, corollis reuolutis, LINN. Spec. plant. p. 445 .

Pbolangium aethiopicum ramofum, floribus albis, petalis reflexis. COMMELIN Hort. Amftel. Tom. I. P. 67. Fig. 34 .

An Afphodelus foliis compreffis, afperis, caule patulo. T O V R N E F. Inffit. p; 344. ?

Rara haec planta per plures annos in poffeftione horti fuit ex femine in caldario culta, fed flores nonnifi a. $1769 . \mathrm{m}$. Augufto produxit, absque perfecto fructu deciduos. Nullibi eam, praeterquam in COM MELIN I Horto, prolixiori deferiptione \& icone illuftratam inveni; vtraque vero $\&$ hic longe abeft $a b$ ea accuratione, qua Dillenianae nitent. Petala nimis reuoluta repraefentauit, \& quibusdam floribus calyces adpicti, radicis imagine plane omifla. 
Sect. 3. Horti botan. Stirpes. 2I5

Patrinm fecundun cel. CO M M EL INV M Promontorium bonae fpei habet.

\section{DESCRIPTIO.}

Radix perennis, fafcicularis, conftans ex numerofis caulibus, teretibus, hinc: inde paullum incraffatis, ve tuberofam fere referat, albis, tenerd epidermide veftitis, iuccofis, fed medulis lignofa, quase fili inftar extrahi poteft, inftructis, fragilibus, obtufis, radiculas ad litera fpargens.

Folia radicalia numerofa, fcapo triplo breuiora, fubulata, ad bafin canaliculata, dein carinato-plana, ftriata, fefquipollicem lata, patentia.

Scapus quadripedalis, fubnudus, teres, glaber, obliquus, ramofus; brafteis 5 bafi giblis, adpreflis, fubulatis, inferioribus foliorum inftar maioribus, fuperioribus fquamofis \& marcefcentibus.

Corymbus terminalis, compreffis, ramis fex; teretibus, longis, alternis, ad exortum florum nodofis.

Flores alterni, mox folitarii, mox bini, vel terni, infidentes pedicellis exiguis, fupra in-

$$
\mathrm{O}_{4}
$$


216 Sect. 3. Horti botan. Stirpes.

craffitis, grifeis, \& bracteolis fubulatis fenfim marcefcentibus fuffulti.

Caljx nullus.

Corolla hexapetala, infera, petalis lanceolato-ouatis, reflexis, obtufis, ad apicem concauis, albis,--extrinfecus verfus apicem viridi - fufcis.

Stamina 6 erecta, corolla paullum breuiora; filamentis filiformibus; antheris erectis, oblongis, poftquam marcuerunt, reuolutis.

Piftillum 1, eiusdem longitudinis; germine obfolete trigono, parmo; fylo longo, fi. liformi; ftigmate trigono.

\section{Animaduerfo.}

Radix fimillima ifti Haemanthi punicei, vt facile confunderentur. Sed in hoc prominet media eiusdem parte tuber rotundum, \& caules eius epidermide obfcurioris coloris tecti, quae vulnerata cicatricem fanguineam relinquit; ob medullam fuccofam flexi toti tranguntur. 
Sect: 3. Horti botan. Stirpes. 217

\section{4. \\ HELIOTRO PIVM angiofper- mum MIHI.}

HELIOTROPIVM foliis nuatis obtuffs fpicis geminis folitariisque, fructibus angiofpermis.

Speciebus iftis 8 Heliotropii, quas ill. A LINNE' in Syftemate fuo recenfuit, nouam nuperrime addidit cel. NICOLAVS LAVRENTIVS BVRMANN M. D. (Flor. Capenfis prodr. p. 4.) fcilicet Heliotropium à fe dictum tomentofum. Ego decimim adiurgam, quae, quantum fcio, nondum ab vilo alio Botanico defcripta exftat. Semina huius mifit a. 1768 . cel. OE DER; nec aegre germinarunt in vaporario, cuius fotum vfque ad maturationem feminum planta probe, tulit. Floruit vero ineunte Iulio.

DES CRIPT 10.

Cotyledones orbiculatae, petiolatae.

Radix annua, perpendicularis, fibris ad latera craffioribus. 
218 Sect. 3. Horti botan. Stives.

Caulis erectus, teres, fupra ramofus, prout totus plantae habitus, hirfutus, calami frumenti craffitie, fricaus, dodrantalis.

Folia fimplicia, ouata, obtufa, quorum fuprema \& iuniora fubundulata, rugofa, conuexa, magis hirfuta \& profunde viridia, inferiora plàn \& venofa, fúbrepanda, oppofita, petials canairulato, in quem fenfim decurrunt, duplo longiora, fefquipollicaria.

Inflore/centian confituunt Spicae mox geminae, quod crebrius, mox folitariae, fe- cundae, reflexae, terminales ramorum,

- infidertes pedunculo filiformi, paullum $\mathrm{i}$ - Atis longiori.

Calyx monophyllus, quinquepartitus, laciniis bafi fubgibbofis, duabus fuperioribus minoribus, tribus inferioribus maioribus, conniuentibus, corollae tubum aequans, perfiftens.

Corolla exigua, monophylla, hypocrateriformis, tubo ventricofo, limbo albo quinquepartito, laciniis ouatis, fauce viridi, extus $\&$ in fauce villofa. 


\section{Sect. 3. Horti botan. Stirpes. 219}

Stamina 5, intra tubum abdita, filamentis nullis, antheris didymis.

Piffillum 1. germine fubrotundo, Aylo nullo; ftigmate pyranidali, obtufo.

Pericarpium eft : capfula fubrotunda, didyma fere, vmbilicata, 4 locularis.

Semen vnicum in quouis loculamento, ro= tundum.

\section{Animaduerfio.}

Angiofpermum vocaui, quoniam, exemplo in genere Heliotropii vnico, lemina vera capfula tecta gerit, nec, prout in quibusdam aliis afperifoliis fit, cortice tantum fa. cile deglubendo veftita, 
220 Sect. 3. Horti botan. Stirpes.

\section{5. \\ SID A anguftifolia MILL.}

SIDA caule erecto ramofo, foliis linearilanceolatis dentatis fubtus villofis, pedunculis axillaribus vnifloris. MILLER's Gardeners Dictionary Spec. 3. Ed. 8.

Maluinda pimpinellae folio anguftiore femine bidente Act. Pbil. Lond.39g. (M I L L.)

Omiffo $a b$ ill. A $L$ INNÉ ex feminibus cel. OEDERI, a. 1769. vere fatis, in horto noftro emerfit. Verum, etfi probe culta, flores primo anno aegrius expandit, quippe quorum plerique tum ante perfectionem emarcefcentes deciderunt. Secundo anno flores tulit perfectos, eosque fructum relinquentes. Dubito tamen ob florum primo iam anno eruptionem, cumpagem tenellam, \& defectum furculorum ad radicem, an vere biennis vel perennis fit.

Indiam orientalem patriam habet.

DES C RIPT I O.

Raclix gracilis, perpendicularis, attenuata, lignofa, fibris lateralibus. 
Sect. 3. Horti botall. Stirpes. 221

Caulis erectus, teres, fefquipedalis, leuiter flexuofus, craflitie calami frumenti, pilis rarioribus horizontalibus adfperfus, fupra ramofus; ramis alternis, axillaribus, patentibus. Folia alterna, fefquipollicaria, lanceolata, ad bafin integra, reliqua parte, ferrata, acuta, venis rectioribus parallelis, fubtomentofa, infra pallidiora, dependentia, decidua, ante explicationem conduplicata.

Petioli hurizontales, filiformes, ad apicem incraffati, foliis dimidio breuiores, pilofi. Sub quibus

Callus obture trifpinofus \&

Stipulae duae, fetaceae, fpinis lateralibus in- fidentes, petiolis longe breuiores, deciduae. Flores folitarii, axillares, in fummo caule \& ramis, pedunculo breuiffimo infixi.

Calyx angulatus, 5 fidus, laciniis parulis, apice leuiter inflexo, carinatis, perfiftens. Corolla calyce duplo longior petalis quinque ad bafin coalitis, fenfim latioribus, oblique emarginatis, patentibus, flaua friis 5 faturatioribus.

Stamina \& Piftilla, vt in monadelphis polyandris.

Fructus conftar ex capfulis's fubroundis, co. alitis, bimucronatis, in quarum qualibet Semen vnicum fubrotundum. 
$22=$ Selt. 3. Horti botan. Stirpes.

6.

\section{ASTRAGALVS echinatus м гнт.}

ASTRAGALV S caulefcens procumbens, leguminibus capitatis ouatis triquetris echi- . natis apice hamofo.

An Afragalus hifpanicus, filiqua epiglottidi fimili, flore purpureo maior. HERM A N N. Hort. Lugd. bat. Icon p. 75.? quod quidem fynonymon cum, figura $L$ i $N$ N A E V S Aftragalo epiglottidi fuo tribuit.

Ita definio fpeciem $a b$ ill. $L$ I N N A E O nondum auctoratam, quam vero per aliquot annos aeftate in horto laete crefcentem vidi. Semina etiam mifit cel. OEDER, quae vna cum priftinis horti a. 1769 . fata votis refponderunt. Probe fert ftationem fub dio in area, \& ne vaporarii quidem ope ad germinationem indiget. Floret initio Augufti frucum ferens verius eiusdem finem.

\section{DESCRIPTIO.}

Radix annua, perpendicularis, ad latera numerofas radiculas fpargens. 
Caules ex radice numerofi, fimplices, procumbentes, diffuri, flexuofi, angulati vel obfolete fulcari, fupra rubri, infra virides.

Folia impari-pinnata, pinnis circiter 17 oblongis, emarginatis, fubcarnofis, ciliatis, fupra glabtis, infra parum hirfutis, pallide viridibus, biplaniis, auenis alternis.

Petioli canaliculati, bafi aphylli, hirfuti, virides, alterni.

Stipulae ad bafin petiolorum binae, triangulares, patentes.

Pedunculi axillares, longi, foljis breuiores, fulcati, hirfuti ; quibus infidet

Capitulum 6-8 florum, bracteis totidem fubulatis.

Calyx ventricofus, quinquedentatus, fubaequalis, laciniis fubulatis, intra duas fuperiores finu profundo incifus.

Corolla papilionacea, pallide rubro - coerulea; vexillo ouato, emarginato, erecto, vngue lineari; alis aequalibus, oblongis, obtufis, apo- 
224 Sec. 3. Horti butan. Stirpes.

apophyfi obtufa deorfum terminatis, vngue anguftiffima lineari; carina falcata.

Stamina diadelpha, decandra.

Piftillum vnum, ftaminibus aequale; germine oblongo, hirfuto; ftylo incuruato, feta-

I ceo, ftigmate obrufo.

Legumen ouatum, triquetrum, deorfum canaliculatum, biloculare, apice hamofo filbulis, pellucidis, fuceofis, diuergentibus, in pilum tenuem definentibus, tectum.

Semen in quolibet loculo vnum, compreffum, reniforme.

\section{Animaduerfio.}

Habitu refert Aftragalum fefamaeum, fedinon tam longos caules fert, nec capitula feffilia, fed pedunculata. Corollae infuper alae non funt minores, fed eiusdem ac vexillum longitudinis. Ratio epitheti in fructu continetur. 
SeI. 3. Horti botan. Stirpes.

\section{7. \\ COTVLA alba LINN.}

COT VLA foliis oppofitis lanceolatis triplineruiis ferratis feflilibus, floribus alternis fubternis feffilibus $L$ I N N. SyJt. nat. Tóm. 2. p.564.

Eupatoriopbalacron Balfaminae foeminae folio, flore atbo difcoide VAILL. DILL. Hort. Eitham. P.138, Tab.113. Fig. 137.

Hane \& Cotulam proftratam ill. A L I N* N É olim (Spec. plant.p. 1272.) ad Verbefinam retulit. Cotulis autem accenfere in $S y$ femate fine duhio diuifio quaternaria corollarum difci \& defectus palearum fuafit. Vtraque inter fe, \& cum tertia quadam fpecie, quae noua videtur, tantopere conueniunt, ye difficile difcrimen definiacur. Quum Cotulam proftritam praeter DI LLENIVM (Hortus Eltbam. p. 139. Tab. 113. Fig. 138.) $z$ IN N Ivs nomine Plantse Coreopfidi affinis (Comenent. Gott. Tom 3. Tab. u) defcripferit; reliquis duabus inter fefe conferendis acquiefcam. 
228 SeCt. 3. Horti botan. Stirpes.

Cotulac albae caulis eft breuior, craffior, leuiter flexuofus, hirfutus pilis non adpreffis fed horiżontalibus, vix ramofus. Folia anguftiora, manifeftius ferrata, ferraturis denciculatis inaequalibus, venofa, tribus venis rectioribus, fubundulata, venis hirfutis, licet prout in altera fuperficies foliorum pilis adpreffis exafperetur. Pedunculi breues velifolitarii, vel ex eadem axilla bini, rarius ternio Calyx non hemifphericus, fed ouatus laciniis latioribus.

\section{COTVLA Oederi m I Hr:}

Cotula caule ftricto adpreffe pilofo, foliis lan. ceolato-ouatis, obfolete ferratis, floribus pedunculatis, fubfolitariis, fquamis calycinis lanceolatis.

Cel. OEDERI, Profefforis Botanices Hafnienfis, de horto noftro eximie meriti; nomine nouam fpeciem infignio, quod ad 1769. femina ciusdem mihi mifit. Annua. hivito Augufti in vaporario floruit, \& femina matura reliquit.

Caulis erectus, frictus, teres, ramofus, ad exortum ramorum nodofus, rubicundus, 
ex pilis adpreffis, prout reliquae plantae partes, fcaber, pedalis, ramis longis indiuifis, oppofitis, patentibus. Fulia fpachulata, lanceolato-ouata, fcabra, feffilia, oppofita, prominentibus deorfum venis iisque retioribus, fufcis, mox integra, mox obfolete \& inaequaliter ferrata, margine in apicibus ferraturarum fufco. Folia teneriora magis hirfuta. Pedunculi pollicares, fupra incraffati, hirfuti, axillares, folitarii plerumque \& vniflori, interdum bini, quorum alter longior. Calyx hemifphaericus, foliolis lanceolatis. Corolla difci plerumque quidem 4- fida, faepe tamen $s$ - fida.

\section{Animaduerfio.}

Vix arbitror difcerni Cotulam proftratam, albam, eamque $O E D E R I$ a fe inuicem. poffe, nifi fimul pilorum in caule directionis, \& calycis eiusque foliorum formae, ratio habeatur. 
230 Selt. 3. Horti botan. Stirpes.

\section{9. \\ COT VLA antbemoides I INN.}

COTVLA foliis alternis pinnato-multifidis dilatatis, corollis radio defticutis. $L 1 N$ N. syjt. nat. 2. p. 564 .

Anantbocyclus Chamaemeli folio $V A$ IL $\mathrm{L}$, D I L L. Hort. Elth. P. 26. Tal. 23. Fig. 25.

Nitidam hanc plantam proprio fcrutinio fubiiciam, quoniam, etfí iam a PLVKENET 10 memoratam, video nondum probe cognofci, vel nuperrime modo rectius innotuiffe. Speciebus, plantarum p. 1256, illam quidem A I I N N $E^{\prime}$ Cotulse anthemoidis nomine inferuit, fed \& aliam, quam Artemifiam niloticam vocat, ibidem ( $p .1188)$ defcribit, quam expuncto hoc nomine in Syftemate (loc. cit.) tanqua ruit $\mathrm{m}$. Augufto a. 1769 , ex feminibus mihi ex Suecia millis, in tepidario.

InfulaHelena \&Hifpania vera patriaconftituitur。

$$
\text { DESRIPTIO. }
$$

Cotyledonss lanceclatae, petiolatae. 


\section{Sect. 3. Horti botan. firpes.}

Radix fibrofa, annua.

Caulir fefquipalmaris, initio erectus, dein procumbens, vix flexuofus, tenellus, pubefcens; ramis alternis, pube magis confpicus veftitis, incuruis, ad fuperius latus conuerfis, patentibus.

Folia pinnatifido - finuara, laciniis difantibus mox parce ferratis, mox integris, obtufis, glabra, patentia, alterna, feffilia, venis produci rifus.

Pedunculi ramei, uniflori, longi $f_{\text {. }}$ pollicares, filifurmes, erecti, villofi.

Flures cernui, ante explicationem referunt

placentan compreffam, mignitudine lentis. Calyx polyphylius, foliolis ousto-oblongis, obeufis, concauis, margine albo, membranaceis.

Corollulice in margine nullae, fed nuda piffilla fub foliolis calycinis abdita, ftigm ate hifido Corollulae difci hermaphroditae, tubulofae, quadrifidae.

Pappus nullus.

Semina mas ginis fubrotunda comprefla, introrfum plana, extrorfum paullum carinata. Semina difci autem magis oblonga, fere triquetra. Receptaculum nudum.

\section{P 3}


$23^{2}$ Sect. 4. Aeris Gottingae ratio.

\section{Sectio 4.}

AERIS TEMPESTATVALVE GUTTING A E R A TIO.

$$
\text { 5. I. }
$$

Quicquid vero fumtuum \& operae horto impendatur: fruftra collocari facile cognofcitur, nifi aëris tempeftatumque benignitas confpiret, ea, quae \& germinationi plantarum faueat \& incremento, \& feminum, ftirpium non minus ex auftralibus regionibus petitarum, maturationi, nec finat, vt plantae, confpicuam iam ftaturam adeptae, fubito orto impetu profternantur, vel afperiori alias climati affuetae inclementioris hiemis vi pereant. Laudandi igitur cell. viri DV HAMEL, GAVT(ER*), KAL M**), LECHE**) \& qui in focietatem oeconomicam Bernae coierunt ${ }^{* * *}$ ), quod obferuationibus fuis botani.

*) Memnires de l'ace eles fciences de Paris 1746. pa క. 63. Sqq. 1747. p.309 fq7 p. 466. Sqq. 1749 . $p, 224, \int q 9$.

**) Vet Acad. Handlingar 176to p. 19. 129. ***) Vet. Acad, Handl. 1763 p. 257.

***) V. egr. vítima pars a. 1768 . libri Abbandlungen und Beobachtungen dirrch d. oekvan. Gefolfycbaft zu Bern. 


\section{Sect. 4. Aëris Gottingae ratio: 233}

nicis hafce meteorum adiunxerunt. Ad cognofcendam vero aëris Gottingenfis naturam quam maxime faciunt obferuationes illuftris H OLLMANNI, venerabilis fehis, per plures annos inftitutae, quarum tamen fummam *) de 13 modo annis, fcil. ab a. 1741. ad 1753 , publici juris facere illi placuit. Vtinam iftae fequentium annorum etiam conftarent, de quibus fere nihil fcimus, praeter ea, quae ex eodem limpido fonte de annis 1760 , 1761 \& 1762 cll. HENSLERVS \& WA GLER S $^{* *}$ ) hauferune, \& quae cl. iurium Dr. F. C. WILLICH ${ }^{* * *}$ ) de anno 1769 . ex fchedis propriis memorine mandauit. Pauca tantum ex propriis obferuationibus, fiquidem ad finem modo praeteriti anni eas calamo excipere coepi, addere poffum. Neque adaëris modo conftitutionem, per aeftarem \& reliqua mitiora anni sempora ingruentem, ftirpium caufa attendere conuenit, fed \& ad eam quoque, quae per hiemern incidit, cuius plantae perennes \& fruticantes feminaque in capfis fuis feruata rationem habere nos iubent; licet maior omnino aëris in plantas aeftiuo tempore \& affini : bus efficacia exiftat.

$$
P_{4} \text { S. } 2 .
$$

*) Comment. fociet. R. fcient. Gott. Tom III. \& IV. **) V. illius cl. viri diff. de morbo variolofo, hus ius diffo de morbo mucnfo.

***) Hannouerfches Magazin, 1769. 
234 Sect. 4. Aëris Gottingat ratio,

\section{§. 2́.}

Quod ad granitatem aëris attinet: obferuatum $\in$ ft per complures annos, maximam mercurii in barometro altitudinem sequalem fuiffe 30 pollicibus cum 36 vel 37 centefimis pollicis men urae Londinenfis: minimam = $28^{\prime \prime}$ to vel $28^{\prime \prime}+7$; ve igitur totum difcrimen I", yt ve! I", 96 Lond, conftituat *). Repentini vero faepe mercurii defcenfus afcenfusque apud nos animaduertuntur, idque non modo hieme fed \& aeftste ${ }^{* *}$ ); quod quidem phrenomenon eodem tempore $\&$ in aliis terrae plagis contigit ${ }^{* * *}$ ). Recentius hoc accidit m. Nouembri a. 17 \% 9 . quo ipfo intra d. 12 \& 15. a $2 y^{\prime \prime}, 80$ ad $28^{\prime \prime}, 83$ Lond. mercurius fublidic. Specificum autem aëris Gottingenfis pondus ad pondus aquse, comparatione facta inter aërem maxime frigidum \& aquam temperate calidam, inuente ill. A SEGNER $* * * *$ ) fub frigore a. 1740. (de quo s. fequ.) effe vt I ad 700 .

5. 3 .

*) Comment. Gott. Tom. 3 p. 65. 20 Tom 4 p.89. **) Loc. cit. Tom 3. p. 18, 45. Uंc. Tom 4. P. 90.

***) l. c. Tum 3. P. 21,64 .

****) Diflert. Objeruationes quaedam of conclsfiomes circa calorem of frigus naximpe biemis 1740 refP. FRID. LV D OV. CROPR. P. 33. 


\section{Sect. 4. Aëris Gottingac ratio. 235}

\section{3 .}

Temperiei aëris noftri ea indoles eft, vt interdum calore aefum adeo locorum fub aequatore fitorum exaequet, nec frigoris vehementia feprentrionalibus regionibus aliquando cedit. - Vt exenspla afferam: die 27. Julii a. 1750. tantus calor inualuit, ve mercurius ad $y ; \frac{1}{2} \mathrm{gr}$. in thermometro Fahrenheitiano afcenderet ${ }^{*}$ ), ideoque calorem naturalem corpuris humani fere exaequaret; $d$. 6. Iulii a. 1752. autem gr. $89 \frac{\mathrm{r}}{2}$ attingeret.

In frigoris intenfitate definienda non piget regredi ad illud a. 1740. , quod vrbs noftra cum reliqua Europa commune habuit, de quo refert ill. A SEGNER ${ }^{* *}$ ) d. 10. \& 11. Ianurii mane marcurium therm. Fahrenh. ad gr. 8 fub o defcendife, \& in camera eius quadras quasdam feneftrarum difruptas, \& inter multa alia liquida fpiritus adeo varios, vt. acetum deftillatum, oleum vitrioli \& oleum tartari meracifinnum, eiusdem vi conglaciaffe. Quod iplum frigus licet mitior temperies intercederet, d.2.2.Febr eadem fere vehementia rediit, ad diem vfque 25. pergens, quo medio decrefcere coepit, fed perdurans tamen mitius \& regelatione fubinde interruptum ad d. 10.

$$
\begin{array}{ll}
P & A
\end{array}
$$

*) Comment. Gutt. Tom. q. p. 13. **) Differt. cit. pag. 24. 


\section{Sect. 4. Aëris Gottingae ratlo.}

Aprilis. Duobus igitur modo gradibus frigus Vpfalise, a b. cELsio eodem fere tempore obferuatum, vehementius fuit. Ita \& frigus a, $1748^{*}$ ) dirum admodum fuit, non modo Januario fed \& Martio menie, adeo vt d. 8. Martii mane ad gr. 6 infra o decideret, quod frigus eodem anno poftea calor 86. gradum aliquoties fuperans excepit. Ad afperiores frigore hiemes heic loci perceptas refertur ifta a. $1749^{* *}$ ), vti \& a. 1751. ${ }^{* * *}$ ), quam \& ill. A L INNE ${ }^{* * * *}$ ) in Suecia fuiffe frigidifimam narrat; vt alias remotiorum annorum, quorum frigus ex thermometro Florentino definitum, non attingam. Nulla vero, quantum memoria recoli poteft, maiorem frigoris vim apud nos experta eft, quam hiems a. 1768 , cuius frigus menfe lanuario illud adeo a. 1740. infigniter fuperauit. Scilicet d. 4. diati menfis mane mercurius a gr. 36. ad 18. fub $\circ$ fiue frigoris gradu niuis mifcela cum fale ammoniaco producti, \& d, 5 . mane extra vrbem, vbi liberior aëris acceffus fuit, ad gr. $23-24$. fub $\circ$ fubfidit ${ }^{* * * * *}$ ). Sub hife frigoris intenfioris exemplis leuioris

*) Comment. Gott. Tom. 3, p. 49.

**) loc. cit. T. 3. p. s6.

***) loc, cit. Tom, 4. p. $3 \%$.

****) Amoen. acad. Vol. 3. p. 365 .

*****) Gotting. Anzeigen 21. St. 1968 . 


\section{SeCt. 4. Aëris Gottingae ratio. 237}

videtur momenti effe indicare, quod hoc ipfo anno 1770 . lanuarii die 8 , mane hora 7 , ad gr. 8 , \& die 10, vefperi hora $8 \frac{x}{4}$ ad gr. 6 , fupra $o$, mercurius in meo thermometro defcenderie.

Differt vero in eo caloris pariter ac frigoris apud nos incenfitas, quod breuiorem longe aprad nos, quam iis regionibus, quae inde nomen trahunt, durarionem habeat. Nec folet heic luci tranfitus ab vna aëris temperie ad alism ica lentus eff, \& pro anni temporibus mutari ac alibi: fed fubitaneas plerumque mutationes init, docente non folum thermometro, fed \& ipfo hominum fenfu, idque faepe vna eademque die. Fallax praeterea tepor vernus redeunte faepe frigore grauiori ferius. - Conferri in hunc finem obferuationes thermometricae ${ }^{*}$ ), quae ad finem Martii menfis, Aprilem Maiumque, a. 176 g. pertinent; quo proxime dicto menfe, praegreffis ium calidis diebus crebrius frigus intenfum adhuc incidit, confumens tenclla multarum arborum folia. Quod non mirum, quum, etfi mercurius $\mathrm{m}$. Aprili aliquot diehus per meridiem a gr. 64. ad 69. vfque afcenderat, m. Maio tamen aliquor diebus ad $\mathrm{gr}, 45$ meridie, quin ad gr. 36 vfque mane coarctaretur.

Lu-

*) Hannou, Magazin r76g St. 4t. 53. 79 . 


\section{Sect. 4. Aëris Gottingae ratio.}

Luculentius adhuc exemplum nouiffisnum eft, quod $\mathrm{m}$. Martio a. 1770 . experti fumus. Blandus hoc ipfo adeo aër initio erat, ve quibusdam diebus circa meridiem mercurius therm. ad gr. 54. pertingeret. Multae vernales plantae, vt Corylus, Farfara, Populus tremula, Helleborus hiemalis \& niger, Galanthus, Leucoium, Crocus fatiuus luteus, Henticic, B tula, Thuya occidentalis, Iuniperus bermudiana, Daphne, aliae, iam florebant, Adonidis vernalis \& Tulfilagnis albae flores prorumpere conabantur. Turgefcere incipiebant gemmae mult ruın arborum, quin quaedam i im fefe expandere, Lonicerarum exemplo. Sed d. 14. poft afcenfum mercurii ad gr. 5 r. p. m. fulmen cum tonitru perceptum, poft quod tam frigida iterum euafit tempeftas, vt-d. 25 . hors 7 . mat. ad gr. 16. mercurius defcenderet, \& copiofifima per plures dies continuos nix decidit, perfiftens, vbi delapfa fuerat, ad d. 25 , quo ipfo iterum deliquefcere coepit, fed pofteris aliquot diebus nouas fuppetias nacta. Die 3r. Martii tamen tam mite rurfus coelum erat, vt hora 12. merid. ad gr. 5o. mercurius fubfifteret; hora vefp. autem 11. ad gr. 4r. Calidiores ad finem $A$ prilis dies fubfequutae initio Maii frigidiores, grandinis \& niuis fubinde delapfu \& noctu d. 4 . congelatione aquae refiduas hyemis infidias prodentes.

Quae 
Sect. 4. Aëris Gottingae ratio, 239

Quae aëris temperiei inconftantia cum rempeftatum vehementia a multis, praecipue aduenis, a vicina nobis Hercynia repeti folet. Errorem vero hunc redarguunt obferuationes, ve quibus spparet, mercurium barometrorum pari fere paffu ibidem ac apud nos ambulare, *) \& faepe aërem eodem tempore temperatiorem ibidem ac Gottingae effe, quin haud raro, vrgente apud nos afperiori tempettate ventos a diuerfa longe, quam ex Hercynia plaga proficifci ${ }^{* *}$ ).

\section{4 .}

Aquae plutialis, quae quotannis delabitur, quantitatem definire non datur, quum nullibi in hac vrbe hyet metrorum vfus ta. Cus fuerit. Id tamen ex tabulis colligitur, variare heic vt alibi annos ratione humiditatis, ficcos effe alios, alios pluuiofos magis. Ita \& menfes Nouembris \& Decembris pluuiae prae reliquis patent. Ver apud nes ficcius effe folet. Pluuia vel niuofa tempettas plerumque comicem habet Boream vel alium ventum inter hunc Zephyrumque incidentem.

Nix vero apud nos \& parciori copia \& per interualla decidit, \& poft breuiorem mo-

ram

*) Comment. Gott. Tom, \& p. gr.

**) loc, cit, T.1. p, $\sigma_{j,}$ 
$24^{\circ}$ Sect. 4. Aëris Gottingae ratio.

ram vel ventorum vi diftrahitur vel deliquefcit, nec facile ante Ianuarium aliquam conitantiam adipifcitur. Plerumque quoque gelu intentius praccedit, quod \& ipfum, quum variet admodum temperies aëris, crebro diffluit, vel decidua pluuia reloluitur.

Grando ad minus frequentia apud nos meteora pertinet, \& rarius ea magnitudine cadit, vt noxam infigniorem creare poffit; cuius tamen rei memorabile exemplum a. 1764. d. 17. Maii occurrit. Nam vt in fchedis fuis confignauit ill, HOLLMANNvs, quas manu feriptas de hoc momento luftrare mihi conceffit, inter horam 3. \& 5., mercurio thermometri ad gr. 75 . euecto, \& barometro ad $2 y^{\prime \prime}, 33$ fubfiftente, vento fpirante ex NNO. poft tonitru aliquoties perceptum grando nuce auellana maxima infignior decidit. Ex alio fonte vero fcio, in hurto botanico tanta vi \& pondere delapfam, vt vno i iłu feneftrarum trium fibimet impofitarum quadrae pertunderentur, \& aliquot centenae hyberna. culi, folopeti quafi impetu transfolfae, frangerentur, plantae quoque numerofae conqual. fatae profternerentur.

Hieme raro ea contingit coeli ferenitas; quae in fepteutrionalibus tantim voluptatem 


\section{Sec7. 40 Aëris Gottingae ratio. 241}

parit, fed per plurimam partem nubibus ob. ducitur, tribus praefertim vltimis anni menfibus; aucumno quoque nebula obfcuratur. An vero nubilus aër aeftiuo tempore ad quosdam prae reliquis menfes fefe adfringat, \& quinam ii fint, quum de hac re, ve de variis aliis, tabulae taceant, quarum pleraeque fummam modo obferuationum, nec fecrfim illas per fingulos dies tradunt, nilhil conftituere poflum.

\section{5}

Inter ventos Boreas videtur reliquis crebrius fpirare morseque tenacior effe, etfi mox ad Eurum mox ad Zephyrum inclinat, procellofus plerumque $\&$ pluuia vel mue ftipatus. Eurtus, prout ipfe ficcior, terram magis eneruat, isque in vernum rempus praecipue cadit. - Procellarum vim vrbs noftra aliquando intenfiorem experitur, quarum egr. iftae anni $1751 \mathrm{~m}$. Ianuario \& anni nuperrime elapf 1768 medio Nouembris notzbiliores exftant.

\section{\$. 6 .}

Omitto varia alis meteora, ve lumen bo. seale, irides rel., quum magis aliena ab hoe loco fint, nec terrae motuum, quos, verum 
242 Set7. 4. Aëris Gottingae ratio.

leues, nuperioribus annis fenfic vrbs noftra, memini.

Tonitru vero mentio omnino iniicienda eft, quod, quamuis rarius vrbi noftrae infeftum fit, \& plerumque absque diuturna mora eam modo praeteruehitui, aliquando tamen ictus in ipfam vrbem exercuit A. 1753 . d. 4 Iulii noctu locum quendam ad portam Grohudenfem, quae occidentem fpectat, legitur fulmine tactum fuiffe. Fulminis tamen materiam maiori nifu trahi in illum vrbis terminum, qui feptentrionem vergit, \& porta Wehndenfi clauditur, cui hortus botanicus vicinus, fatis compertum eft. Vt ne ad annum 1713. regrediar, quo in platea Wehndenfi fulmen, poftquam domum vicinam penecraffet, monetam ab homine quodam in vefte geftatam absque eiusdem vel aedium laefione fudiffe, narratur ${ }^{*}$ ) : pofterioribus annis fcimus bis lacobi templum feriifie; \& nuperrime a. 1769 , d. 16 lulii hora vefp. i f. finte aquilone, fub barometri altitudine $29^{\prime \prime}, 40$, thermometri autem gr. 69, turrim cuftodiendis naleuolis dicatam, non multum ab acdibus Profefforis Botanices diftantem, duorum homi-

num

*) De quo cafu retulit cl. GVDEN in litteris ad ill. focietatem fcient, Gotting. 
num internecione, percuffiffe *). Huc etiam fpectat obferuatio de lumine ifto, quod noctu inter $17 . \& 18$. Aug. a 1768 . mox poft tonitru vehementius perceptum in apice turris templi modo dicti apparuit ${ }^{* *}$ ). - Et e. iusmodi quidem tonitrales tempeftates vrbi noftrae impenderunt fine vel vlla vel fub exigua modo barometri mutatione ${ }^{* * *}$ ).

\section{S. 2 .}

Facile intelligitur, quorfum baec omnia de aëris noftri conftitutione \& no tatu dignio. ribus eiusdem phaenomenis fpectant, nempe vt quae eius in plantarum horci noftri incremencum \& viģorem virtus fit quodam modo pateat. Rem generatim arduae difficilisque indaginis effe, quin iunctam plurium eruditorum operam, perque numerofos annos continuatam, requi-

*) V. de hoc fulminis iatu cl. IIVNGBERG feriptio in Gott. Anzeigen v. gemeinnuzigen Sachen St. 56. a. 176y.

**) Rem recenfet cl. LICHTENBERG in Gött. gelebrten Beyträgen St, 20. 4.1768.

4**) Comment, Gott. Tom. 3, po 16. 33. 
244 Sect. 4. Aëris Gottingae vatio.

requirentis, non diffitcor; nec miror, quod in obferuationibus defiderentur varia, quae lucem nobis fubminiftrarent, quum in hifce plantarum refpectus haberi non poffet. Quaedam ta. men perceptae aëris noftri qualitates eiusmodi funt, vt inde fine hypothefeos metu, quam: angue magis fugio, in vfum noftrum aliquid ftatui queat.

Id ante omnia meminiffe oportet, vegecationem fiue euolutionem \& vigorem ftirpis um, exiamfi modo in externis caufis maneam, non vna vi, fed pluribus fefe mutuo iuuantibus, perfici, ideoque, \& praeter aëris effeEtus, terrae naturae \& fertilitatis, humiditatisque refpectum effe habendum; \& in aëre non pondus modo, elafticitatem, calorisque gradus confiderandos, fed \& mifcelam aduencitiarum variarum particularum, quarum materiae aëris electricae infigniorem praerogatiuam adiudico. Et horum mutua actione contingere videtur, vt vitium vnius alterius faepe beneficio refarciatur; vnius rurfus vire tus alterius inclementia fufflaminetur.

5. 8.

In aêris nofti conflitutione infignioris momenti effe exiftimo ad inconfantiom re. pen: 


\section{SeC?. 4. Aëris Gottingae ratio. 245}

pentinąmque mutationem, quam definitos gradus attendere. Non potuit tamen intenfa frigoris vis, quae aliquando fefe exferuit, ve a. 1768 . varias plantas perdere, quae alias im. pune hiemis afperitatem tulerunt; quod vel ipfa pomaria experta funt, in quibus multae, Perfica, Armeniaca, Vicis, quin hinc inde Cerafi, Pyri \& Mali teneriores vel perierune omnino, vel vix prodeuntibus nouis ad bafin trunci furculis feruatae. Miror, quod Mori, Colutea arborea, Iuglandes, Aefculi rel. non plus noxae contraxerint.

\section{§. 9.}

Calore vero longe maiorem, in plantarum vigorem, potentiam coeli ferenitas exferit, quae liberum folis acceffum concedit; diesque ferenos in primis, prout cl. LECHE ${ }^{*}$ ) fecir, in calculum redigere iuuat. Non enim fplendor folis calore femper iunEus eit, \& longe celerius vegetiusque fcimus plantas crefcere folis radiantis, quam foci in vaparariis \& hybernaculis adiumento.

$$
\text { Q2 Elt }
$$

7) K. Svenskes Vetensk, Acad, Handl, sybz po.30s. 
246 Seit. 4. Aeris Gottingae ratio.

Eft fcilicet materize lucis infignis in vim irritabilem fibrarum firpium fufcitandam, qua ipfa praecile ad animalem naturam proxime accedunt, efficacia, qua fit, vt folia, caules, \& fpicae frumenti verlus iolem fefe flectant, parallelumque cum ifto fitum affectent, vt ftirpes ante feneftras collocatae ad easdem inclinent, foliorumque fuperficies concaua euadat. Quae omnia eo alacrius contingunt, quo intenfior caloris folaris vis aërisque ficcitas *). Hinc fub diuturniori nubilorum dierum per hiemem mora vel claulis diutius ob frigoris intenfioris niuisque vim hybernaculorum valuis, folia decidunt, \& indicae in primis \& auftralioris Americae ftirpes torpefcunt, pallefcunt, tabentque \& ab intrinfecus contracto vitio aphidibus infeftantur, quae eadem vitia in oleribus in cellis feruatis confpio ciuntur.

$$
\text { 5. 10. }
$$

Dies docebit, an incrementi plantarum gradus ad definitos menies apud nos, ve in Sue-

*) Cfr, B O N v E T Recbercbes fur l'ufage des fesila les dons les plantes pog. 79, 131 142. 299. \& alibi, G L E D I T S C H verm. Bemerkungen aus d. Arzneyw. Kräuterk. a: Oecon. P. t. pas. I. Sqq. rbi figurs Pbytoclinometri eius additur. 


\section{Sect. 4. Aêris Gottingat ratio. 247}

Suecia *), fefe adftringat. Magis videtur rebus horti noftri confuli, fi verno tempore plus pluuiae decideret, cuius vero loco Eurum impetuofiorem \& terrae fuccos abripientem experimur, quum tamen futuri per aeftatem vigoris fundamentum aëris humiditate fruatur, prout in arboribus folo ficco crefcentibus, vt Quercu, Fraxino, Pino fylueftri, craffities annulorum humiditati aeftatis refpondet ${ }^{* *}$ ).

Quum vero tam parce apud nos nix decidat, \& tam breuem moram trahat: intelligitur, cur fub hiemis \& veris apud nos afperitate noftra plaga alpinis ftirpibus alendis, vt quae niuis copia \& duratione contra frigus in folo natali muniuntur, minus opportuna fit. Operae igitur pretium erit tentare an ad con-

filium

*) In arboribus hoc explorauit cel. LECHE, fcilicet parcum modo incrementum fieri Maio menfe, infiznius longe Iunio quam Iulis, \& hocce quam Augufto; cuius diuerfitatis caufa non in folo calore quaeri poteft. V. Vetensk. Acad. Handl. 1763 p. 264. Et ill. A L I N N E' (Amoenit. Vol. 4. p. 404. S. 1. Vol. 6. p. 370.) peracto folftitio arborum incrementum quie. fcere notat.

**) loc. cit. p. 24. 
248 Sed. 4. Aëris Gottingae ratio.

filium ill. A $\mathrm{LTNNE}$ *) ramufculorum arbosum coniferarum refectarum tegmine nix retineri diutius vel frondibus arborum fuperftratis fotus alpinarum conftantior feruari poffit.

\section{II.}

Verum mirari fubit, quod in ferutandis viribus, quae ftirpium vegetationi fauenc, non magis obferuatores ad electricam aëris vim refpexerint, cui tamen peculiarem hac in re poteftatem ineffe fufpicor. Conftitit enim poft primam cel. F R A N K I I N I coniecturam, dein re ab ipfo confirmatam, creberrimis Gallorum, Anglorum, Italorum, Suecorum, Germanorum experimentis, quin \& ipfa cel. RICHMANNI morte, fulminis materiem cum ignis electrici, per machinas eliciti, natura eandem effe. Porro experiundo innutuit, electricae materise per omnem atmofphaeram dominium patere, ex tellure fuperiora petere, ex hifce rurfus collectam nimis per fulmina, vti \& per pluuias \& quidem per hafce praecipue defcendere, \& conftanti nifu in aequilibrium tendere. Euiaum quoque eft, non folum tempeftate tonitrali, fed extra illam quoque, coelo adeo omnino fereno,

per

*) Ansoen. Toms \&o p. 22s, 


\section{Sect. 4. Aëris Gottingae ratio. 249}

per atmofphaeram vigere, \& hanc aliquando, fulguribus vehementioribus explofis praecipue fub calore infigniori euanefcere; \& licet omni anni tempore per atmofphaeram difperfa fit, aeftate tamen copiofius coaceruari \& manifeftiorem vim exferere. Quae omnia non attingerem, nifi \& igni electrico infignis in incremento plantarum accelerando vis competeret. Docent haec euidentius experimenta ill. virorum MAMBRAY, NOLLET, IALIABERT, RVNEBRG*), aliorum, fudio deditaque opera cum plantis machinae electricae admotis, facta, quae vt repetantur in aliis exemplis, ve an ignis electrici eadem in quaslibet plantas poteftas fit, \& qui gradus incrementi, inueftigetur, maxime optandum. Et nonne laetus ifte plantarum vigor, \& incrementum poft fulgura pluuiis imbribusque iunEta confpicuum, electricae potius materiae, quae aquae vehiculo vfa eft, quam ipfi pluuiae, adfcribendum, quod \& fragrans ifte odor, quem terra poftea fpirat, vlterius confirmat. Operae igitur pretium effet, plantarum caufa in hanc aëris dotem inueftigandam incumbere. Cui fini varia inftrumenta infer-

Q 4 viunt,

- *) Qui commodiffimum apparatum defcripfit 18 Kgl. Vetensk. Acad. Handl. 1757 p. 74. 


\section{Sett. 4. Aeris Gattingae ratio.}

viunt, vt dracones volarites ${ }^{*}$ ), qui \& extr* tonitru perceptum diuaricatione filorum \& fcintillis attactu eliciendis aëris conditiunem declarant; bacilli praeterea ferrei fuper rebus electicis erecti, fiue tubi ex bracteis ferreis formati, in quibus attsctu fcintillae cum fragore eruperunt, laminarum aurearum admotarum agitatio percepta, lumen in apice fefe manifert uit, campanularum appenfarum fonitus, quin adeo funus tonitru aemulus excitatus; vt alia phoenomena tacenm. Ad gradus vero electricae vis praecife definiendos eleatrometris carere non poffumus, quorum cll. GLARATH, HAMILTON, NOLLET, D'ARCY \& LE ROI, RICHMANN, H A R T M A N N, varia inuenerunt. Nec vetat experimentis hilce indulgere periculum coniuncłum. quum euitari poffit fcita follertia, dum nimirum obferuator fibi caueat, ne ad hofce apparatus nimis prope accedat, $\&$, inualefcente nimis aëris electrica vi, ab vlteriori

ten-

*) Qunrum notrum genus ex muecinio fericeo fuper bacillos tenues expanfo, papyraceis vulgo adhibitis, qui pluuia \& ventis facile deftuuntur, praeftantius, inuenit cel. FRANKLIN. $\checkmark$ Eius Experiments and Obfervations on Eles

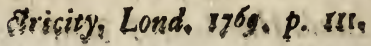


28CE. A Aëris Gottingae ratio. 258

tentamine abftineât *). - Quum itaque elect ricae aëris materiae, pariter ac arte elicitae, in plantas vis ex diftis elucefcat: in fitu horti noftro fupra defcripto, qui illi excipiendae fauet, fingularis opportunitas in incrementum ftirpium eius redundare videtur; $v$ trum vero tum modo ifta, quando fulmina ex nubibus excutiuntur, locum habeat, an incugnita quadam de caufa conftantior fit; nonnifi fingularibus experimentis eo praecife fine inftitutis euinci poteft,

\section{22}

Aft multa adhuc reftant futura indagine de aëris noftri in plantas efficacia digna, quibus ill, a L INNE', KALM, LECHE in Suecia, S TILLINGFEET in Anglia, DP HAMEL, A D AN $S$ ON in Gallia, follicite inuigilarunt, vt nimirum tempus diesque, quo gemmae plantarum erumpant, folia explicen-

$$
\text { Q.5 tur, }
$$

*) De cautelis fub hifee experimentis neceffariis cl. BERGMANN Inträdes-tal om Mögelig. beten at förekomma Askans Skadelign verknine gar pag. 97. \& Fig. vbi apparatus a cl. wit$C K E$ in hunc finem inuentus defcribitur, \& cl. H A R TMA N N I Anmerk. üb. donôthige Achtfamkeit bey Erforfcbung der Gewittereles

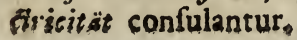




\section{Sect. 40. Aèris Gottingaè ratio.}

eur, flores emergant, \& femina fructusque: maturefcant, quae demum harum omnium in variis numerofis plantis mutationum fucceffio fit, definiatur. Quarum cognitio non folum curiofae climatis variorum locorum comparationi fatisfaceret, fed, quod ill. A I INNE' prae primis extra dubium póuit, certiorem normam exbiberet, quo tempore fario \& transpofitio plantarum inftituatur, exoticae plantae ex hybernaculis \& in haec rurfus transferantur, \& varia alia opera hortenfia commodiffime perficiantur. Quae 0mnia tutius longe ex plantarum quarundam fponte crefcentium mutationibus, quam definito ex calendariis tempore, cui aèris tempe. ries sarius fefe adfringit, conftituuntur. 


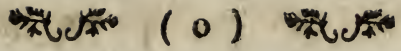 \\ CORRIGENDAETADDENDA.}

Pog. 6. 79. Tolle dubitationem de Scolopen drii iure ciuitatis apud nos, quod iam memini me circa pagum Rheinhaufen reperiffe, alii alibi.

p. 23. Plantis Cellenf. \& Luneb, adde Eu. phorbiam Characias.

P. 26 lin, antepenult. Ioco vicinis lege vicinas.

p. 3 lin. 9. lc. Serapiam I. Serapiadem.

p. 32 Adde plantis circa Rheinhaufen Cam: panulam Ceruicariam.

p. 43. Pone Varietates Tritici repentis colloca: Triticum radicibus repentibus, vaginofis, foliis hirfutis locuftis octifloris. HALL. Hilt. $n_{0}$ 497. $\gamma, \mathrm{Gr}$. fpica triticea compa\&ta, hirfutum ariftatum 1. $5 \mathrm{CH}, p_{0}$. \& \& $\delta, \mathrm{Gr}$. fpica tritices compacta longioribus ariftis donatum I D. P. IO. Crefcit in aquofis Gottingae.

p. 48. lin. 9. 1c. Hernnirial. Herniaria. culare.

p. 54 . lin. I, voci Polygonum adiunge aui:

p. 59. lin. 16 loco T.1. $\beta$. lin. 18. le, 1 V B: I. I. $B$.

p. 57. In notis citatio libri Housvater pertinet ad Vol.s. $P .1$.

p. 80. Pone Sphagnum infere Phafcum, \& pone Marchantiam, Ricciam.

P. 90 lin. 17. Ic. accedere 1. accidere.

p. 103 l. is lc. annexas 1. annexa.

p. 112. lin. 16 lc, calo 1, calor, lin, 22 le。 smplientur 1. amplietur.

p. 140.1 . $4.1 c$, radii 1 , in ambitu. 


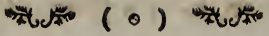

p. 147. Ic. Afcleprus 1. Afclepiàs.

p. 161. Pone Teucrium flucidum adde Teucrium Chamaedrys.

p. 20 r. lin 9. Ic. $x$ o. 1. N I C. LA V R.

p. 2 I 9 lin 5 dele cit.

P. 237. Pone lin, 5 , adde: Suafit b. M A Y E$R$ V s, olim nofter, in commentatione a 1755 . fo. cietati R. fcient, oblata, vt medius calor cuiufuis menfis ex obferuationibus plurium annorum collatis erueretur, qua ipfa re farrago obferuationum thermometr. ad pauciores, easque conclufionibus inde ducendis vtiles, reuocari poffet. Hoc confilium ipfe b. vir fequutus in thermometro propria eiusdem manu confructo, quod in poffeffione ill. KAEST NERI eft, heic loci tanquam extrema Iulii, menfis calidiffimi, calorem medium gr. Fah. renh, 70, Ianuarii frigus gr. 27. effe, ftatuit. 
$=-$

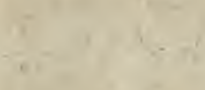

$=$

$\sqrt{2}$

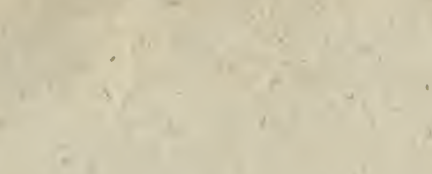

..

$2-$

c

$=$

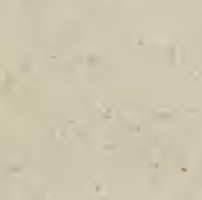

r

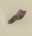

(1)

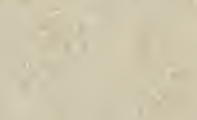

. 



$$
f .2 \Rightarrow f .3 \text {. } f .4 \text {, }
$$

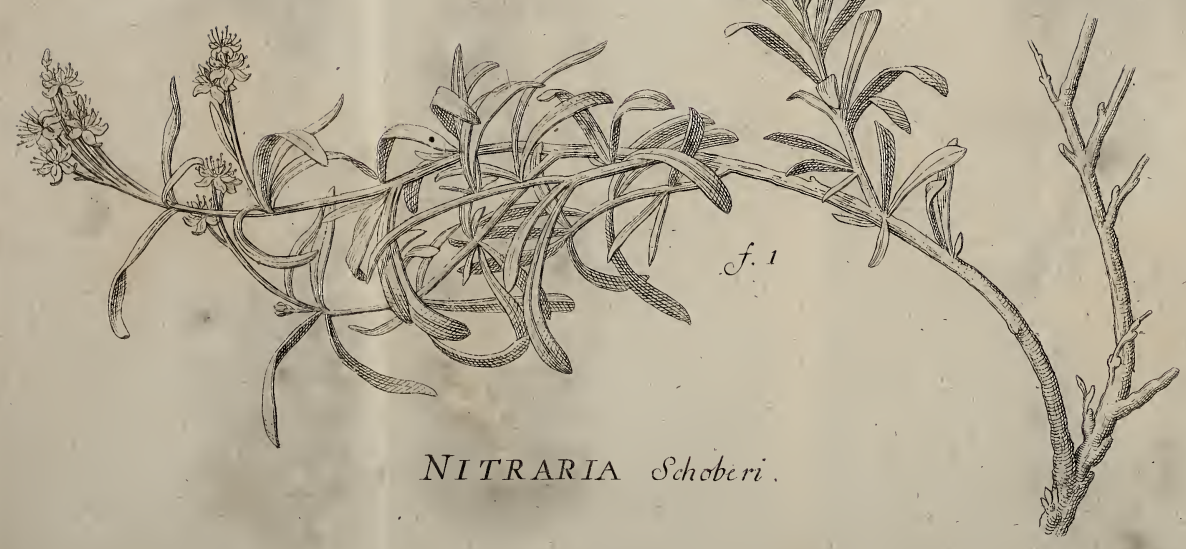





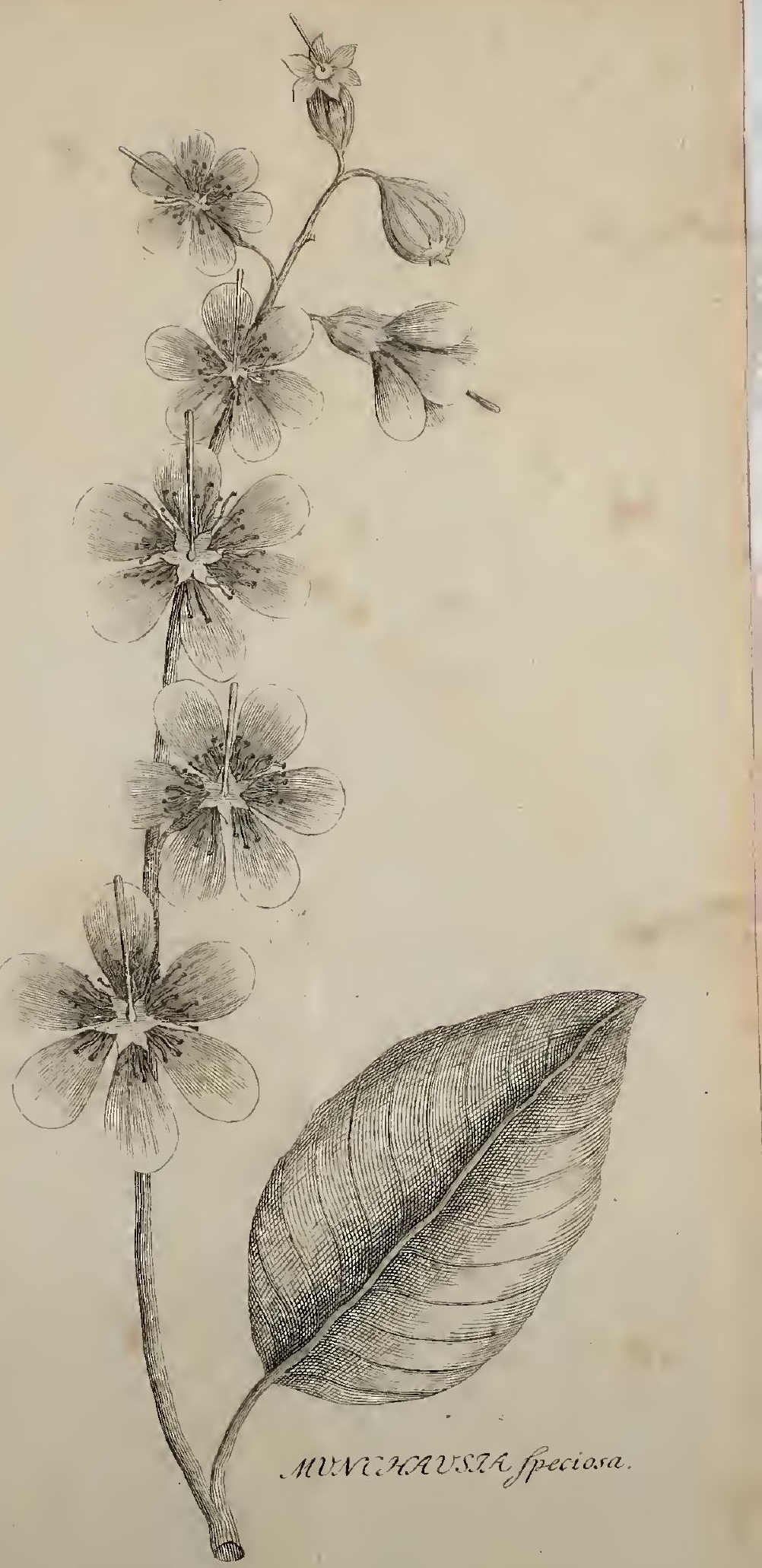






